\title{
Szmodics Péter
}

Evaluating the organizational knowledge based on business process management 
Department of Information Systems

Supervisor: Gábor András, CSc

(C) Szmodics Péter, 2017 
Corvinus University of Budapest

Doctoral School of Business Informatics

Evaluating the organizational knowledge based on business process management

Ph.D. dissertation

Szmodics Péter

Budapest, 2017 



\section{List of Contents}

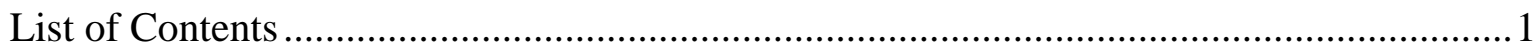

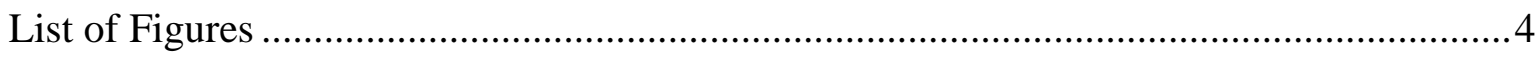

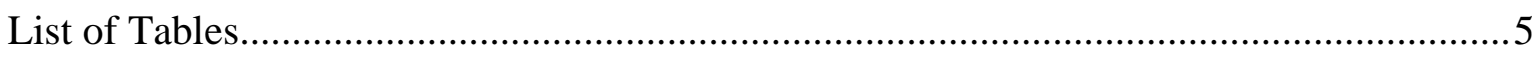

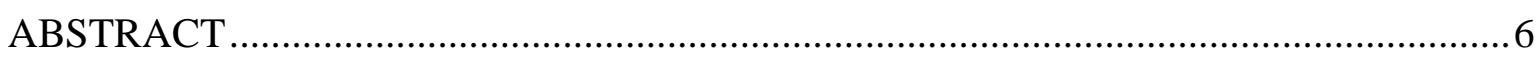

1 INTRODUCTION

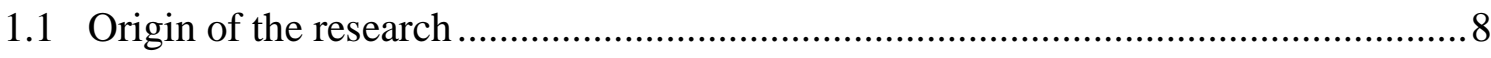

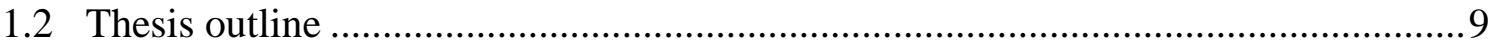

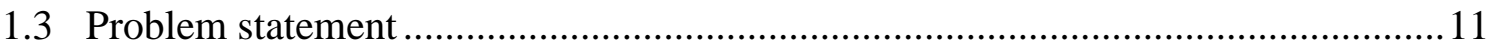

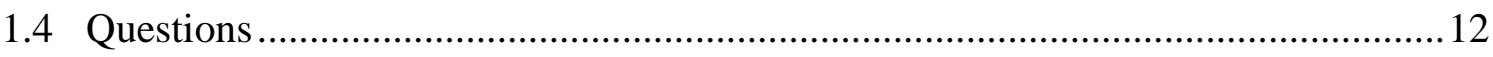

1.4.1 Question 1 - Can the application of knowledge management be defined at all? What are the limitations of definability?

1.4.2 Question 2 - Is organizational knowledge assessable with the process management tool and concept library and can it be evaluated? Under what circumstances can the assessment and the evaluation be realized?

1.4.3 Question 3 - Can the level of knowledge management be defined?

Under what circumstances is it possible to determine the levels? .

1.4.4 Question 4-With what accuracy and relevance can the organizational knowledge management be measured based on business process management? ........13

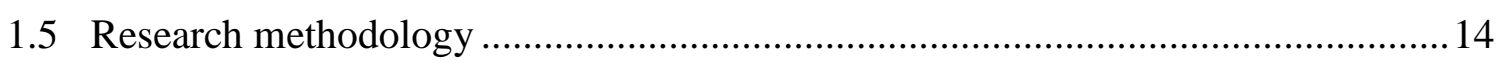

1.5.1 Qualitative and quantitative research ……………........................................ 14

1.5.2 Exploratory research and research based on validation .................................... 15

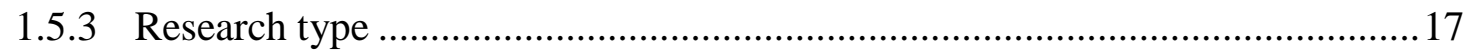

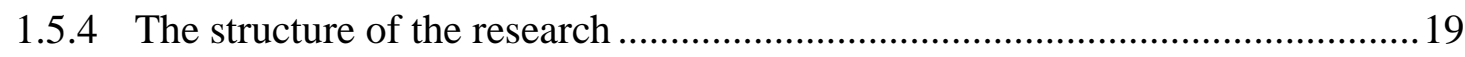

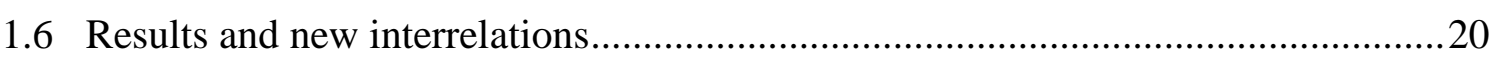

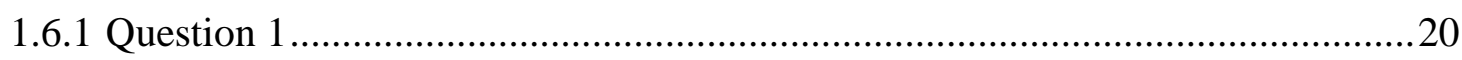

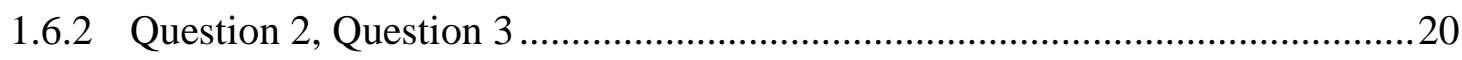

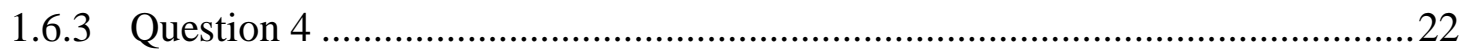

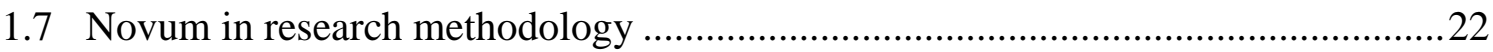

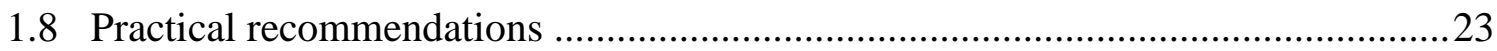

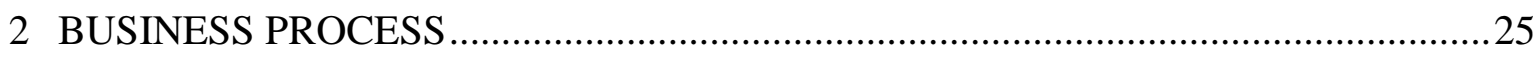

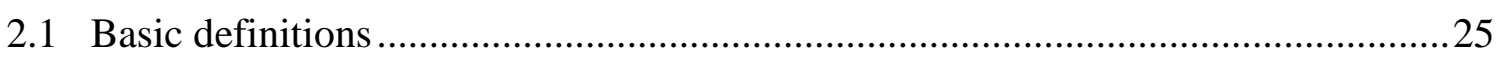




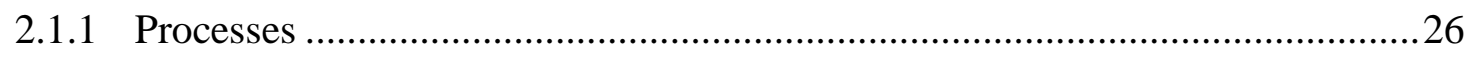

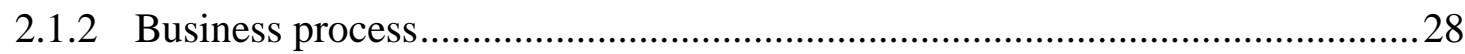

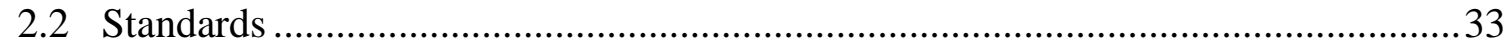

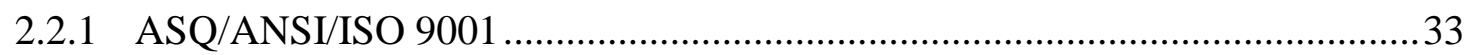

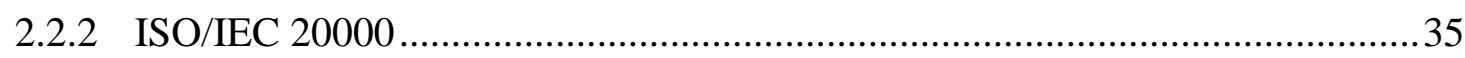

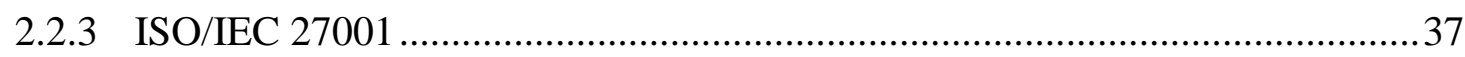

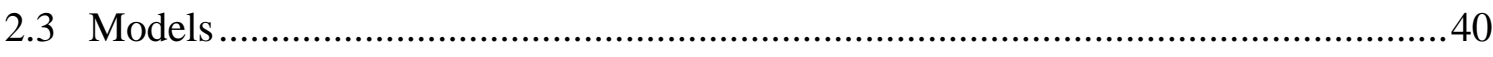

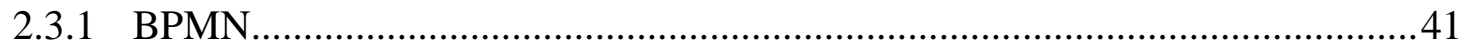

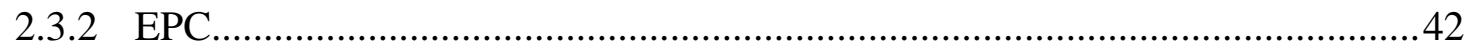

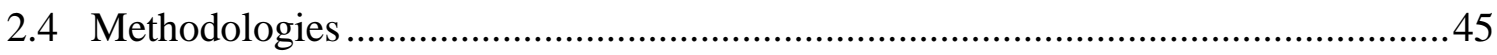

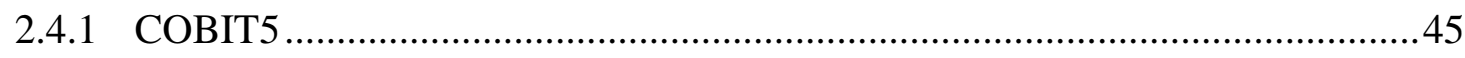

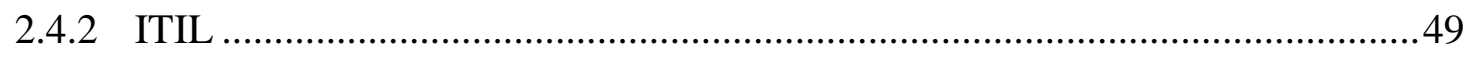

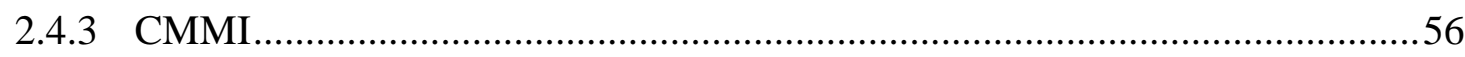

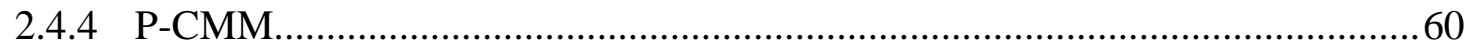

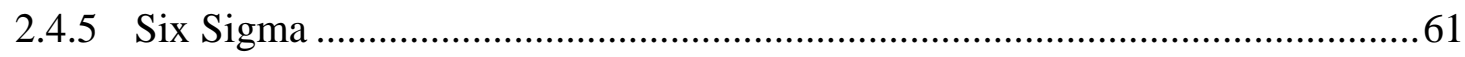

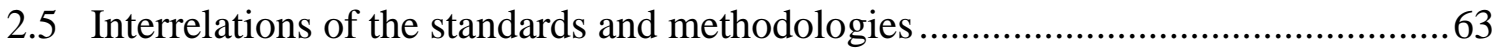

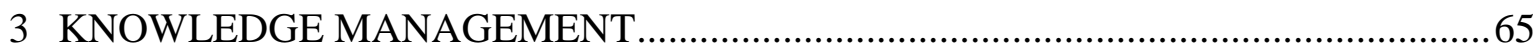

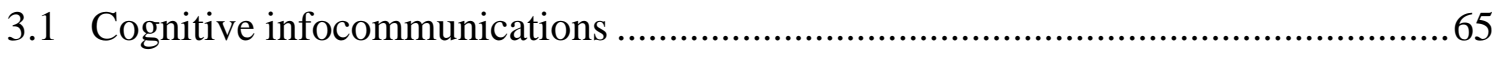

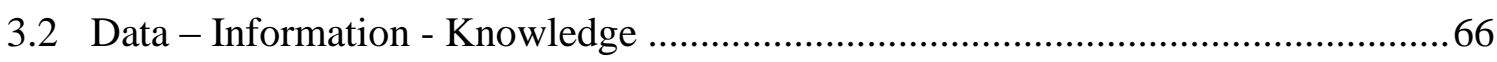

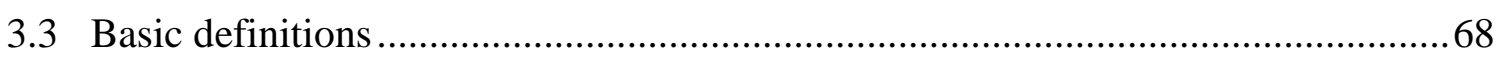

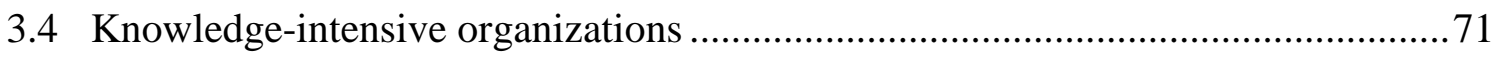

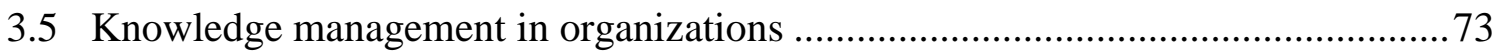

3.6 The source of the knowledge as bridge between the KM and BPM .......................76

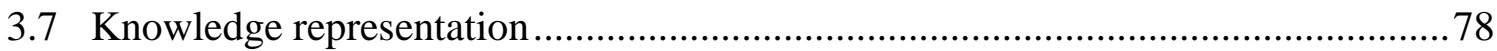

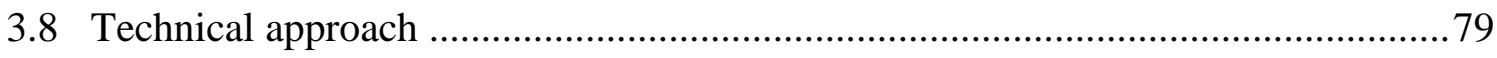

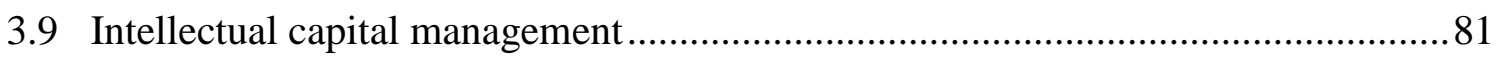

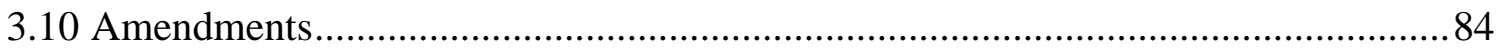

4 THE RESEARCH METHODLOGY - INTERRELATION OF THE BUSINESS

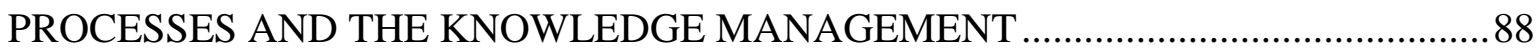

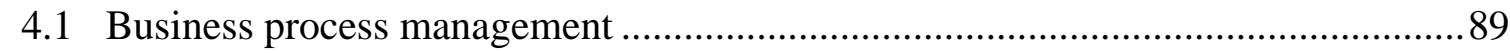

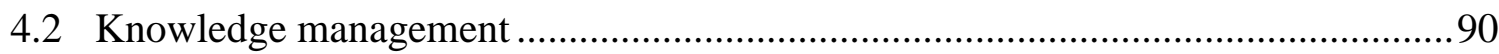

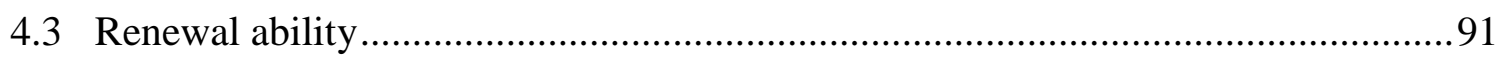

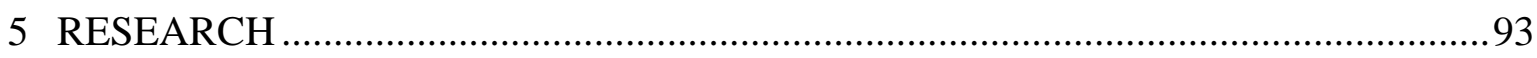




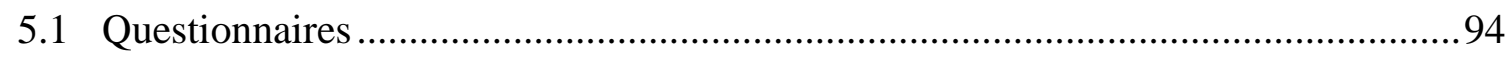

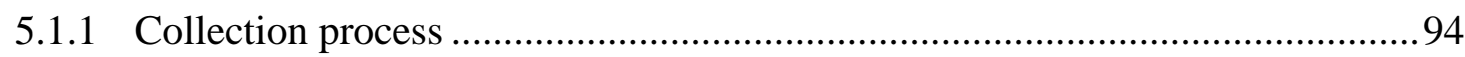

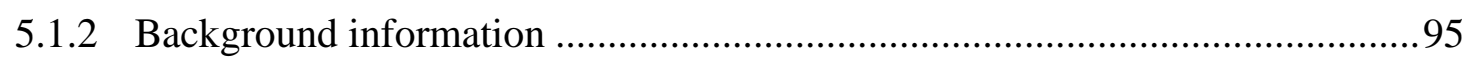

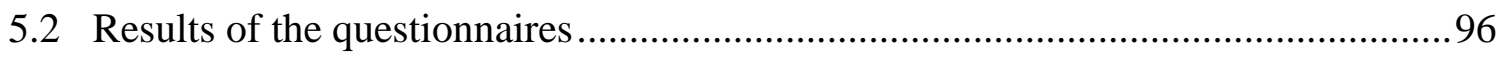

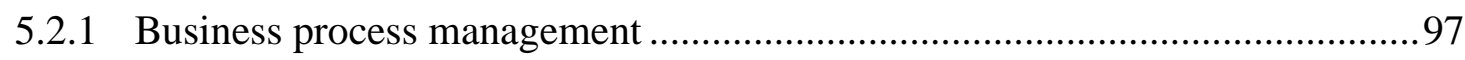

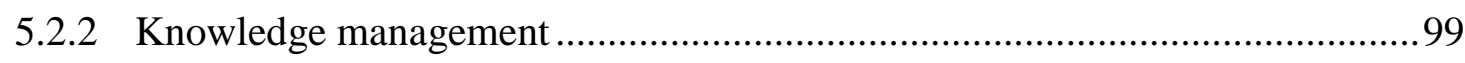

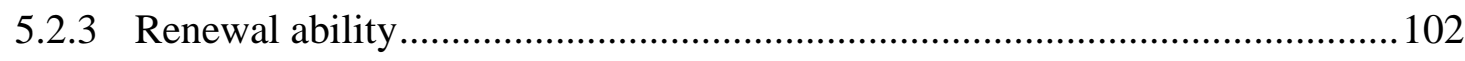

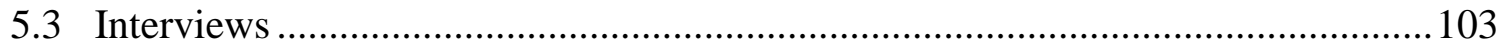

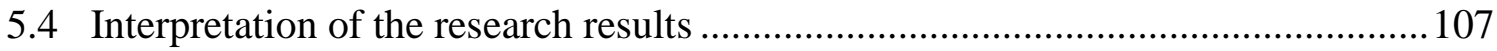

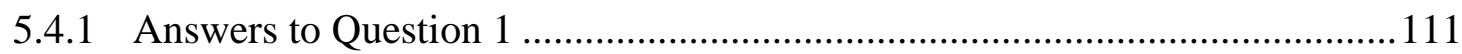

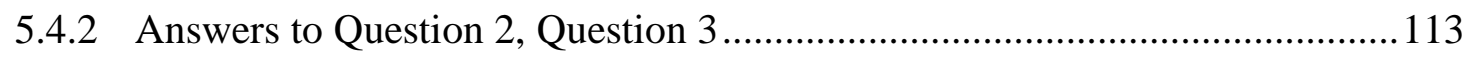

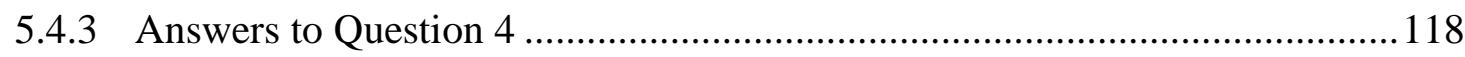

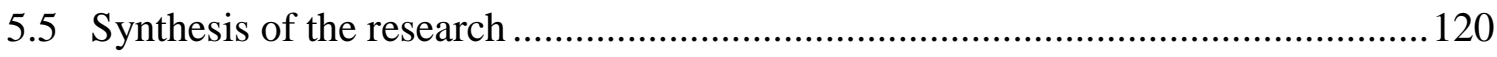

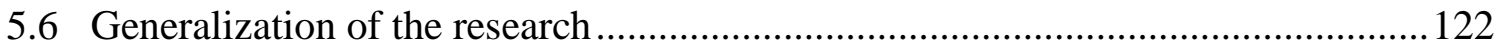

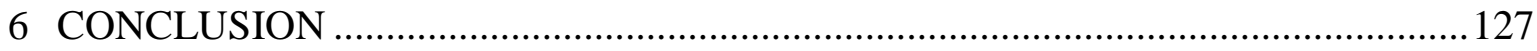

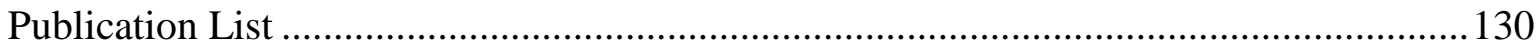

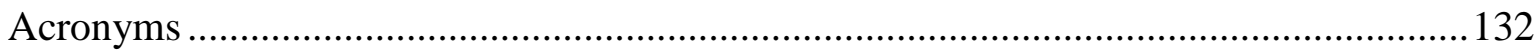

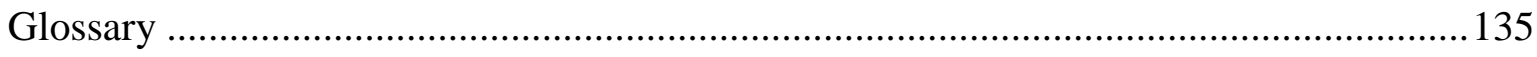

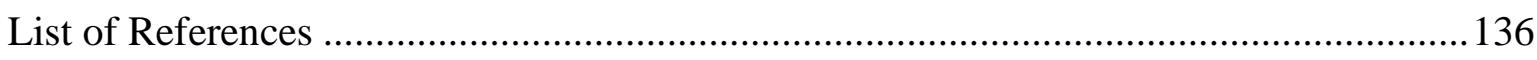

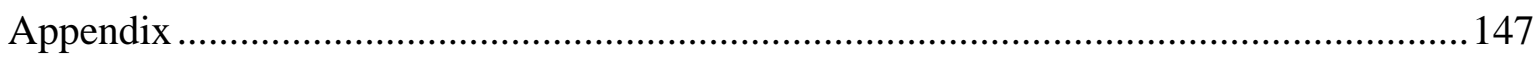

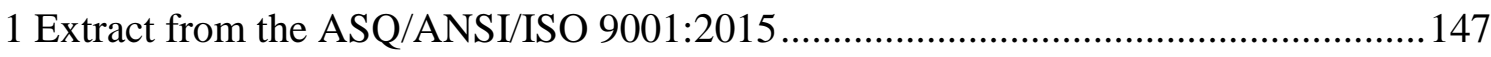

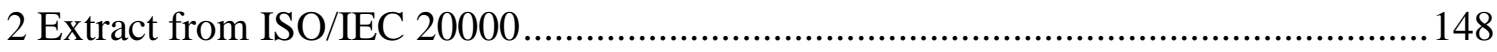

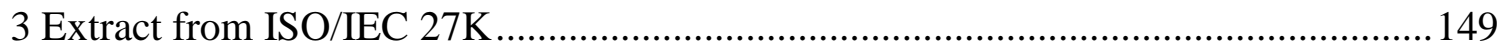

4 Extract from the CMMI Processes and Practices ..................................................... 150

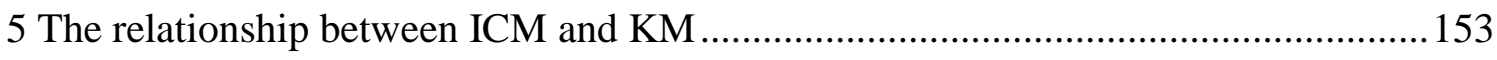

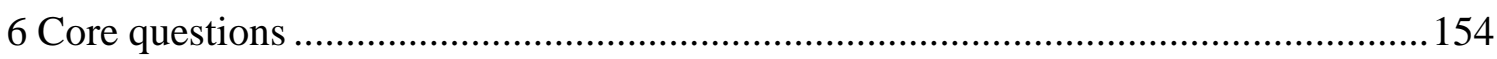

Domain A - Business process management ....................................................... 154

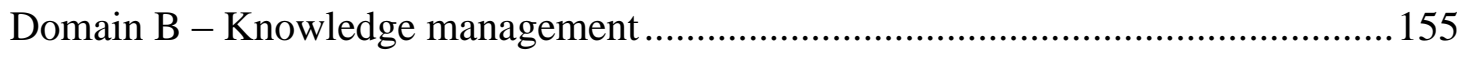

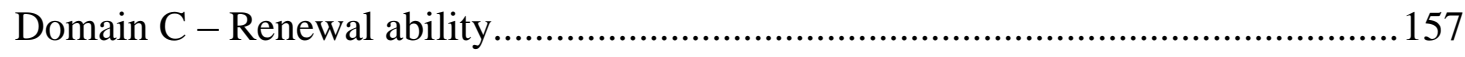

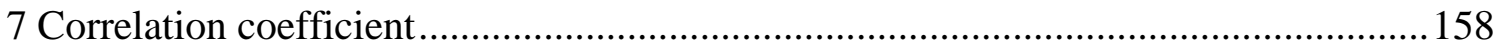




\section{List of Figures}

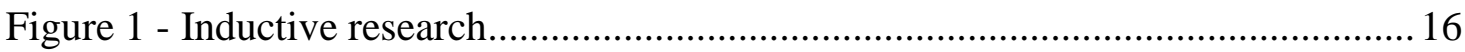

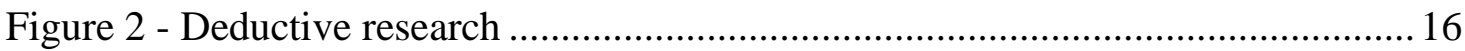

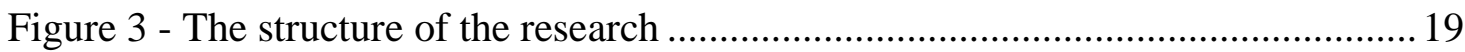

Figure 4 - Relationships between basic terminologies............................................... 32

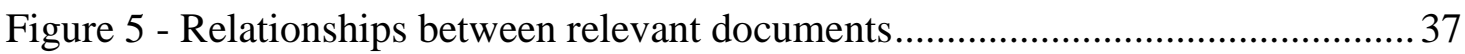

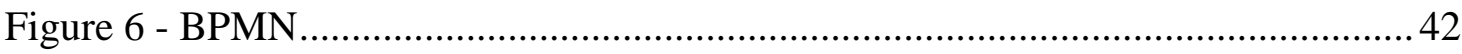

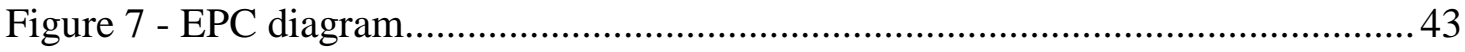

Figure 8 - COBIT5 Governance and Management Key Areas ....................................46

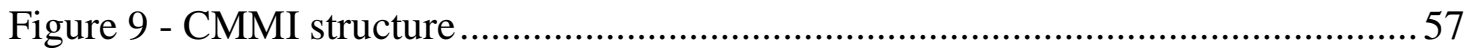

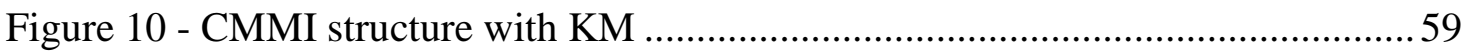

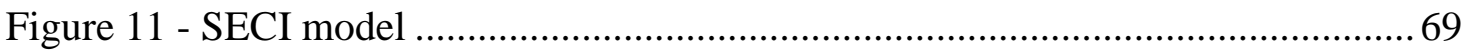

Figure 12 - Spiral of Organizational Knowledge Creation ...................................... 70

Figure 13 - Types of knowledge process within an organization .............................. 75

Figure 14 - Substitute knowledge, Complementary knowledge ................................. 84

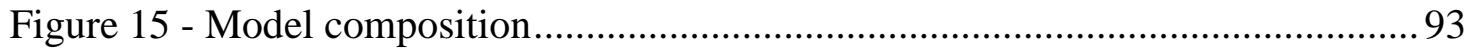

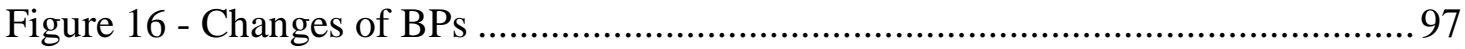

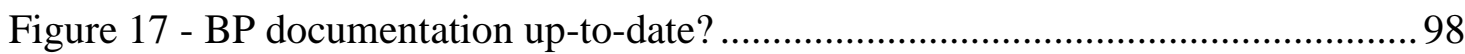

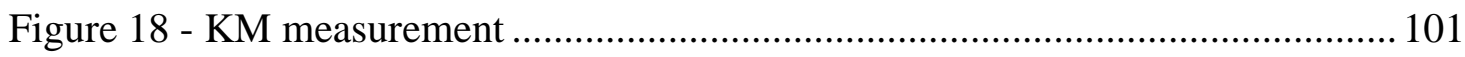

Figure 19 - Relation of Realized value and Knowledge Management level............... 123 


\section{List of Tables}

Table 1 - Manage Human Resources - Outcomes........................................................ 47

Table 2 - Manage Human Resources - Work Products ................................................ 48

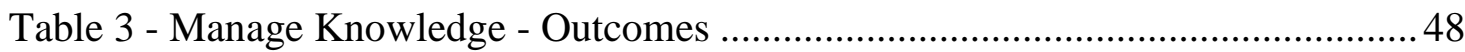

Table 4 - Manage Knowledge - Work Products............................................................ 49

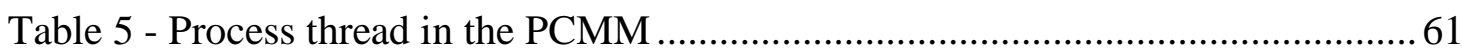

Table 6 - Interrelations of the standards and the methodologies .................................64

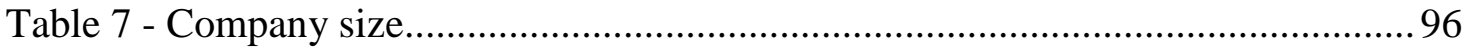

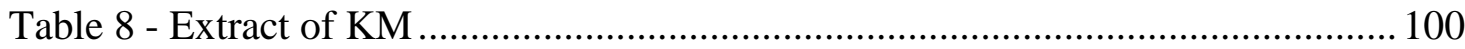

Table 9 - Interview - Interviewee profile .................................................................. 103

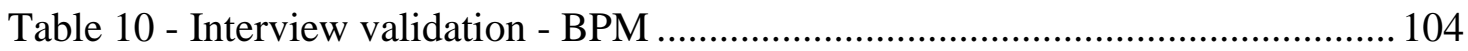

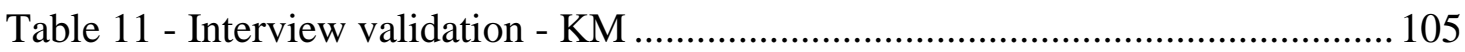

Table 12 - Interview validation - Renewal............................................................... 106

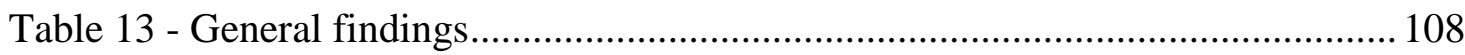

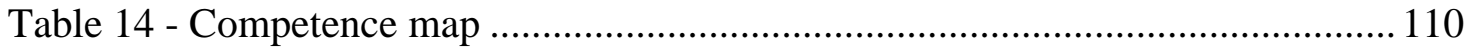

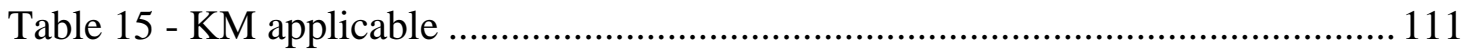

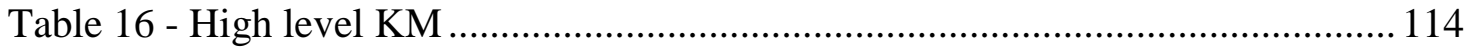

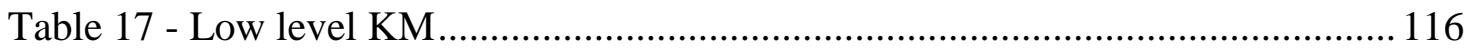

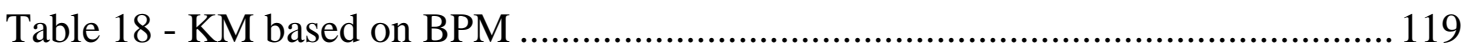

Table 19 - Competence map - KM based on BPM ............................................... 120 


\begin{abstract}
The continuous technical development has created a dynamic environment which allows the organizations to drive their operations in more realistic and more complex manners. In the developed economic structures the knowledge management is usually handled as the main strategic instrument and a comparative advantage. The knowledge and its management are present in every organizational entity. The awareness about them, the way how they are structured and especially how they are evaluated differ indeed substantially.
\end{abstract}

Understanding the role of knowledge-based processes is one of the key elements to interpret correctly the possible value chains within the organizations. The current research's aim is to introduce a pragmatic approach about how to manage knowledge effectively. The domain is quite challenging, on one hand it has to be taken into account how the context of the knowledge is present within the organizations, on the other hand, the practical dynamism of the knowledge management has to be articulated.

The research relies mainly on business process management (BPM) procedures and methodologies, since these can deliver a systemic structure for the relevant processes, for the roles involved in the processes and for the business process management, itself. Taking into consideration the BPM's possible sample space, a common understanding about the BPM domain is introduced, in which the knowledge management is embedded.

The desired outcome of the research is to present a holistic, but practical framework about the effective knowledge management based on the business process management. The novum of the research is that it examines the knowledge management's status within the organizations and it gives an evaluation for that in a practical way. 


\section{INTRODUCTION}

The business process management (BPM) is one of the most interesting domains amongst the research areas nowadays, since it has a direct connection with the core scientific researches and the real life scenarios, too. From this perspective, the knowledge management (KM) is similar to the BPM, it also has direct connection with the research and with real business problems.

The aim of the research is to provide the background on both of the domains: where they originate from, what interrelations they have, and how they are currently situated amongst the given circumstances.

The business process management is enabled and enhanced with the rapid development of the information and communication technology (ICT), the KM's case is similar. In general, both of them are present within the organizations. Actually, they are not just alive within the business environment, but every slice of human interactions might be also involved in both of the domains. The latter area has a large study field, therefore the current research's scope is narrowed to examine mainly the business related phenomena, so that can deliver more reliable results with probable better validation.

From a business perspective, it is true for the most markets that there are more competitors who would like to fulfill better the customer's requirements. The economic space for business entities is usually similar and there is a significant overlapping. The competitors usually have similar resources standing for their provision, that they try to establish comparative advantages with.

Thanks to digitization, the development level in technologies has turned into such a high level, that the most business processes can be structured, replicated and reused. If the business entities want to keep their advantages on the long term, they need to think in a way that is based not only on simple processes, but on processes that get closer and closer to the real mechanisms. If the actors want to drive the market, they have to 
come up with such solutions that are not simply copyable and reusable for the competitors. The business entities that follow the forerunners have to strive to be able to adapt to the market leader, copy it or in ideal case, they have to introduce new comparative advantages.

The technical and organizational procedures' parameters can be set within the workflows of the organizations, but the human actors' interactions are more likely difficult to be determined. It is partially because of the humans' perception which might be significantly diverse on individual level. This is mainly caused by the attitude, the motivation and the knowledge. Assessing and evaluating the knowledge of one single person can be already a difficult problem, but handling and managing the knowledge on unit or on higher level is even more difficult, because it has not just more input variables, but more interactions.

The effective knowledge management leans on personnel with good managing and leadership skills and good organizational business processes. The main focus of the research is the latest one, how to transform the BPM's results into effective knowledge management.

In the next paragraph, the origin of the research is outlined.

\subsection{Origin of the research}

The technology, the basics of computing and the ICT are connected. Combining them with the business information systems with an outlook on financial studies gives an opportunity to get acquainted with practical business fields.

Bridging the interactions of human actors and the technical environment or amongst human actors with different background (usually with technical and non-technical) is difficult. The technical and documentation-related obstacles can lower the delivered business value, in which the process has to be handled as part of the change management (CM). 
The effective knowledge management can significantly enhance the business processes' efficiency, on the backhand the ineffective one can be the trigger of irreversible losses. The effective business process and knowledge management have not just reflective mechanisms on themselves, but mutual ones on each other, too.

The knowledge has real value addition on business processes and it can provide competitive advantage. While evaluating its value in practice is not easily justifiable, the assessment and measurement of the knowledge management is challenging from both the quantitative and the qualitative aspects. During the ongoing business, the decision-making requires a common framework involving the knowledge management, on every level. Even the business continuity might suffer from the not properly set knowledge management, if not carefully planned. Setting the knowledge management on a balanced and acceptable level without using too many resources is also a complex question.

The aim of the current research is to reveal the relevant results of the academic researches and practices and to give an overview about their current application.

In the next paragraph, the thesis outline is delineated.

\subsection{Thesis outline}

The thesis has six chapters that build up a line of coherent domains with the respective theoretical background and the related practical methodologies.

In 'Chapter 1' the aim and background of the research are introduced, first a short introduction is given which is followed by the thesis outline, this current element shortly lists the parts of the research. Finally, the research's questions and problem statements are presented where the research methodology is introduced.

'Chapter 2' is about the business process management. Its aspect incorporates mainly the organizational roles and the business process management. Particularly their documentation- and complexity-level will be introduced which is interpreted in the research as the basic element of the knowledge management. The theoretical and the 
practical key factors of the business processes are also discussed. In addition, the related standards, models and methodologies are reviewed as well.

'Chapter 3' covers the knowledge management. The knowledge management's practice has in scope the followings: documentation of the knowledge, competence mapping of the human resources and the tracing of the knowledge usage. Understanding the role of the substitute, complementary, rare-unique and business critical knowledge elements is one of the priorities. The other one is how to handle them efficiently. Not just the present state of the knowledge of the specific entities has to be known, but the past and the future ones, too. In addition, the ability to learn and to renew the knowledge can give a projection to the innovation. Similarly to 'Chapter 2', the related theoretical background is introduced firstly then the connected concepts.

'Chapter 4' sets against the business process management and the knowledge management, since these two fields have common interests and common areas covered. Their intersections are examined in this chapter. The possible gaps and probable causes for misunderstandings are taken into consideration also in order to reveal the expectable problems. After gaining a common understanding about the domains, a holistic framework is collated.

'Chapter 5' goes about the discussion of the research questions first by introducing the research itself from practical point of view. In order to piece them together in a realistic way, inputs are being collected from real life examples, the first explanation are done here and then the results are discussed.

'Chapter 6' is the conclusion part of the research that elevates the coherent body of knowledge about the so far achieved results and it also provides the basis for future research.

In the next paragraph the research questions are described. 


\subsection{Problem statement}

The research is conducted amongst knowledge-intensive business entities. Knowledge intensity is understood here in a way, wherein the value addition of the organizations is driven mainly by knowledge. Assessing means that there is the possibility to translate the organizational phenomenon within the organizations into a model, in which their specific levels can be depicted. These levels, as an aggregate, can be later on evaluated based on specific requirements and/or best practices. Applicability addresses the usability of the above model; if it fits the requirements then it is applicable, otherwise not.

In the research, the business process management and the knowledge management are examined. The aim is to construct an applicable framework in which the knowledge can be evaluated within a living organization. The basic input is the business process management for assessing this. The framework, how to establish an effective knowledge management practice, is derived from this.

The main problem is how to evaluate the organizational knowledge based on the business process management. The identification, capturing, sharing and reusing the knowledge can usually be assessed and measured just goal-oriented, narrowed to specific cases. Here it is also one of the goals how to give to the problem-set a higher level approach and a more general overview by maintaining the BP- and KM-focus.

Logically the problem is built up as following. Can the knowledge enrichment (Török, 2014), knowledge intensity of the business processes measured or at least delimited? Can the organizational knowledge practice assessed in a framework taking into the consideration the practical business process management? After setting up the structure, the following should be answered: is it possible to determine the boundaries of the knowledge management? At last, the practical optimum of the knowledge management should be configured.

In the following paragraphs the research questions are explained more detailed. 


\subsection{Questions}

\subsubsection{Question 1 - Can the application of knowledge management be defined at all? What are the limitations of definability?}

The applicability can cover multiple dimensions at the same time: the surrounding environment, the corporate culture, the size of the business entity, the sector in which it is active, the nature of the business problems, the structure of the business processes and automatization level of the processes. These can be all the parts of the research. Since the combination of all the elements can create an interminable set, the - from research's perspective - relevant elements will compose the set of the final evaluation.

Identifying the knowledge intensity is one crutch, evaluating its level within the organization is the other pair of the crutches. Answers to this question can help with determining the connection amongst the business processes and the knowledge management.

\subsubsection{Question 2 - Is organizational knowledge assessable with the process management tool and concept library and can it be evaluated? Under what circumstances can the assessment and the evaluation be realized?}

Answering this question needs a deep analysis of the business process management itself. The organizational environment and its internal actors should be considered. The organization itself has the regulation and its culture and there are systems embedded, in which or with which the human actors do their interactions. The systems are built up with specific logic and interfaces, normally the workflows are semi-automated. The human actors establish the inputs for the systems depending on the current procedures. All the human actors have to follow their workflow and they possess definite knowledge that helps them to get along and which drives the business processes. 
In order to get answers to this question, it is required to analyze the BPM standards, models, methodologies and the same has to be done with KM. Once these are clarified, their interrelations have to be determined.

The main challenge here is how to highlight the relevant and the necessary (even if they do not seem to be relevant) elements in order to get a general interpretable picture about their proceedings.

If the interrelation of the BPM and $\mathrm{KM}$ can be described and, in addition, the knowledge can be measured in a specific environment, the coming question rises apparently.

\subsubsection{Question 3 - Can the level of knowledge management be defined? Under what circumstances is it possible to determine the levels?}

The optimization is in operations research the selection of the best element from a set of alternatives. Normally the maximizing or minimizing might be the goal of similar activities; in this research, the potential for organizations is examined. The proposed outcome of the research should give an instrument for the organizations about how to balance the costs and benefits during the knowledge management without imposing unnecessary risks. The research does not try to determine the optimal level, but it tries to reveal some steps in order to articulate its predecessors.

In the following paragraph, the potential-related question is put forward.

\subsubsection{Question 4 - With what accuracy and relevance can the organizational knowledge management be measured based on business process management?}

Assessing and measuring the knowledge management on organizational level requires a holistic view, since it has to handle more inputs, and at the end, it should somehow summarize the results in a common understanding, preferably in a simple way. Since 
this territory is very complex, it should be based on traceable and demonstrable evidences from the input side, the causal analysis should follow a straightforward logic. In addition, the course for presenting the results has to be clear either it is quantitative or qualitative.

If the evaluation of the organizational knowledge can be described in a reasonable structure, its delimitation of it might also be analyzed from a plausibility perspective. To get the answer for the questions, the practical results of the research have to be outstretched.

In the following sections, the research methodology will be introduced.

\subsection{Research methodology}

When establishing the structure, the followings were taken into consideration: general scientific expectations, requirements of the Ph.D. school and the nature of the domain to be examined. The current research does not articulate strict hypotheses but it uses rather a set of interrelated questions. Giving answers to these questions gives an exploratory profile to the research. The Corvinus University of Budapest's Business Informatics Ph.D. School belongs to the field of social sciences, therefore the selected research method might be considered as a relevant one.

In the followings the research will be described in more details, first the basic approach.

\subsubsection{Qualitative and quantitative research}

During the organizational research, the most common way is to use quantitative or qualitative research.

Quantitative research quantifies the data and tries to give a generalized result on a specific topic, usually a large number of cases represents the specific population. The data collection mechanism might be based on interviews, questionnaires. Its findings 
are descriptive based on statistical methods. It can be used to recommend a final answer or a decision. (Babbie, 2003)

The qualitative research tries to develop an understanding about a specific domain, it tries to uncover hidden relationships by generating the common grounds for later quantitative researches. The sample size is usually not representative. Collecting this kind of data is not that structured as in the case of quantitative research, but rather unstructured, applicable form is more like a discussion or depth interview what provides non-statistical data. Its outcome is exploratory. The findings can be used to outline the base for further discussion and quantitative analysis. (Babbie, 2003)

From practical approach, it might be also valid to use the adequate combination of the upper methods, since the same question might be analyzed from different perspectives. The methodological triangulation (Webb et al., 1966) allows the followings:

- simultaneous application of various qualitative procedures,

- simultaneous application of various quantitative procedures,

- and combination of quantitative and qualitative methods. (Jick, 1979)

In the present research, both of the methods are relevant, and a specific combination of them is used.

\subsubsection{Exploratory research and research based on validation}

In general, the researchers' intend is either to set up a new theory or to validate/argue/confute on an already alive one. The current research's aim is to build up a new theory with the help of already existing theories, practices and a specifically designed research framework.

The logical buildup of the research impels the line of the research. Two main directions are available: the inductive and the deductive approach. The main difference is that the inductive approach' aim is to generate a new theory and the deductive one's is to test a theory. 
The inductive approach (Figure 1) starts with collecting the relevant data. If it meets the requirements, the next step can follow it: identifying the patterns what later on can be developed into a theory. The inductive approach supports the exploratory research. (Babbie, 2003)

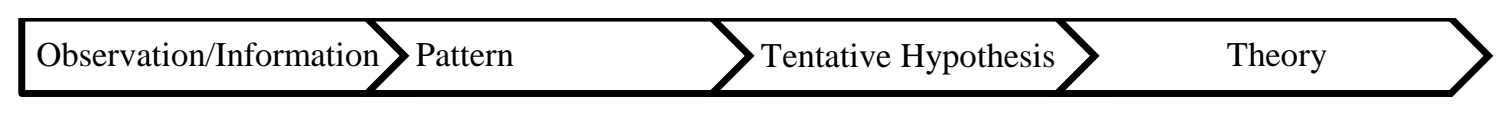

Figure 1 - Inductive research

The deductive approach (Figure 2) is the reverse process of the inductive one, it starts with the theory and according to it, the hypotheses are set. The data analysis helps to identify whether the hypotheses are supported or not, it is based on validation. (Babbie, 2003)

\begin{tabular}{|l|l|l|l|l|}
\hline Theory $\quad$ Confirmation & Observation
\end{tabular}

Figure 2 - Deductive research

The current research domain does not allow the deductive approach at this point, therefore the inductive approach is favored.

The exploratory research is constituted on the inductive logic, it is applicable especially in such cases where the domain is largely unexplored. According to Szabó (2000) the exploratory research has three main goals:

- “developing applicable methods for further research,

- providing a better background of the domain,

- and serving as testing the feasibility of future researches."

The procedure how the research runs allows a more widen opportunity for the author (Benbasat et al., 1987). Similar researches (Török, 2014, Varga, 2014) utilized this, but before them, there was already an exemplary practice in place (Klimkó, 2001) with similar synthesis. The mentioned thesis' nature was not validatory, but explorative, the author articulated research-related expectations. "Amongst the questions there are no deductive ones that could be aimed at validating hypotheses. All questions are of inductive nature.” (Klimkó, 2001) 
In the next paragraph, the realization of the research is introduced.

\subsubsection{Research type}

There are different research strategies what could be followed, Yin (1994a, 1994b) classified them as the followings:

- experiments

- historical analysis

- procession of a case study

- questionnaire surveys

- secondary analysis

The current research focuses on business related issues therefore questionnaires and simple case study researches (interviews) in business and management are in the foreground (Eriksson and Kovalainen, 2012). The research area covers organizational processes, company settings including human interactions. Goals and research questions are built on questionnaires and a small number of direct feedbacks.

The research area covers various technical executions, during the design of the research multiple origins of possible data were taken into consideration. Patton's theory (1999) utilizes also the triangulation. Triangulation uses multiple data sources to produce an understanding. Patton distinguishes the followings:

- of data sources (data triangulation),

- among different evaluators (investigator triangulation),

- of perspective to the same data set (theory triangulation),

- and of methods (methodological triangulation)

Data triangulation examines the consistency of different data sources from the same method, e.g. comparing people with different viewpoints. Investigator/analyst triangulation uses multiple analysts. This can be used for understanding the different ways of seeing the data. The theory/perspective triangulation uses multiple theoretical perspectives to interpret the data. The methodological/methods triangulation checks the consistency of findings generated by different data collection methods. 
In the following two paragraphs, two currently applicable methodologies are introduced, the questionnaires and the interviews.

\subsubsection{Questionnaires}

The questionnaires help in the research to gather data either in quantitative or qualitative way, from individual units about their attitudes, beliefs, knowledge and opinion about the research-domain. This data collection method is a subset of the general survey techniques. It can be used in the current case in two ways: it is the primary strategy for data collection and it can be used in conjunction with other case study techniques, such as interviewing, observations. (Barlow, 2012)

During the development of the questions, many tactical conditions have to be taken into consideration, especially the issues of designing: how to deal with behavior, how to ask questions about attitudes and intentions, how to use open-ended and closedended questions, how to measure knowledge, how to evaluate performance, etc. (Bradburn et al., 2004)

In case of structured questions, the followings have to be examined: where to use multiple-choice questions (specific choices), dichotomous questions (yes/no multiplechoice questions), and ranking scales questions (for importance, preference relations or orders).

\subsubsection{Interviews}

Although Yin did not directly specify the interviews, they are also being introduced here. An interview is a process of seeking knowledge and understanding via conversation. The interview's data is transcribed and the transcription is used in the analysis process.

The interviews have the followings of high importance: possible inconsistencyconsistency issues, communicational difficulties, attitude, the standardization and length of the questions, and the length of the interviews. 
The type of interviews might be: structured (questions and responses are definitive, standardized), semi-structured (predefined questions are asked, but allows expert freedom), unstructured (questions and answers are not specified in advance). (Chasteauneuf, 2010)

In the coming paragraph the desired combination of 1.4.1, 1.4.2 and 1.4.3 is described.

\subsubsection{The structure of the research}

Based on the introduced methods and theories, in this point the current research's structure is explained. The research itself has a historical background from 2014, when the first run of the research took place, the flow of the research is partly based on the result of that.

The data collection happens based on qualitative questions (questionnaire), the outcome is exploratory in order to determine bases for quantitative analysis. The next step is the qualitative result's transformation into quantitative data. The first analysis is followed by interviews, their goals are to set up a validatory framework. During the interviews the observation-style gets dominant role, the interview-respondent receives wider freedom, the listener will avoid giving advices and getting involved deeper in the content (Figure 3).

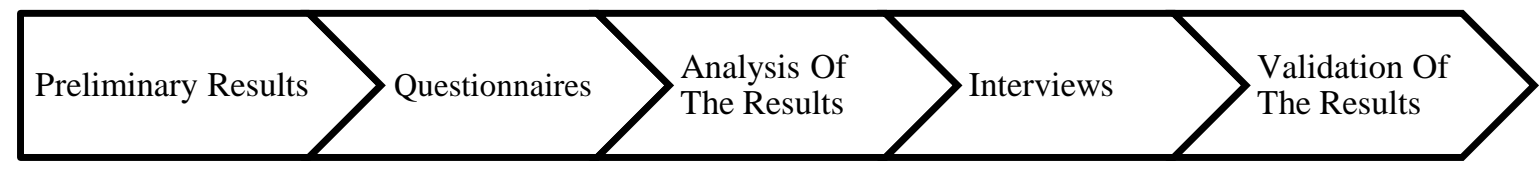

Figure 3 - The structure of the research

The research is inductive, the explorative direction is the priority, because at the end a theory-set is built, however there are some deductive approaches during the validatory steps. A combination of quantitative and qualitative methods is used, too. From the triangulation perspective the data, the theory and the methodological ones are used. Multiple data sources (evidences), theories and methods are used to get confirmation 
about the consistency of the examined phenomena. The following section describes the business processes in detail, which is one of the research's two pillars.

\subsection{Results and new interrelations}

\subsubsection{Question 1}

Under what circumstances is the knowledge management applied? Can it be defined? What are the characteristics?

The set of the possible relevant dimensions are practically infinite, therefore the scope of the research was narrowed to the knowledge intensive organizations. Based on the theories, the standards, and the methodologies the following assumptions were determined: the knowledge management is considered applied when the competencies are documented, if there a knowledge repository in place, if there are training plans, and if the knowledge management is handled on strategic level.

The main outcomes are the following:

- the applied knowledge management's relevance is high in case of cyclical business processes,

- the organizations' work management is based on reliable knowledge,

- the digitization of the knowledge management systems is an enabler for other knowledge management-related processes.

At the same time the passive, not utilized knowledge of the workforce is not considered as an inherent part of the knowledge management processes.

\subsubsection{Question 2, Question 3}

Under what circumstances is the knowledge management measured? Can it be measured? What are the characteristics? Under what circumstances is the applied level 
of the knowledge management determined? Can it be determined? What are the characteristics?

The two questions are handled together in the result interpretation.

The organizations have internal workflows and business process management. All the human actors have to follow their workflow, and they possess definite knowledge that helps them to get along and that drive the business processes.

An analysis of the business process management standards, models, methodologies is needed as a prerequisite and the same has to be done with the knowledge management. The main challenge for measurement is how to highlight the relevant and the necessary (even if they do not seem to be relevant) elements in order to get a general interpretable picture about their processes.

Once the phenomenon is measured, then its relative levels might be assessed. Identifying the various levels might give an instrument for the organizations about how to balance the costs and benefits during the knowledge management without imposing unnecessary risks. The research does not try to determine the optimal level, but it tries to reveal some steps in order to articulate its predecessors.

In the research, two mutually exclusive sets are discussed: the high level knowledge management, and the low level knowledge management.

Based on the theories, the standards, and the methodologies the following assumptions were determined: the knowledge management can be measured, if the competencies are measured, if the knowledge sharing is known, if the knowledge repository's utilization is measured, and if the knowledge bearers are measured.

The high level knowledge management's characteristics show that the reliable knowledge is one of the most significant factors among the interrelations. Another key outcome is that the more highly cyclical business processes and the better measurement of the BPs are positively correlated.

The low level KM is complementary to the high level. 
The low level knowledge management applies the most important basic principles of the BPM. The BP documentation is tightly connected to the operative work (critical knowledge elements are taken into consideration). The more hierarchical the organization is, the higher the measurement level is. The higher the measurement level is, the better the employees rely on documented procedures.

\subsubsection{Question 4}

On what level can the organizational knowledge be assessed and evaluated based on business process management? What are the characteristics?

The organizational knowledge assessment and evaluation are complex, and they should be based on traceable and demonstrable evidences. To get the answer for this question, the practical results of the research have to be outstretched.

The assumptions for the sufficient level of business process management is whether the business processes are identified, whether they are structured and documented, and whether the employees know the BPs.

The substitute and competitive competencies have a very strong correlation and significance. The main conclusion is that having the required level of substitute knowledge bearers within the organization is definitely a competitive factor in organizations where the BPM is on high level.

\subsection{Novum in research methodology}

The research takes into the consideration not just the related theories, but the practice as well. The standards, the methodologies, and the utilized best practices give an opportunity to enhance the research's holistic nature with the real business environment. Both the introduced theories and practices give such an alloy that is based on validated results. 
Once the relevant inputs are determined, they are measured against real business entities. The measurement is expanded with validatory steps (interviews) in order to check the feasibility of the research. This was proven a strong plus during the research, because it gave more confidence.

Beside the holistic nature of the research, the research is inductive and explorative; the point was to identify such patterns that later on can be developed into a theory.

The results are right by quantified plausibility; however, the domain needs further researches.

\subsection{Practical recommendations}

The research had a similar, preliminary research, its results and the gained experience could be utilized in this research as the current case is almost identical.

The research covered in the early stage an extent domain about the interrelations of the business process management and knowledge management. With the help of the reviewers, it was acutely narrowed that allowed a more focused research and this decreased the utilized effort. The smaller, better defined domain provided a not too complex dataset.

The aim was to collect one hundred responses. In the practice it turned out that this number cannot be achieved via online questionnaires with the available resources. Multiple additional personal interactions were needed to reach the aimed number, and in the meanwhile the interactions' complexity was growing. Collecting the same information on multiple channels (online vs. hard copies) increased the work's complexity.

The planning of the interviews was easier than expected; fortunately the domain seems to be quite challenging, and many candidates showed interest in it.

One interesting input was from the response-givers that the research should not contain technical terms at all. Even if it seems to be the subject of the common language, in fact, it is not. 
During the research just the correlation coefficients were measured, since it was quite exhaustive and it gave a comprehensive and logical picture, it was sufficient in the current case. However, in order to identify more complex interrelations it is recommended to use factor analysis (Kovács, 2011).

Based on the above experience, the main recommendations for researches are:

- to limit the extent of the research in order to maintain the focus and the handling ability of the data,

- to utilize direct, personal channels instead of indirect (online) channels for primer data collection,

- to stick to achievable goals and to estimate the required effort in case of changing the scope, even if it is just a technical change,

- to always ask for help if it is needed.

The main outcome is that the research should stick to the research goals, but at the same time it has to be embedded in realistic environment. Beside this, throughout the research, every feedback should be welcomed, especially in the planning phase. 


\section{BUSINESS PROCESS}

In this section, a detailed description is provided about the key factors of the business processes, the related international standards, the most common models, and the methodologies. However, first, the background of the processes is presented.

In the next paragraph, the process-related key definitions are introduced.

\subsection{Basic definitions}

The processes are present in every science-domain, they have special significance in natural sciences, and therefore a couple of related thoughts are indicated here.

Every process runs in a specific environment, they usually have a start and an end. The essence happens between the start and end, e.g. transformation of goods, producing value added information. There is usually also an actor, who executes a specific task in order to solve the problem that started the process. This arisen event is the trigger event. The processes need resources to be proceeded. In addition, they need time and at least one interaction.

The processes can be reversible or irreversible. The reversible processes can be reversed without causing any particular changes in the system or in the environment. The irreversible process changes its surrounding elements permanently in each cycle. In connection to this in physics the entropy is commonly understood as a measure of disorder (Shannon, 1948), on this, both the reversible and irreversible processes have affect. Disorder as a specific state for an organization might be practically interesting, so is the noise. Having noise within the environment has to be mentioned also, because it is a vital element of the complete system. The reversibility, the state of order, and the noise are factors of the systems' stability. The organization might be in unstable, 
neutral, and stable state. The preferred outcome is to determine a stable organization which can be influenced and altered as per the business expectations.

Among the processes there are such which enable the mechanisms for the others, and there are also bottlenecks. Enabling the processes means that the connecting, related processes are triggered, and all of the required resources are at service, so the process can move on. The bottleneck is a kind of limited throughput in the system. With a bottleneck the organization can work just with limited capacity, because there is a weak element in the chain (constraint). Measuring the whole system based on the system theory principles and using the proper algorithms can help with its identification.

In addition, the driver process has to be introduced also. The drivers are those processes that determine the main profile of the specific entities; all of the other processes support these. From business aspect, the driver processes are the value added business processes.

These basic definitions are used later on as an approach in the discussion. The definitions are articulated on a basic level but they are sufficient for the logical reasoning.

In the next paragraph, the organizational processes are analyzed from a general interpretational view.

\subsubsection{Processes}

There is a growing interest in analyzing processes in connections with organizational activities. There are different perspectives from which the processes can be studied:

- the lifecycle of the project: start, development, change, closing;

- level-wise: top, middle, bottom, holistic, targeted, etc.

All of the perspectives have their own justification, and in specific environment they can probably be used with high efficiency. In this chapter a logical interpretation is followed, in which three main concepts of the (strategic management) processes are 
used, in order to provide a systematic approach for defining the business processes. (Van de Ven, 1992)

The first of the concepts is a logic that explains causality amongst the dependent and independent variables. This variance theory conception handles the process as an input-process-output model, where input equals to independent variable and output equals to dependent variable (Mohr, 1982). According to Van de Ven (1992), this model is too robust, because the process itself is a black box and clear connection between the input and the output cannot be perceived.

The second one is the category of concepts which "refers to actions of individuals or organizations". In practice, workflows, communication frequencies and similar activities are the part of this. During the representation of these processes, the actual occurrence can be measured, not how it came off. (Van de Ven, 1992)

The last one is a sequence of events that covers the change over time. There are a lot of remarkable models, the research related are Scott's (1971) and Greiner's (1972). Both of them constructed organization development models, and both of them examined the activity phases from the beginning till the end.

Scott covered the main company characteristics and delineated them against the different stages of development: product line, distribution, organizational structure, performance measurement, control system, etc. The main outcome of his model: the more developed the organization is, the more complex problems it can solve. For example, at 'Level I' there is a single product, one distribution channel, there is no formal organization structure, performance is measured based on subjective criteria and the control system is on personal-level. Skipping 'Level II', on 'Level III' there are multiple product lines, multiple distribution channels, the organization is specialized and integrated, the performance management is impersonal, the control is indirect and more likely based on the analysis of the business results.

Greiner determined five stage levels of organizational growth through evaluation and revolution, and assigned problematic areas. The stages are the followings: growth through creativity - leadership crisis, growth through direction - autonomy crisis, growth through delegation - control crisis, growth through coordination - red tape 
crisis, and at last, on the top level, there is the growth through collaboration without identified crisis.

Mohr highlights the inputs and the outputs, Van de Ven the interactions, Scott and Greiner emphasize how the organization system's collaboration is getting more abstract and indirect as the complexity is increasing.

Although Van de Ven's set is worked out mainly for strategic processes, its logic is quite applicable in case of business processes, too, since it helps a lot with distinguishing the relevant elements because of its matching analogies.

After gaining an organization-related approach, the focus gets narrowed down from the general level. In the next point, the business processes and the related terms are introduced.

\subsubsection{Business process}

There are multiple definitions for the business process (BP), in the research the following definition is used: the business process is "a collection of activities that takes one or more kinds of input and creates an output that is of value of the Customer" (Hammer and Champy, 1993). The tasks to be conducted within an organization are directly or indirectly linked, and as one of the outputs they deliver product or service to the business entities' clients.

Davenport (1993) defines the business process as structured and measured set of activities, with clearly defining the inputs and outputs, and the structure how the specific set of acts are done. This definition has a more emphasis on structuring.

Rummler and Brache (1995) highlight the role of the organization's external customers, they distinguish the primary processes and the support processes. The primary processes and products can be seen by the external customers, the support processes cannot, but they are essential prerequisites for the primary ones. The primary processes are involved in the direct value addition, the definition is quite close to Porter's value chain approach (1985), in which the primary activities were operations, 
logistics, marketing and service; the secondary activities were the supporting ones, e.g. procurement, infrastructure management, etc.

Two additional basic concepts have to be listed which are relevant in this topic: business process reengineering (BPR) and total quality management (TQM). The BPR focuses mainly on the analysis of the workflows and their redesigns, its aim is to reshape the organization fundamentally. According Galliers (1998), it is required to have a "shared vision" and a "review of existing structures and processes" in order to implement successful changes. In order to avoid making unfeasible change proposals, it is necessary for the relevant stakeholders to have a general picture about the current organization. The TQM supports mainly the continuous improvement of an organizational entity, its basic concepts is presented in section 2.4.5.

As a consensual definition, the Hammer-Champy definition is used. In the next paragraph, the workflow's significance is introduced.

\subsubsection{Workflow}

The BPM and the workflow are expressions that are used in similar environment with similar meaning, especially when they are not properly identified, although they are not identical. "Workflow is a technology used to support business processes" (Csepregi, 2010). The workflows can be conducted without doing business processes; however, the workflow engine is the base of BPM. In general, the workflow is really close to the interactions of the coworkers, while the BPM can trigger a higher level procedure (in value, and it is more abstract). The workflows are the parts of the BPMs, and they are the pure technical level of the BPMs. The workflows have a supportive function in order to fulfill the BP's technical requirements.

According to Gartner's definition: "the workflow is a form of flow management technology that coordinates interactions between people and software systems" (Hill, 2010). The definition has the same meaning as in the current research. The people are the human and the software systems and the related technologies are the non-human elements. The workflows are usually document- and task-centric, they allow the users 
and coworkers to cope with the business problems in a semi-structured or structured way.

Other definitions of workflows are also available: the workflow is "an automation of a business process, in whole or part, during which documents, information or tasks are passed from one participant to another for action, according to a set of procedural rules" (Lawrence, 1997). It can be stated that the definitions are similar, they cover the same approach.

To sum it up the general findings are the followings:

- the workflow is an automation of a business process,

- the business process is related to those business activities that realize business objectives (and value for the customer).

In the following points, the main characteristics of the BPs are introduced.

\subsubsection{Roles and actors}

The analysis of the relevant or analyzed processes should cover what are conducted, where, when and by whom. The 'what' is the specific task, the 'where' is the spatial or virtual environment, the 'when' is the timely characteristic (interval, deadline), and the 'who' is the specific actor who performs the task.

People with diverse background normally share the same values, although the priorities are different (Schwartz and Boehnke, 2004). In order to be able to handle the different background, normalization is needed in the system, the individuals who are the actors of the specific tasks have to work in a controlled environment. In the organizations, there are usually ordinary actors and individuals with high influence (Dear and Moos, 1986), by setting the control environment properly not just their management can be more secured but their recognition, too.

In an organization, the actors can form "a group of participants exhibiting a specific set of attributes, qualifications and/or skills", this is the definition of the Workflow Management Coalition (WMC, 2015), and it is used for defining the role. 
If something should be measured precisely, there is a requirement to maintain a control system, wherein the specific roles' have defined responsibilities (this approach will be explained in details in 2.4.2). It is also important to consider the possible risk and security related issues as a part of the management (broader background in 2.2.3).

Some relevant topics are discussed later where their justification is in the right place. In this section, a couple of additional information-focused phenomena are introduced that are related to the role conducting actors.

The not properly identified actors can form unbalanced power within the organization. The information asymmetry (Stiglitz, 2004) in economics is the part of the decision theory, where one party has better information, and this leads to unbalanced power. Since the current research is about the process and knowledge management, its significance is high, because the role of the human factor is quite high. Tightly related problems are the moral hazard and the information monopoly, these are not discussed detailed just highlighted as inherent elements of the BPM and KM.

The principal-agent problems (Samuelson and Nordhaus, 2010) are connected to this domain, too, since the asymmetry can cause imperfect information (Osborne, 2004). If the different roles are not appropriately aligned with a common (organizational) interest, then they might alter the business processes according to their own perceptions, goals. The presence of the above problem-sources can support such actors who form unwanted information brokerage; in this case, the issues related to information dissemination and information cascade may pick up.

In the following paragraph, the business process characteristics are aggregated.

\subsubsection{The main technical characteristics of the business process}

Although Hammer and Champy's (1993) definition is used as the main reference, but an additional deep reference is introduced: the technical side of the realization to make the picture complete. The below technical model (Figure 4) depicts the business processes as a set of directly or indirectly linked activities which as one realize a 
business objective within the context of an organizational structure, defining the roles and relationships. (Hollingsworth, 1995)

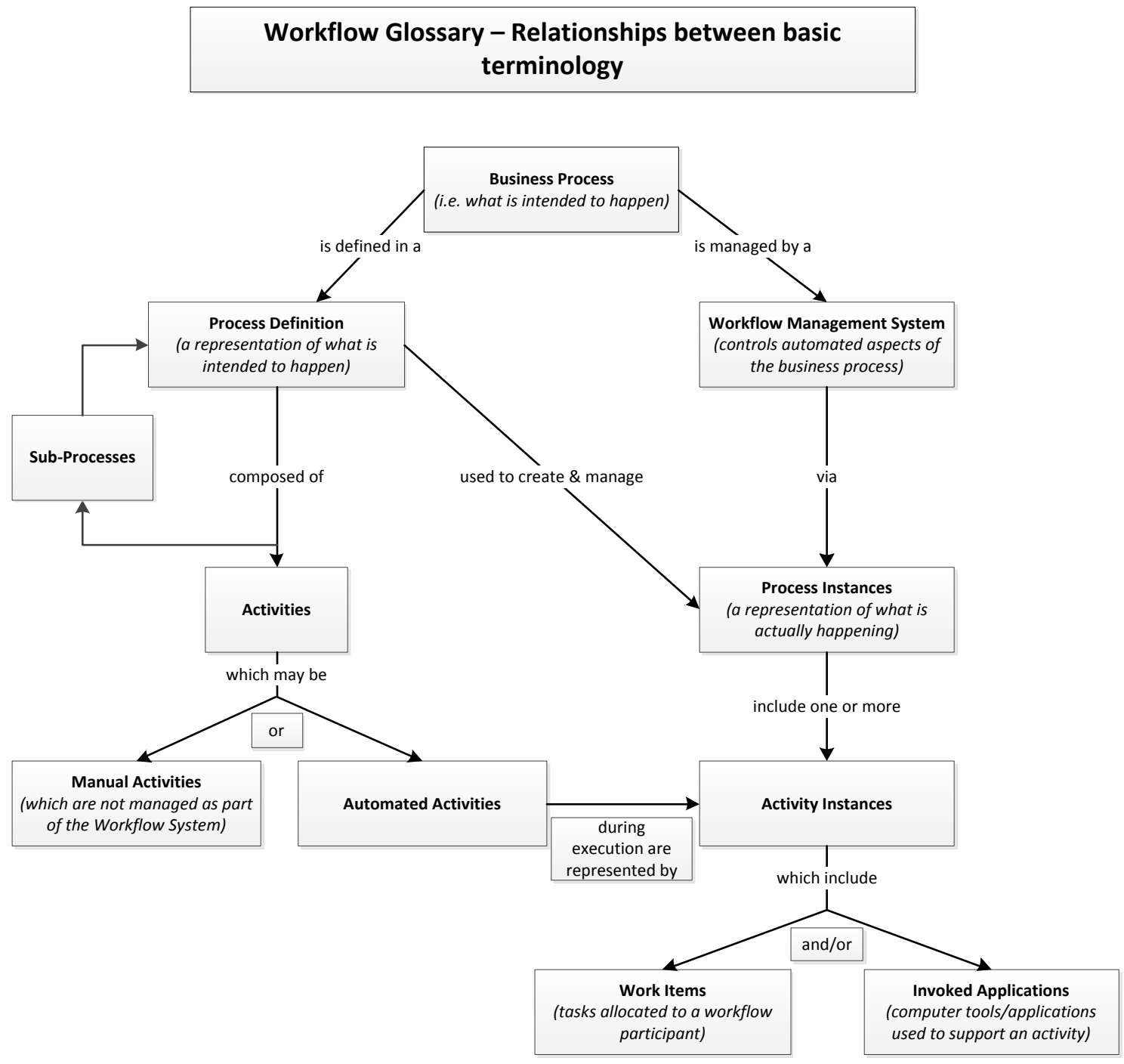

Figure 4 - Relationships between basic terminologies

Source: Workflow Management Coalition (WMC, 2015)

Among the business processes, there are automated and manual activities, parallel and sequential routings, deadlines, and condition handling (particularly pre and post). On Figure 4 it can be seen how the interrelated terminologies cooperate, what the inputs and the outputs are. Most of the elements of the business process management can be handled by the workflow management system from a technical point of view, too. However, there is an exception: manual activities. These are the activities that are done by human individuals, and this is the complement set of the workflow system that 
makes it complete to compose the whole business process management. This is the part where the knowledge management is the most relevant, since this part should be somehow incorporated into systems that are more explicit. This paragraph covered an outlook about the technical side, the research will stick to the original business process definitions (2.1.2).

In the following paragraph, the business process-related standards are introduced.

\subsection{Standards}

The evaluation and assessing of the knowledge management is a complex task even in the case of small business entities with a low number of possible interactions. In case of larger sizes, the tasks' complexity grows, especially if there are more functions involved.

The international standards that are based on wide experience are utilized to draw a unified and focused framework of the KM within organizations. In the followings, the most relevant standards are introduced.

The used standards are developed by the International Organization for Standardization (ISO) and its partner organizations. These standards can be used directly (even on international level), or could be tailored as per the domestic requirements (country) and local demands (regulations). The most important benefit of using these standards is that they can significantly raise the awareness about the processes for the cooperating business entities. In the next three paragraphs, the most relevant (knowledge-related) standards are shortly introduced.

\subsubsection{ASQ/ANSI/ISO 9001}

The ASQ/ANSI/ISO 9001 (ISO 9001) is part of the ISO 9000 family of standards. The ISO 9000, ISO 9001, ISO 9004 and ISO 19011 form the quality management standards. ISO 9000 specifies the terminology, ISO 9004 determines the guidelines 
and the elements that have to be considered during the effectiveness and efficiency measurements. The ISO 19011 gives hints for auditing the quality and the environmental management system.

The ISO 9001 standard is about how to adopt a quality management system on strategic level and on operational level. Its main focus is to provide a consistent framework for the business in order to meet the customers' needs. It clearly defines the general requirements, the documentation requirements, the management responsibilities, the resource management, and the realization of them. In addition, the measurement and improvement opportunities are also stated. This standard is the core of the quality management, and since this is a general standard, its logic is used in every ISO standard.

In case of ISO 9001 one of the most important part is the 'Human resources' part in which the competence, the training, and the awareness related requirements are set (ISO, 2015, ASQ/ANSI/ISO, 2015). Additionally, it is stated that there is a requirement to maintain evidences within the system, this one also emphasizes that the process-oriented approach is a main precondition to handle the whole in a system.

The standard first introduces the requirements to understand the organization then the expectations of the interested parties (Clause 4.2 'Understanding the needs and expectations of interested parties'). The interested parties can be customers, governments and non-governmental organizations, shareholders, and employees. A proper quality management system (QMS) needs to include the relevant parties' requirements, related information should be made transparent and available for them and the whole process has to be measured, and - if required - the traceability has to be maintained, too.

The authorities and the responsibilities of the roles have to be assigned, communicated, and understood throughout the organization ('5.3 Organizational roles, responsibilities and authorities'). The processes should run according to the intended outputs.

Clause 7 covers the support processes (Appendix 1) what addresses the $\mathrm{KM}$ in the deepest essence. The '7.1.6 Organizational knowledge' covers the knowledge management expectations. The knowledge has to be determined and it should be fit with providing the required products and services. The knowledge has to be 
maintained and made available as the necessity dictates. The change management should take the knowledge into consideration. Acquiring the new knowledge has to be planned based on the current, accessible knowledge. The internal (e.g. captured knowledge, intellectual property) and the external (e.g. from customers gathered knowledge, free online resources) knowledge are both parts of the complete KM. The 7.1.6 points out that the organization should prevent the unintended loss of knowledge and it has to raise the performance in gaining knowledge by establishing a measurement system. Therefore, the knowledge capturing and sharing should be measurable. The critical knowledge elements have to be highlighted and the knowledge gaps have to be identified.

The Clause '7.2 Competence' determines the requirement of the necessary competence. The persons should have the appropriate education, training, and/or experience, where applicable actions have to be taken (e.g. training, mentoring). The evidence of competence has to be documented and maintained. (ASQ/ANSI/ISO, 2015)

In the next paragraph, the service-oriented approach of the ISO is introduced.

\subsubsection{ISO/IEC 20000}

As long as the ISO 9000 series was developed to help the organizations with implementing a reliable, justified, and evidenced QMS, the ISO/IEC 20000 (ISO 20000) standard might be considered as a complement for the service management, with the same expectations. The service management is a "set of capabilities, including processes, required to direct and control a service provider's activities and resources to fulfill service requirement as agreed" (ISO/IEC, 2010).

The ISO 20000 is meant for the service management systems (SMS), it specifies the service providers' requirement for design, transition, delivery, and improvement of services (ISO/IEC, 2010). It can be used for both the service providers and the service buyers (service users), since it can give a consistent framework about the service supply chain and about the measurement. The ISO 20000 does not specify everything 
in details, but it gives advice about designing the processes. This standard is commonly used in the ICT service management.

From the knowledge management aspect, ISO/IEC 20000-1's 'Chapter 4' is the most relevant since it covers the resource management, its approach is similar to 9001:2015's 7.1.6 section (Appendix 2). The QMS scope can include every aspect of the organization, the SMS' scope is defined for design, transition, delivery and improvement of services (ISO, 2013).

The '5.5 Capacity Management', the '5.6 Change management', the '5.7 Configuration management', and the '5.8 Human resource management' are the most important processes of this part. The human resource as the critical resource for service providing can be assessed in this model.

The ISO/IEC 20000-1 provides the requirements for 'ISO/IEC TR 20000-4 Process reference model' (PRM) and ISO/IEC TR24774 informs it about the guidelines for process definition (Figure 5). ISO/IEC TR 20000-4 transforms the inputs into a process reference model, this model requires beside the business logic representation of the service management the alignment of the entity-specific expectations. The reference model is described with specific purposes and related outcomes, these purposes and outcomes are the minimum necessity to meet the ISO/IEC 20000-1 requirements.

As an end step the processes are assessed based on the PRM and according to the principles of ISO/IEC 15504 (ISO 15504). The purpose of this part "is to facilitate the development of a process assessment model" (ISO/IEC, 2010). The process reference model, derived based on the requirements of ISO 15504, should be a logical representation of the process elements within the service management (Kunas, 2012). 


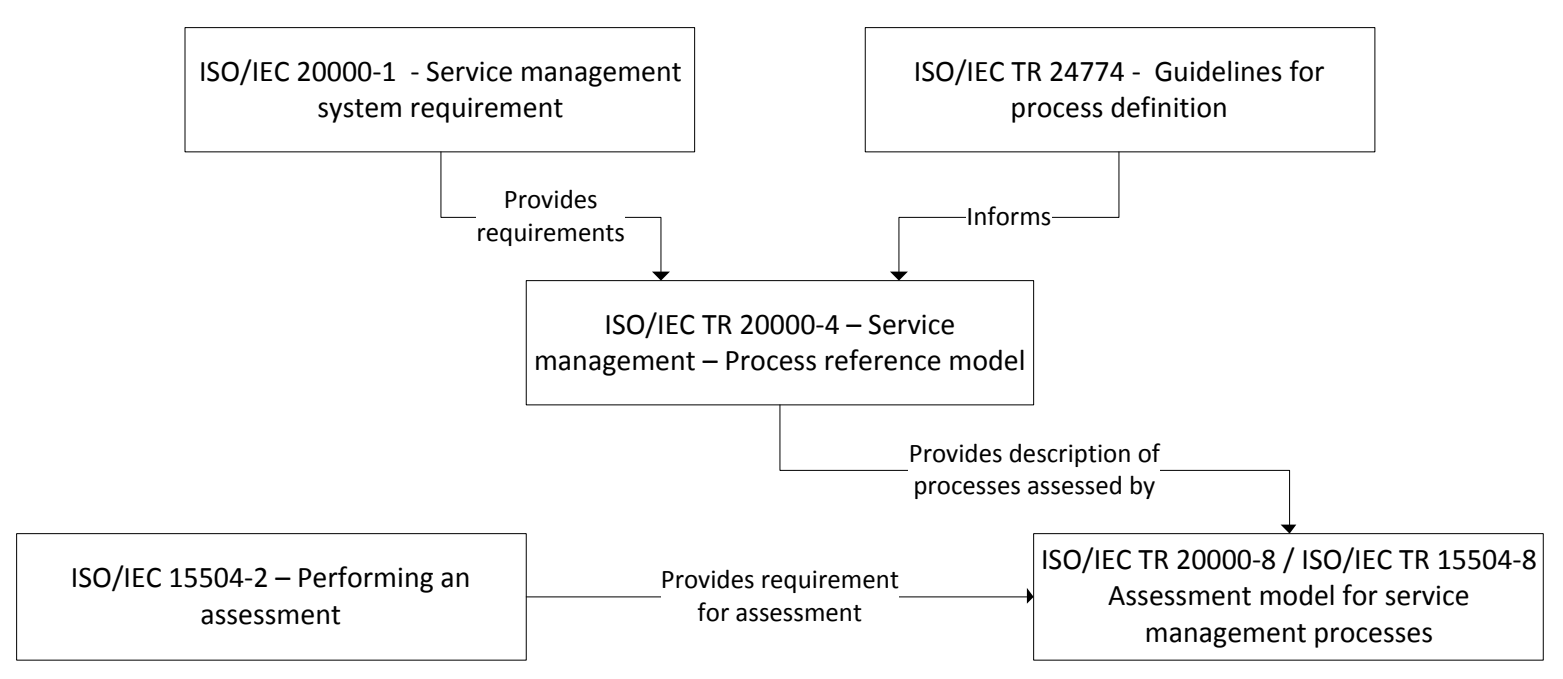

Figure 5 - Relationships between relevant documents

Source: own edition (ISO/IEC, 2010)

The ISO/IEC TR 20000-4 is the core of the whole process, the PRM allows to think in a measurable environment that can be the base for assessment. The most important parts are the '5.5 Capacity management', the '5.6 Change management', the '5.7 Configuration management', the '5.8 Human resource management', and the '5.9 Improvement'.

For service management, these standards give the assessment foundation. In order to enhance the QMS and the service management, it is also needed to focus on those elements that might have negative effect on the BPs' outcomes. The next standard targets this question.

\subsubsection{ISO/IEC 27001}

The ISO/IEC 27001 (ISO 27001) is for those organizations that would like to keep information assets secure. It covers the requirements of the risk management (RM), the security awareness, and the business continuity management (ISO/IEC, 2013, ISO/IEC, 2016a).

The structure of this standard is similar to the two former ones (Appendix 3 covers examples from the whole ISO/IEC $27 \mathrm{~K}$ for demonstration purposes), the common 
thing is that their logical path is similar, the requirements are set for the responsibilities and for the managing, but the content is here risk-related. The '5.2 Resource Management' is the same as in the former cases, just the domain differs. But why is risk management interesting from the knowledge management aspect? The potential impact of the knowledge might be critical in the case of a large companies (e.g. possible reputation issues), or it might be a success factor for a small-sized company (e.g. innovative mindset). So the ISO 27001 is similar to a legal framework, it defines the basic ground rules that have to be followed as a zero-level requirement.

The ISO 27001 is applicable in all cases where the preservation of confidentiality, integrity, and availability (CIA) has to be maintained. Authenticity, accountability, reliability, and non-repudiation can expand the basic requirements.

The accepted system should be working based on such events for which evidences can be provided. The evidences should be relevant, reliable, and have 'general acceptance'. In addition, it is a question who can present the evidence and how it is presented. Taking an analogy, in law the Frye standard was used first as common denominator. An expert opinion had to be based on a scientific technique (Frye standard). The technique was admissible when it was generally accepted as reliable in the relevant community (scientific, expert). Beside the technique, this approach involved also additional procedures and principles (Bernstein, 2001). The original notion was expanded (Daubert standard) with defining the scientific knowledge: the scientific knowledge can be demonstrated as the product of scientific methodology derived from the scientific method. Relevant factors are, whether the testing is testable at all, it was peer reviewed and published, its error rate is known, and what the degree of its acceptance within a relevant scientific community is (Welch, 2006). This approach reflects the complexity of the domain, former it was necessary to determine the eligibility of specific applied processes in the legal framework, especially if no computer-aided technology was available.

The current technical environments allow wider scope of activities, forming evidences is getting more and more environment-centric. As a general finding, it can be stated that the complex evidences are easier to be assessed than the general ones. For example, the machine-learning methods can be used in information (ICT) environment for de-anonymizing source code authors in programming. The code resulting from 
difficult programming tasks is easier to attribute than easier tasks and skilled programmers (who can complete the more difficult tasks) are easier to attribute than less skilled programmers. (Caliskan-Islam et al., 2015, Caliskan-Islam et al., 2016)

The organizations are active in a manufactured uncertainty. The activities' characteristic is reflexive. Continuous monitoring, adjusting, behavior-calculation face insatiable demands for information and pressures for accountability. (Giddens, 1990, Giddens, 1991)

Derived risks may be defined as a systematic way of dealing with hazards and insecurities induced and introduced by modernization itself. Risks, as opposed to older dangers, are consequences which relate to the threatening force of modernization and to its globalization of doubt (Beck, 1992). One of the risks is identified as knowledge. Its type and state of accumulation, distribution, and availability might be critical during operations.

The examples above were interpreted on wider level, but they are also true for the organizations who deal with production or ICT services. The standard takes into account the relevant business and/or regulatory requirements. The risk management concept is built up within the context of the given organization. The risks are assessed, accepted based on specifics, at the end they are measured against the impacts against the CIA-model. The economic entities use information systems and most of them take care of business continuity. The risk of business interruption is dependent mainly on ICT infrastructure. A comprehensive approach has to be developed that seeks to mitigate against all major business interruptions (Cerullo and Cerullo, 2004). Since the knowledge management is part of the organizational ICT system and it bears inherent value, the risk management framework addresses it, too. On long term if the knowledge is not secured, the innovation, one of the competitive advantages, can be also threatened (Galunic and Rodan, 1998).

The ISO 27001 standard handles the resource management similar to ISO 9000 and ISO 20000. The organization has to ensure that all personnel are competent to perform the tasks. Competences have to be determined, the gaps have to be analyzed and closed, and there should be evaluations that get the steps measured. Documented records are also necessary. 
The basic organizational processes are expanded by information security management policies and the management of different assets. The duties are also segregated, based on this segregation one defines the roles and the access management. The data, information, and the knowledge are also the assets of the organization, their classification and protections is also a priority for the organizations. The standard directly handles the intellectual property right management, too.

All the ISO standards follow the same logic, all of them have relevant connections with knowledge management, especially through resource management.

In the next paragraph, the relevant methodologies and best practices are shortly introduced.

\subsection{Models}

The business models are good means to provide a common communication platform about the process flows. Normally a system consists of human elements and physical, non-human elements. The gap between the human and non-human elements and business objectives can be closed, just if they communicate in a common language. The 'spoken' and 'understood' language should have the same meaning (semantic). In order to get a basic overview about a complex system, it is required to have a model that translates the details into a measurable system. Once this model is available, it can be evaluated. Based on the evaluation, the analysis and optimization will be manageable.

The following standard-classification will be used as grounding in the current paper (Ko et al., 2009)

- execution (BPEL, WSFL (Leymann, 2001), XLANG (Thatte, 2001)),

- interchange (XPDL , BPDM (Bock, 2008)),

- graphical (BPMN, UML (OMG, 2015), EPC),

- diagnosis (BPRI, BPQL).

The execution standard helps with the deployment and automation of business processes, with the interchange standards the data can be transferred from one place to 
the other and the related the diagnosis standard establishes the capabilities for administrative purposes.

The graphical standard allows describing the business processes visually in a graphical way.

In the coming two paragraphs, two very important graphical standards will be introduced the Business Process Model and Notation v2.0 (BPMN) and the eventdriven process chains (EPC).

\subsubsection{BPMN}

The graphical standards are readable by most of the humans and they are easy to be interpreted, even without previous induction. The BPMN is one of the most expressive way to present the business processes, it is also available for the other three elements of the above mentioned classification, they can cooperate with that. The BPMN originates from 2004 when the 1.0 version was released by the Object Management Group (OMG), now it is at 2.0 version, latest release was in 2011 (OMG, 2011). This graphical notation is one of the instruments for bridging the gap between the human actors and the ICT-environment. The standard modeling notation is very important for the readability and the alignment of different business teams.

The BPMN can handle events, flows, gateways, activities, and it offers precise flow control semantics. It can also handle various levels of granularity and more roleperspective at the same time. Its theoretical background is based on the Petri nets (Harvey, 2005). Figure 6 shows the collaboration model-type, one of the specific types. This diagram is a best practice to show one process in one pool. 


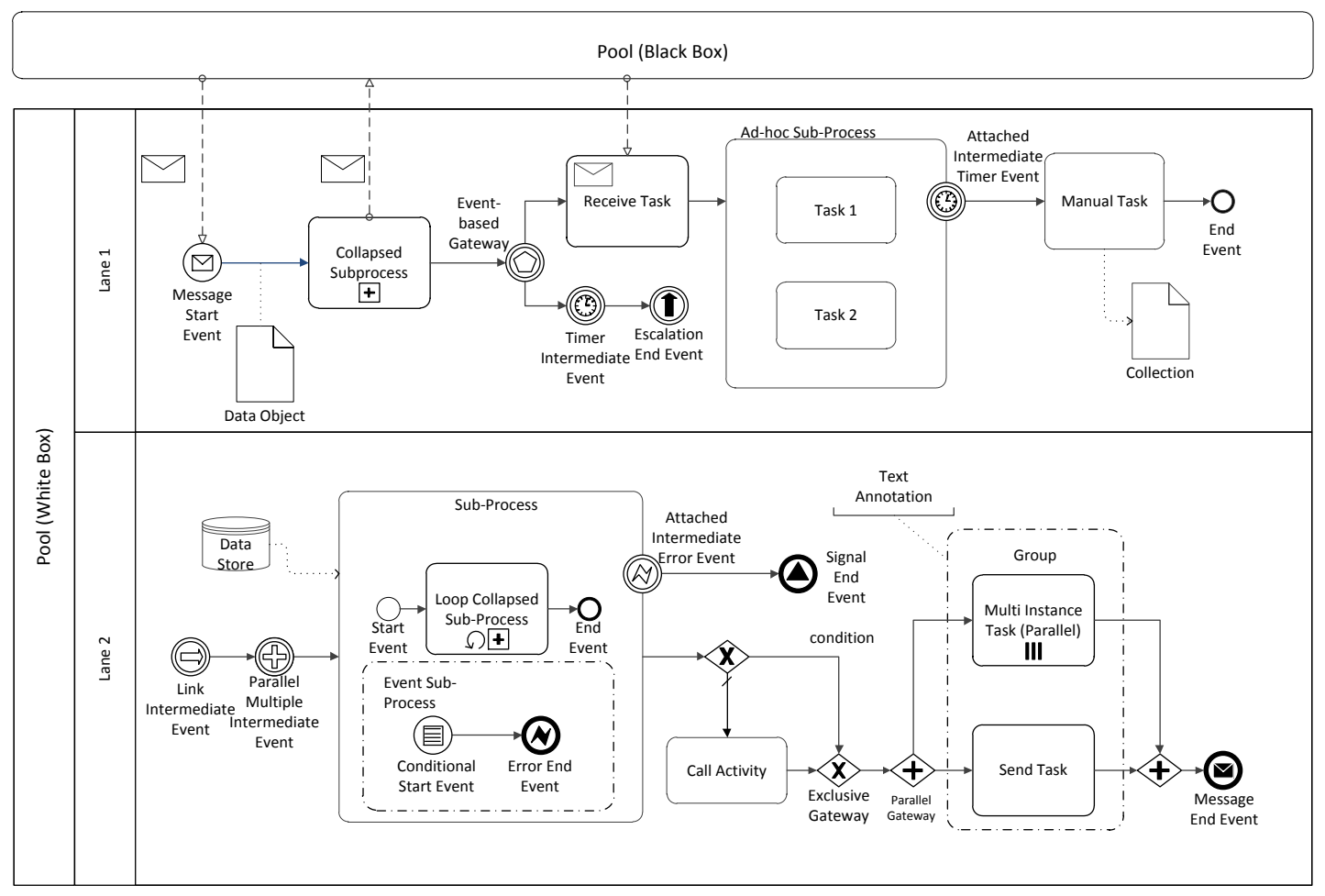

Figure 6 - BPMN

Source: own edition (Anonymous, 2015)

BPMN is a collection of multiple model types, the coming EPC is a specific modeltype.

\subsubsection{EPC}

The EPC represents the control, the logical and temporal flow of individual function of a process. It delineates the chain of functions and events. The events are the trigger of the functions, the results of the functions are events. The EPC begins with, at least, one start event or a connecting process path and ends with, at least, one event (or a connecting process path). Figure 7 shows how simple the structure of the model is. (Scheer, 1992, Scheer, 1998) 


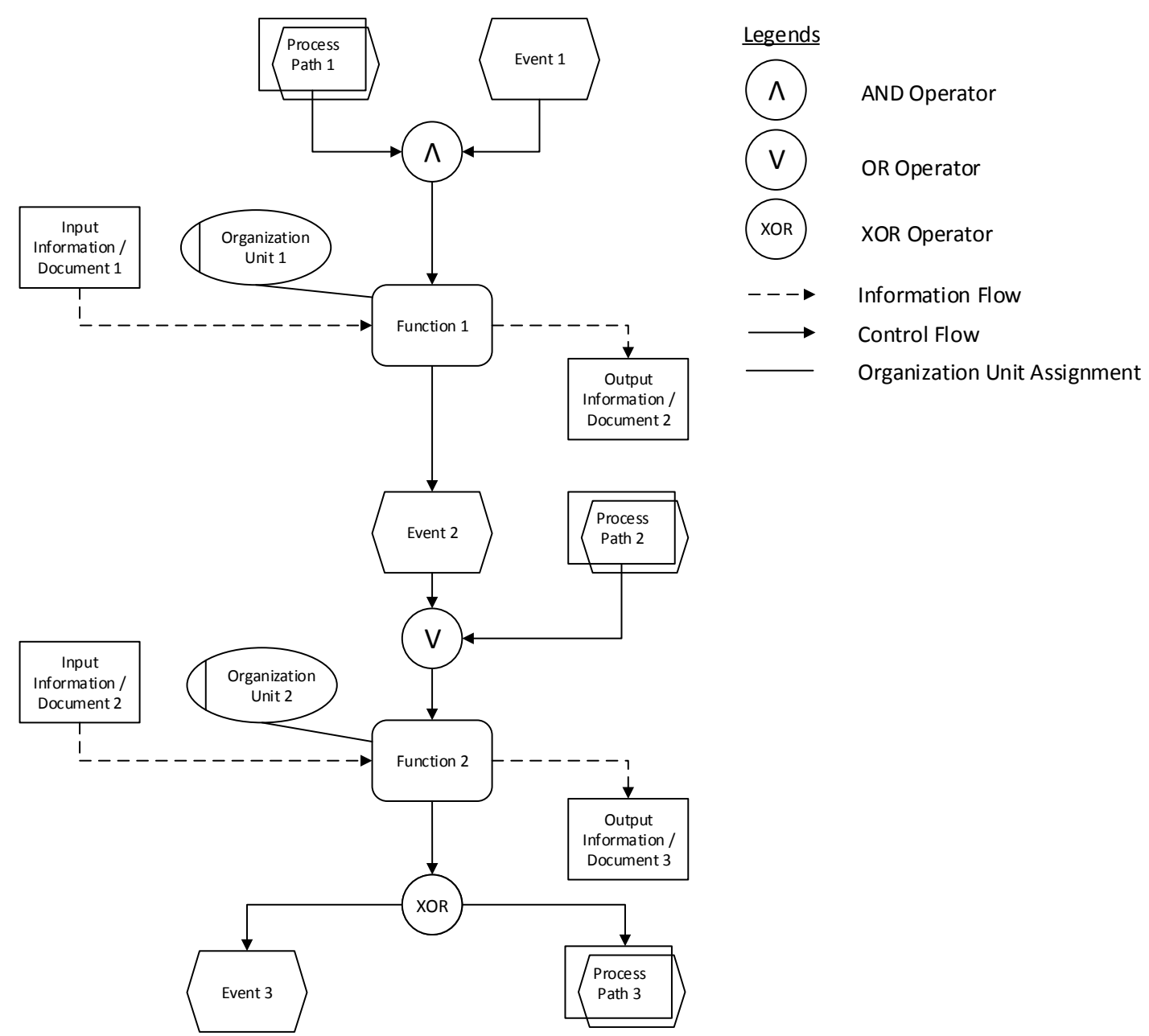

Figure 7 - EPC diagram

Source: own edition (2015)

The EPC has the following objects:

- event - trigger or result,

- function - activity or task,

- organization unit - role or actor,

- application system - usually an ICT system,

- input information / document - references, documented knowledge, information carrier, email, etc.,

- process path - process interface, link to another EPC,

- logical rules - decision (single input, multiple outputs)

- OR - one or more possible paths will be followed as the result

○ XOR - (only) one of the possible paths will be followed

- AND - the process flow splits into two or more parallel process paths 
- logical rules - preceding functions (multiple inputs, single output)

$\circ$ OR - any combinations of the event trigger the following function

○ XOR - one (only) of the possible events will trigger the following function

- AND - all preceding events must occur to trigger the following function

The model allows getting involved every role, every document, and all the processes. The logical operators makes the EPC model able to cope with all of the logical operations, 'AND' covers the conjunction, 'OR' the disjunction, 'XOR' the antivalence (exclusive), and indirectly the negation, the equivalence, the inhibition, and the implication (etc.) can be derived, too.

For addressing the explicit, built-in knowledge management, it is good to have this integrated view of process across the business entity. The process-based and the rolebased view can be presented for the same processes, the visual representation enables to represent what to do and how to do.

Not just the common understanding can be enhanced with the EPC, but also the process awareness can be increased, by providing a prompt learning and improvement tool for a wide range of audience. This solution can help with the process change management and impact analysis, too.

The BPM related models and tools have a huge warehouse, here they were shown just with presentation purposes, in order to reveal what can be built into the system and what can be drawn from the system.

Since the focus of the thesis is more on the interaction of the human and the nonhuman side, the pure technical side was briefly introduced and not discussed in detail, so the knowledge-management perspective is predominate.

Some basic international and global standards were already introduced and the basics of the BPM models. In the next point, the connecting methodologies and best practices are brought out to complete the business process management aspect. 


\subsection{Methodologies}

The best practices and the methods are based on both the theoretical research and the practical experience. The above list of standards is close to those methodologies that are introduced in this point. The 2.3 point has at the same time the logic that these methodologies take into account.

In the coming paragraph, the following methodologies are described (all of the sources are from international origin and they are widely accepted among the knowledgeintensive business entities):

- COBIT5,

- ITIL,

- CMMI,

- PCMM,

- Six Sigma.

\subsubsection{COBIT5}

The Control Objective for Information and Related Technology (COBIT $®$ ) is a framework for information technology management and governance, the latest release is the version five. Its focus is on the risk management, but ensuring compliance to requirements and managing security related domains are also covered. Its principles are: "meeting stakeholder needs, covering enterprise end-to-end, applying a single integrated framework, enabling a holistic approach and separating governance from management" (ISACA, 2012). 


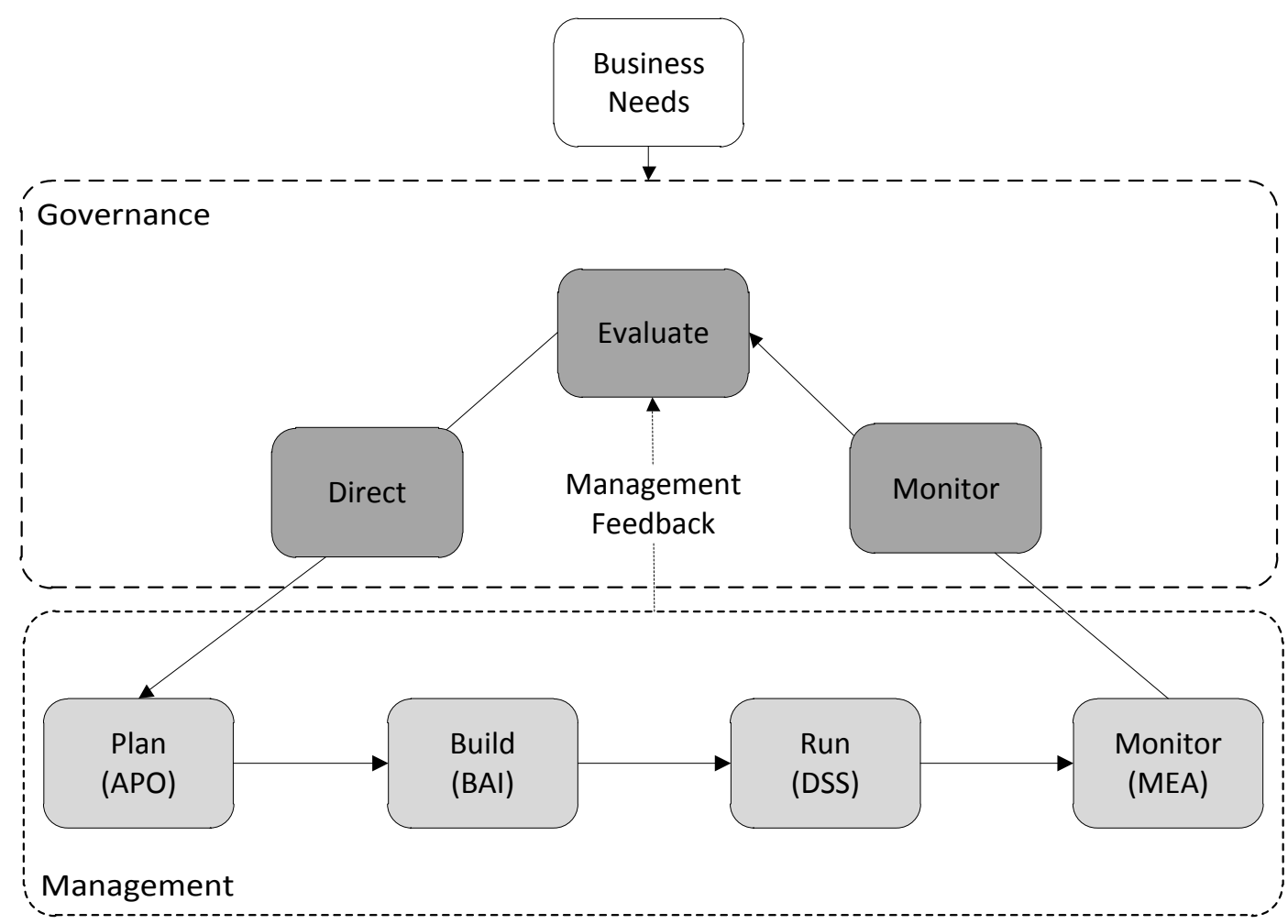

Figure 8 - COBIT5 Governance and Management Key Areas

Source: own edition (ISACA, 2012)

The governance's objective is the value creation. From the knowledge optimization aspect the resource optimization is relevant. The governance, in fact, has to resolve the conflict of interest in order to facilitate the value creation (Figure 8).

The COBIT5 covers the enterprise from end-to-end, deals with the organizational resources devoted to governance, like frameworks, processes, practices, information, and people. A lack of specific resource might weaken the value creation. The thesis' possible outcome is to answer that question, whether there is a connection between the knowledge awareness and the value creation process.

Applying a single, integrated framework is important, because it gives a complete coverage, and it provides an aligned space for the business processes, it also highlights the necessity of the knowledge base. Like in point 2.3.2, it is emphasized also here that the knowledge has to be documented, codified.

Enabling a holistic approach describes those factors that enable reaching of the objectives. It is initiated from governance level and it is broken down on the specific enabling levels: policies, processes, organizational structures, culture, information, 
services, and people (competences). The latest one is the most important for the current research.

Separating governance from management means that the governance will ensure that the stakeholder requirements are met. The management follows the objectives that are set by the governance. Both levels take care of knowledge management. Governance has the following functions in scope: Evaluate, Direct and Monitor. Within this scope the EDM04 is important for the KM, it is the 'Ensure Resource Optimization'.

The management has these designations:

- "Align, Plan and Organize (APO)",

- "Build, Acquire and Implement (BAI)",

- "Deliver, Service and Support (DSS)",

- "Monitor, Evaluate and Assess (MEA)".

From the management level the APO07 and the BAI08 are relevant. APO07 is the 'Manage Human Resources', BAI08 is the 'Manage Knowledge'.

APO07 explains the individual performance's and the corporate goals' alignment within the organization, it covers not just the roles and the responsibility definition but the skill maintenance, too. BAI08 helps ensuring that the coworkers are enabled to work effectively. The COBIT distinguishes the outcomes which are represented by goals (preferred realization of the processes), and work products what the inputs and the outputs (explicit work items, documents) are. In Table 1, Table 2, Table 3, Table 4 outlines of the Manage Human Resources and Manage Knowledge can be seen (Delak, 2015).

Table 1 - Manage Human Resources - Outcomes

\begin{tabular}{|c|l|}
\hline \multicolumn{2}{|c|}{ APO07 Manage Human Resources } \\
\hline \multicolumn{2}{|c|}{ Outcomes } \\
\hline APO07.01 & $\begin{array}{l}\text { The IT organizational structure and } \\
\text { relationships are flexible and responsive. }\end{array}$ \\
\hline APO07.02 & $\begin{array}{l}\text { Human resources are effectively and } \\
\text { efficiently managed. }\end{array}$ \\
\hline
\end{tabular}


Table 2 - Manage Human Resources - Work Products

\begin{tabular}{|l|l|}
\hline \multicolumn{2}{|c|}{ APO07 Manage Human Resources } \\
\hline \multicolumn{2}{|c|}{ Work Products } \\
\hline APO07.WP1 & Staffing requirement evaluations \\
\hline APO07.WP2 & $\begin{array}{l}\text { Competency and career development } \\
\text { plans }\end{array}$ \\
\hline APO07.WP3 & Personnel sourcing plans \\
\hline APO07.WP4 & Skills and competencies matrix \\
\hline APO07.WP5 & Skills development plans \\
\hline APO07.WP6 & Review reports \\
\hline APO07.WP7 & Personnel goals \\
\hline APO07.WP8 & Performance evaluations \\
\hline APO07.WP9 & Improvement plans \\
\hline APO07.WP10 & $\begin{array}{l}\text { Inventory of business and IT human } \\
\text { resources }\end{array}$ \\
\hline APO07.WP11 & Resourcing shortfall analyses \\
\hline APO07.WP12 & Resource utilization records \\
\hline APO07.WP13 & Contract staff policies \\
\hline APO07.WP14 & Contract agreements \\
\hline APO07.WP15 & Contract agreement reviews \\
\hline
\end{tabular}

Table 3 - Manage Knowledge - Outcomes

\begin{tabular}{|c|l|}
\hline \multicolumn{2}{|c|}{ BAI08 Manage Knowledge } \\
\hline \multicolumn{2}{|c|}{ Outcomes } \\
\hline BAI08.01 & $\begin{array}{l}\text { Sources of information are identified and } \\
\text { classified. }\end{array}$ \\
\hline BAI08.02 & Knowledge is used and shared. \\
\hline BAI08.03 & $\begin{array}{l}\text { Knowledge sharing is embedded in the } \\
\text { culture of the enterprise. }\end{array}$ \\
\hline BAI08.04 & $\begin{array}{l}\text { Knowledge is updated and improved to } \\
\text { support requirements. }\end{array}$ \\
\hline
\end{tabular}


Table 4 - Manage Knowledge - Work Products

\begin{tabular}{|l|l|}
\hline \multicolumn{2}{|c|}{ BAI08 Manage Knowledge } \\
\hline \multicolumn{2}{|c|}{ Work Products } \\
\hline BAI08.WP1 & Classification of information sources \\
\hline BAI08.WP2 & Published knowledge repositories \\
\hline BAI08.WP3 & Knowledge user database \\
\hline BAI08.WP4 & $\begin{array}{l}\text { Knowledge awareness and training } \\
\text { schemes }\end{array}$ \\
\hline BAI08.WP5 & Knowledge use evaluation results \\
\hline BAI08.WP6 & Rules for knowledge retirement \\
\hline BAI08.WP7 & Communications on value of knowledge \\
\hline
\end{tabular}

(Competence and competency have the same meaning, both describe a person's capability to do something adequately.)

Delak (2015) used COBIT5 for evaluating processes from knowledge management perspective for the enabling processes, for assurance and process assessing. The two main domains are introduced here the 'Manage Human Resources' and 'Manage Knowledge'. These domains give a clear overview about the outcomes, the expected behavior of the processes and the work products. The work products are those evidences that justify that the specific process steps were done, their content is the justification itself whether the processes are conducted with the sufficient and proper level of data and information. This approach is really close to the current research.

In the next paragraph, the ITIL service management is introduced.

\subsubsection{ITIL}

The Information Technology Infrastructure Library v3 (ITIL) is a practice set for information technology service management (ITSM). Its primary goal is to get aligned the business objectives with the provided services. In 2.2.2 section, the service-related standard has analogous objectives. The ITIL describes the processes not organizationspecifically, but the ITIL-processes are applicable in general for every organization.

The ITIL has five volumes, these cover the whole lifecycle of the organizations: 
- Service Strategy,

- Service Design,

- Service Transition,

- Service Operation,

- Continual Service Improvement.

The "Service Strategy" is used for understanding of the business requirements and the objectives, the "Service Design" transforms the strategy into a plan, the "Service Transition" itself develops the capabilities for the new service introduction, the "Service Operation" is responsible for the service management, and the "Continual Service Improvement' is meant for the small- and large-scale improvements (OGC, 2007). These volumes build the main footings of the model. The knowledge management is the part (at least indirectly) in every phase, and the service transition covers the knowledge management as an own process in the deepest way.

The knowledge management was added just in the latest, third version to the complete model. It is the part of Service Transition that focuses on deployment of services. In the current (2011) version the $\mathrm{KM}$ is one central process responsible for providing knowledge to all other processes. This knowledge should be consistent and readily available amongst the employees and in the different groups of the organization.

In case of the ITIL, the knowledge management's goal is to improve the effective sharing of knowledge. This practice handles the knowledge management on strategic level, the most important for this is to get closed the identified knowledge gaps as soon as possible, so the knowledge transfer can enable the other processes, therefore it is one of the most important enabler processes.

The knowledge management is understood within the Data-to-Information-toKnowledge-to-Wisdom (DIKW) structure (see 3.2). The key activities are capturing, analyzing the data and transforming it into information. The methodology reuses the previous experience of similar projects for establishing the knowledge-related capacities. The wisdom's role is set as an umbrella above all the sub-ordinated items also; however, it is quite general, and it is not really applicable in the practice. 
The main objectives of the ITIL's KM are the retrieving, the sharing, and the utilizing of the knowledge. These objectives' processes have to be incorporated in the service knowledge management system (SKMS). The SKMS contains data, information, and knowledge processing layers, and on the top, there is a presentation layer. It promotes the service continuity aspects, the individual learning, a strict log management about the usage of the system, and the evaluation of the above-mentioned elements. One of its key goals is to reduce the dependency on personnel for knowledge. This approach is connected to 'Question 1.3.3' which tries to reveal the conditions of the balanced and acceptable level knowledge. (OGC, 2011)

From the practical point of view, the knowledge is meant to be held in a central logical repository, also the experience, performance figures, requirements, typical skill levels are maintained for further reference.

Maintaining as many $\operatorname{logs}$ as possible is good for profiling those roles and typical business processes that might have a repetitive characteristic in similar cases, similar environment. Collecting data in databases (even in not well-structured) ones can be the base of constructing and generating the typical way of business processes, workflows and determining the typical characteristics of job profiles (role). Using pattern-analysis can identify the similarities and impactful differences as well. The log management should have a continuity, not just the common processes' and the related actions' have to be stored, but the exceptions to. The summary of the normal and outlier processes gives the whole set what can show the real processes. After discriminating the information from the noise, different types of statistical and data mining techniques can be used for revealing the not trivial interrelations. Data should be collected also about the BPs' surrounding systems, because that is the environment where the specific KM is applied.

If the log management's scope does not cover all of the relevant processes, or if there is a discontinuity in the collection, then the result might be misleading and the consequences will not have the full potential, especially if the specific missing phenomenon is impactful for the business.

During the $\log$ collection, the following should be taken into consideration: completeness (relevant scope covered), continual (there should be no interruption), 
normalization (common output for being able to provide inputs). The log management has a more broaden specified requirement, especially for security purposes, but for KM the most important is to get the impactful items covered relevant for KM.

During the application of the analysis of the logs, it is important to analyze the data in normal format and as complete as possible. With the help of the analysis, one can have a clear overview what the relevant BPs and workflow (business logic) are, what the successful roles (which role gives results) are, how to close issues (revealing successful information distribution channels, e.g. right escalation), what the additional critical success factors (which knowledge base item is utilized, which technical device is utilized) are, and it can give an answer where to apply all of these outcomes (in which environment).

The next sub-sections give an insight how these logs should be collected in practice.

\subsubsection{ITIL Documentation}

The ITIL heavily relies on documenting the processes and their outcomes. The internal mechanisms within the organizations are based on documented processes, the case is the same for KM, all KM-related processes are somehow maintained in a documented form.

The documents establish the knowledge base, all of the items are in a category system stored. These categories are usually in a hierarchical order, one can dig down from the top-level categories into the sub-oriented categories.

The knowledge documents of the ITIL includes different types (OGC, 2011):

- Reference

- External

- Question / Answer

- Error / Cause

- Problem / Solution

The references contain general information that are not the essential part of the knowledge base, but can be utilized for acquiring background information. The 
external documents are files that are connecting to the specific topic. The questions and answers cover general question with its explanation and resolution. The error is a specified question that clearly describes an issue that needs a solution, the cause of this error is appended to the origin so the error can be resolved earlier when it next time happens. The problem is an aggregate of errors, issues, this item has a wide range of description, the problem is not trivial, its root cause is broaden as well, so is its solution.

Once the documents are saved, they turn into draft status, after this status, it goes to triage status, here it is reviewed whether it has the proper format and content. Once accepted, the next stage is the revision, an expert checks and then improves the document and submits it for review to the KM team. It is decided during the review process whether the document can be published.

The documents can be created, modified, and put in retired status.

\subsubsection{ITIL Roles}

The ITIL puts an emphasize on maintaining the BP standards, not just the documentation of the work items is a must, but the roles' responsibilities are also clearly defined. The KM distinguishes the following roles (Skyrme, 2011, Anonymous, 2016b):

- Knowledge Management Process Owner

- Knowledge Manager

- Knowledge Expert

- Knowledge Analyst

- Knowledge Contributor

- Knowledge User

The Process Owner is accountable for defining of the whole KM process, the practices should be effective, this role ensures the involvement of all relevant stakeholders and it is responsible for the proper information dissemination. This role is also a bridge between the KM and all the other BPs. 
The Knowledge Manager implements the KM process, and this role is responsible for the operative management. As an outcome of the manager's work all employees within the organization should be aware of the KM processes, the processes should be relevant and consistent. The quality assurance, the submission of knowledge-related work items and scope of publishing is also within the responsibilities. The overall review, the maintenance of the activities, and the continual improvement should be driven by this role.

The Knowledge Experts reviews the submissions, and based on the technical expectations, they can amend these. Keeping the KM-related documentation in current and relevant status is their responsibility.

The Knowledge Analysts review the possible submissions beforehand, the semantics (content) and the syntax (format, readability) are checked by them. The Analysts coordinate in this relation the Experts' work. They prevent the duplications and multiplications of the knowledge base $(\mathrm{KB})$ by filtering the systems in advance, so the redundancy is kept by them on low level. The no longer required documentation is retired by this role.

The Knowledge Contributors identifies those ideas that might be applicable for submission, they identify the required changes to the existing documentation and give an assistance with keeping the documentation current and relevant. Closing the gaps in the documentation is widely supported by this role.

The Knowledge User is the end-user of the complete process. This role-takers should be aware of the $\mathrm{KM}$ process, they have to utilize the $\mathrm{KB}$, and in order to close the process-loop they provide feedback. Keeping the process in good shape can be reached if the feedback are given within a short timeframe.

\subsubsection{ITIL Measurement}

The definition of the expected documentation and the roles are not sufficient. If a process is not properly measured, then its justification cannot be validated, and the 
baselines for the improvement cannot be set. When creating the baselines, all of the important factors (qualifier) have to be taken into consideration.

The established baselines can describe the process main characteristics within a given time interval, and by time these baseline can be significantly modified that can be caused probably by the changing business environment.

The methodology recommends key performance indicators (KPI), if there is an external party involved then these KPIs can be transformed into service level agreements (SLAs). The KPIs are the followings (Anonymous, 2016a): number of KM documents created, number of times a KM document is accessed, number of times it was effectively utilized, number of KM documents with an expired review date.

The KPIs can show the dynamism of the document management of the KM, by time, the number of documents should grow keeping the focus that these documents should be reliable, useful, relevant, and up-to-date. The number of accessing can give feedback whether these documents can be looked for, and whether they are really an asset in solving the possible business issues.

The ITIL is a very wide and general methodology, still with its help the basic requirements for the $\mathrm{KM}$ can be determined. How this happens in practice is the responsibility of the given organization, but it gives a comprehensive set about the business logic from the BPM point of view.

When building up the measurement system in a knowledge intensive business environment, it is a must to cover the quantitative processes; the more granulated the logging of the events is, the better exploration of the business can be achieved. Since the KM has not got connection points in every aspect with the BPM system, there should be set up some quality measurement system in order to close the gaps. Otherwise, the KM should be aligned with the current BPM as tight as possible.

The next paragraph will introduce the most important model of capability and maturity. 


\subsubsection{CMMI}

The Capability Maturity Model Integration v1.3 (CMMI) models are best practice collections that might help the organizations to improve their processes. CMMI is defined for 'Acquisition' (SEI, 2010a), 'Development' (SEI, 2010b), and 'Services' (SEI, 2010c) operations for organizations. The KM aspect is similar in the three cases, the references are based on the 'Services'.

The CMMI has two ways of interpreting the KM as successive, improvement steps.

The two improvement paths use levels for evaluation. The first enables the organization to improve the processes based on the individual steps, the other one enables the organization to improve a set of related functions. These paths are interrelated, the first is the capability level-basis, the second one is the maturity levelbasis. The capability is the continuous, the maturity is the staged representation of process improvement. To reach a particular level, the organization must satisfy all the precondition goals.

Capability has four levels, level 0 is the incomplete, level 1 is the performed, level 2 is the managed and level 3 is the defined one. The maturity levels start with initial level 1, the levels above that are: the managed (2), the defined (3), the quantitatively managed (4) and the highest level, the optimizing (5).

Some of the interesting and relevant elements will be highlighted in the followings on the maturity line from the KM aspect (Figure 9).

On maturity level 1 (initial), the organization's success depends just on the competence of the people and not on proven processes, on this level there are usually budget and schedule issues.

On maturity level 2 (managed), there is already an agreement with the customer about the delivery processes, the process quality assurance is set. Responsibilities are assigned, people are trained on the process, and there is a regular monitoring and control on the process. 
On the defined level (3), the standards, process descriptions, and work procedures are tailored to suit the particular work group. The defined process has clear "purpose, inputs, entry criteria, activities, roles measures, verification steps, outputs, and exit criteria" (SEI, 2010c).

The quantitatively managed level (4) allows measuring the processes in statistical terms in the life of the processes. The process performance can be measured using quantitative techniques and predictions.

On the optimizing level (5), the organization can continually improve based on the quantitative understanding of its business objectives. At level 5, the organization is concerned with the overall organizational performance.
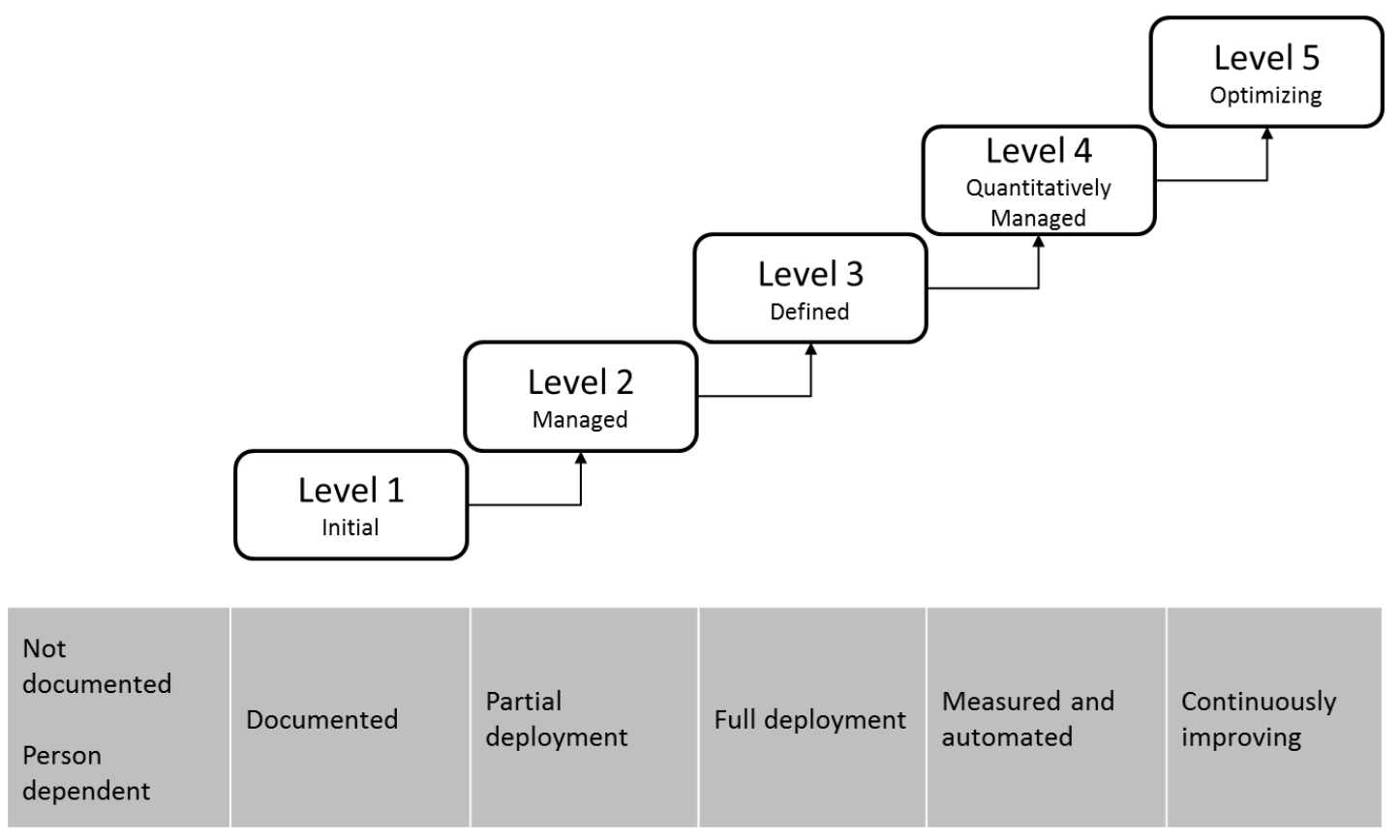

Figure 9 - CMMI structure

Source: own edition (SEI, 2010c)

The CMMI is a very complex set of practices, it defines generic goals and specific goals what should be followed by the business entities. The generic goals are those goals what are necessities in every case and in every domain.

The knowledge management is handled as a generic goal, it means it does not depend on the domains, but it is generic. The general practice (GP) 2.5 'Train People' and GP 3.2 'Collect Process Related Experiences' are relevant in the current research. GP 2.4 
'Assign Responsibility' is also important, because this practice assigns the responsibility and authority for performing the process. (Figure 10)

Responsibility is defined for having also accountability for performing the process. For responsibility assignment a job descriptions used or such living documents what have similar content. There is a very important outline stated also, a confirmation is needed from the role takers whether the people assigned to the responsibilities understand and accept them.

The aim of 'Train People' (GP 2.5) is to ensure having the minimum skill and expertise for performing the process. This practice has many connections, because it has a relation to every human-entity involved process and practice. As per this practice, the process owner has to have the specialized knowledge in the specific domain.

The 'Collect Process Related Experiences' (GP 3.2) practice is about collecting process related experience, information, and artifacts (work products, lessons learned, best practices, process improvement suggestions). These are collected in the process library. This one is another approach than in the previous case, it is more about how to identify the requirements for a specific project type and this practice is not just for the current running processes, but it provides inputs for similar cases later on within the organization.

The CMMI has not just practice aspects, but process aspects, too. The most important processes are Organizational Training (OT) and Organizational Performance Management (OPM). 


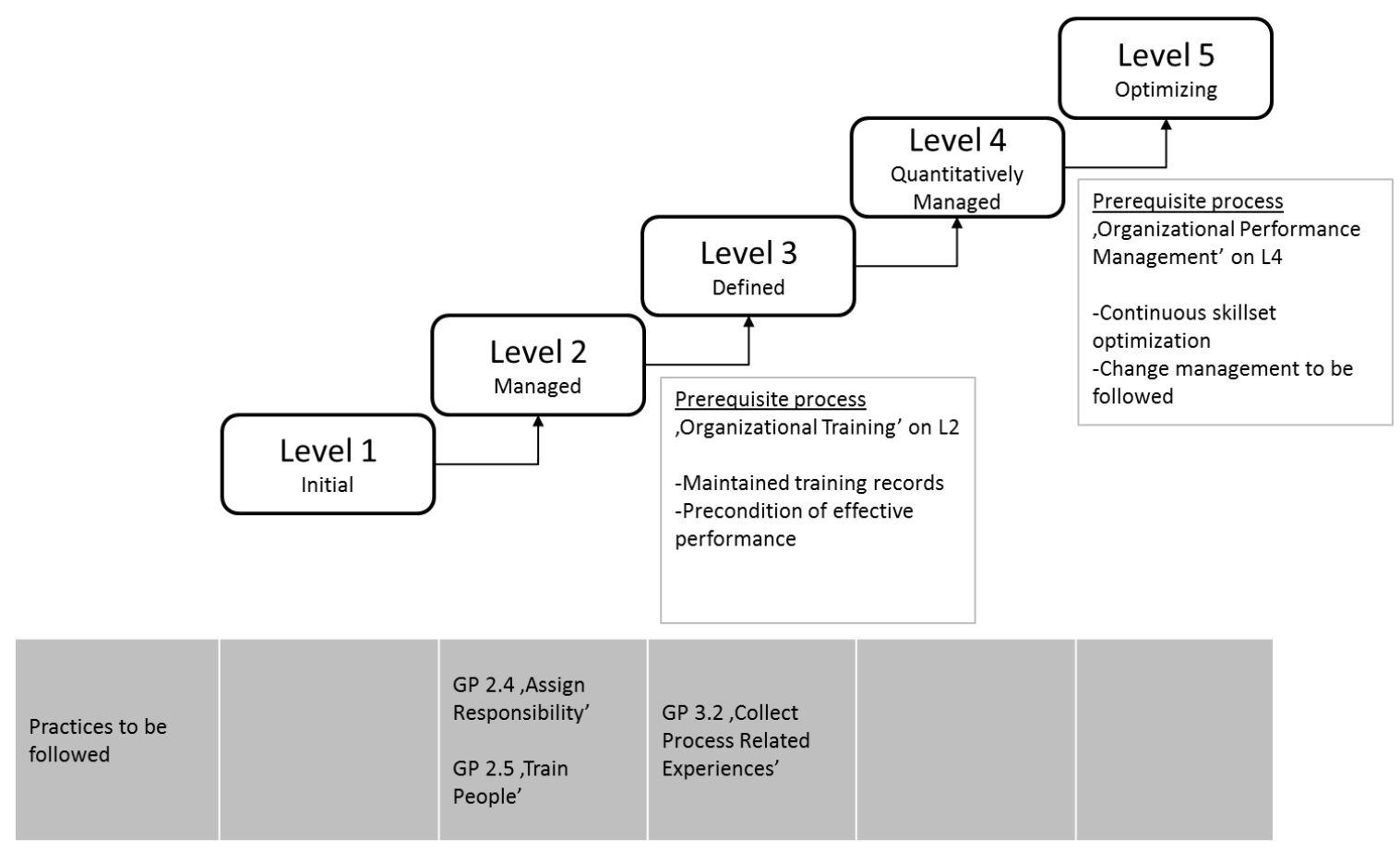

Figure 10 - CMMI structure with KM

Source: own edition (SEI, 2010c)

The OT has the purpose to develop the people's knowledge so they can perform effectively. For this, identification of the training is needed, while providing the training itself is also needed. The training capability has to be set up and the training records have to be collected in order to assess and evaluate the training effectiveness and to identify the improvement opportunities. This process is the precondition of CMMI level 3.

The OPM's goal is to manage proactively the organization's performance. It is about improving product quality, productivity, process efficiency, customer satisfaction, performance in supply chain, and improving the use of resources within the whole organization. It means that on one hand the change management has to be followed up from knowledge management side, and on the other hand the skillset of the people has to be optimized continuously. Having this process in place is the precondition of CMMI level 5.

Even if the CMMI is a complex set of practices, it directly pinpoints the KM-related requirements. (Appendix 4)

In the following point, another CMM will be introduced, the People CMM (PCMM). 


\subsubsection{P-CMM}

The People Capability Maturity Model v2.0 (PCMM) is also a maturity model, but this one focuses on the continuous improvement of the human resources solely. This model is similar to the CMMI, but other problem areas are in the foreground, like: the work overload, the distractions, the not clear performance objectives, the poor communication, and the lack of knowledge.

Table 5 shows the process areas of the PCMM, there are 5 maturity levels here as well, like in the former case. The processes are collected in process threads, every thread covers a specific logically consistent process scope.

Level 1 has no process area; on this level, the organization are yet inconsistent.

On level 2, there are basic people management practices: it is ensured that the people are able to meet their work commitments. The training and the development are to ensure that the coworkers have the required skills.

On level 3, the organization develops a professional culture for having well-understood competences.

On level 4, the organization has the capability to predict its performance and capability. On this level, the individuals are managed within a group, the interactions are supported, the groups are empowered to decide how they would like to conduct the activities, the asset creation (documenting knowledge) is also a priority amongst the others. The organizational capability of the enterprise is referred here as the aggregated level of knowledge, skill, and process ability.

At last, on the highest level, everyone is responsible for continuous improvement. Once the improvement areas are identified, with the help of the change management they are rapidly introduced, while the organizational performance alignment is in place and maintained. (Curtis et al., 2009) 
Table 5 - Process thread in the PCMM

\begin{tabular}{|c|c|c|c|c|}
\hline \multirow[b]{2}{*}{$\begin{array}{l}\text { Maturity } \\
\text { levels }\end{array}$} & \multicolumn{4}{|c|}{ Process Area Threads } \\
\hline & $\begin{array}{l}\text { Developing } \\
\text { individual } \\
\text { capability }\end{array}$ & $\begin{array}{c}\text { Building } \\
\text { workgroups \& } \\
\text { culture }\end{array}$ & $\begin{array}{c}\text { Motivating \& } \\
\text { managing } \\
\text { performance }\end{array}$ & $\begin{array}{l}\text { Shaping the } \\
\text { workforce }\end{array}$ \\
\hline 5 Optimizing & \multicolumn{2}{|c|}{$\begin{array}{l}\text { Continuous Capability } \\
\text { Improvement }\end{array}$} & $\begin{array}{l}\text { Organizational } \\
\text { Performance } \\
\text { Alignment }\end{array}$ & $\begin{array}{l}\text { Continuous } \\
\text { Workforce } \\
\text { Innovation }\end{array}$ \\
\hline 4 Predictable & $\begin{array}{l}\text { Competency } \\
\text { Based Assets } \\
\text { Mentoring }\end{array}$ & $\begin{array}{l}\text { Competency } \\
\text { Integration } \\
\text { Empowered } \\
\text { Workgroups }\end{array}$ & $\begin{array}{l}\text { Quantitative } \\
\text { Performance } \\
\text { Management }\end{array}$ & $\begin{array}{l}\text { Organizational } \\
\text { Capability } \\
\text { Management }\end{array}$ \\
\hline 3 Defined & $\begin{array}{l}\text { Competency } \\
\text { Development } \\
\text { Competency } \\
\text { Analysis } \\
\end{array}$ & $\begin{array}{l}\text { Workgroup } \\
\text { Development } \\
\text { Participatory } \\
\text { Culture }\end{array}$ & $\begin{array}{l}\text { Competency } \\
\text { Based Practices } \\
\text { Career } \\
\text { Development }\end{array}$ & $\begin{array}{l}\text { Workforce } \\
\text { Planning }\end{array}$ \\
\hline 2 Managed & $\begin{array}{l}\text { Training and } \\
\text { Development }\end{array}$ & $\begin{array}{l}\text { Communication } \\
\& \text { Coordination }\end{array}$ & $\begin{array}{l}\text { Compensation } \\
\text { Performance } \\
\text { Management } \\
\\
\text { Work } \\
\text { Environment } \\
\end{array}$ & Staffing \\
\hline
\end{tabular}

The different models try to translate the processes somehow into a quantitative model in order to be able to assess and evaluate it in a quantified way, preferably statistically. In the next paragraph, the latter mentioned methodology is introduced, this one is taken into consideration during the research mainly because of its philosophy.

\subsubsection{Six Sigma}

The Six Sigma is a set of tools what can help with achieving maintainable process improvements within the organizations. It is heavily based on quantified data and derived statistical approaches. Its main focus is to have a measurable and quantifiable result rather than assumptions. 
According to this methodology, the processes should have an acceptable average performance (if they are not one-time projects) and an acceptable variation. The variation itself is a quantified output what comes from the (preferably automatic and reliable) measurement systems. The causes for variation might be common or special ones. They might come from the environment, from a configuration issue, or from the human actors.

The methodology uses principles and tools to identify the causality within the process set. First the value-added and non-value-added processes are separated. The valueadded are those processes what have customer-facing outputs, these outputs and outcomes can be utilized by the internal or external customers. The non-value-added processes are the supporting processes.

The methodology also deals with constraints. The constraints are those limitations of the system that narrow the throughput. The methodology emphasizes that the constraints should be removed or realigned so the throughput of the system can be increased while decreasing the operation expenses.

The knowledge as constraint can be interpreted on associate/worker and on manager level. The individuals' knowledge integration, even on associate level, might face difficulties, since it requires a broad span of knowledge and expertise (Smith and Zeithaml, 1996); otherwise, they cannot be involved directly in the BPs (Grant, 1996a). The lack of the proper knowledge about the organization's resources and its interrelations with the environment can be also a constraint (Lockett and Thompson, 2004).

Measuring the systems based on data is accepted as common practice and logical. In the research, the main question is whether the knowledge management-related phenomena can be somehow translated into quantifiable data; if yes, the knowledge management can be justified on statistical basis.

In the Six Sigma methodology, it is important that there are distinguished roles that can highlight the role of the knowledge management, and with the help of this the KM's framework can be better deployed. The distinguished roles are the so-called Subject Matter Experts (SME). The SMEs are those individuals who have the highest 
experience level within the organization. They can enable other individuals to perform better. (Kubiak and Benbow, 2009, Munro et al., 2015)

The methodology is a bit outlier from the previously introduced standards and methodologies; its relevance is in the root cause analysis and handling different knowledge levels (SMEs). Even if they are not intentionally knowledge managementfocused, they are good at least in the construction of the baselines of the KM.

If the Six Sigma is applied within an organization, then it is a Six Sigma organization, its KM covers the knowledge, skills and abilities (KSAs). This philosophy main building block is that all of the employees should know what they are doing. The employees should have an opportunity in advance to acquire the necessary KSAs in order to be able to perform successfully within the specific role.

This methodology points out that an ongoing assessment of the constraints is required within the organization. The employees' attitude about aligning the proposed processes, changes might differ based on their own perceptions. If the confidentiality is given then the employees have higher willingness to cooperate. There is a contradiction in this: on one hand, the KM should be made explicit; on the other hand, the organizations' members require confidentiality during the KM process. Six Sigma processes have to be planned carefully because of this.

Another interesting conclusion of this methodology, based on the experience of its appliers, that an underperforming process' root cause is usually a deficiency in KSA, however this assumption can be often mistaken (Pyzdek, 2003).

In the following point, the interrelations of the introduced standards and methodologies are described.

\subsection{Interrelations of the standards and methodologies}

Three main domains are covered in this research: the knowledge management is the main pillar, the business process management is the supporting pillar, and the risk 
management is their environment, the RM can be understood as a complement for the $\mathrm{KM}$ and the BP.

The knowledge management's most relevant (explicit) methodologies are the PCMM and COBIT5, they have coherent an explicit expectations towards the knowledge management. The process management aspect has a way richer resource: ISO 9001, ISO 2000, CMMI, ITIL, and Six Sigma, while ISO 27001 creates the space for the other two domains (KM and BP).

Table 6 follows the logic of the outlined domains, however the table is not deeply stratified, it gives a summary of the relevant relations. This is a collection of the most relevant background standards and methods.

Table 6 - Interrelations of the standards and the methodologies

Source: own collection (2016)

\begin{tabular}{l|c|c|}
\multicolumn{1}{|c|}{ Domain } & Standards & $\begin{array}{c}\text { Methodologies and best } \\
\text { practices }\end{array}$ \\
\hline $\begin{array}{l}\text { Knowledge } \\
\text { Management }\end{array}$ & $\begin{array}{c}\text { ASQ/ANSI/ISO } \\
\text { 9001:2015 - Quality } \\
\text { Management System }\end{array}$ & Maturity models \\
\hline $\begin{array}{l}\text { Business Process } \\
\text { Management }\end{array}$ & $\begin{array}{c}\text { ISO/IEC TR 20000- } \\
\text { reference model }\end{array}$ & ITIL - Service Management \\
\hline $\begin{array}{l}\text { Risk } \\
\text { Management, } \\
\text { Security }\end{array}$ & $\begin{array}{c}\text { ISO/IEC 27001:2013 } \\
\text { Six Sigma - Statistical }\end{array}$ \\
\hline
\end{tabular}

In the coming section, knowledge management related aspects are introduced. 


\section{KNOWLEDGE MANAGEMENT}

Business process management and knowledge management can jointly reveal the key elements for the correct interpretation of the possible value chains within the organizations in cases where the processes are not purely technology driven. The current research introduces a pragmatic approach about how to manage knowledge effectively, based on theoretical and practical background. As a first step, the related standards and best practices were introduced in section 2. In this chapter, the knowledge management's main orientations are reviewed.

\subsection{Cognitive infocommunications}

Cognitive infocommunications investigate the interrelation between the research areas and cognitive sciences. Cognitive computing's approach can be perceived as analogous to the human brain: not only has the structured data to be examined, but the illstructured data as well. The ill-structured data might cause such problems what "have unclear goals and incomplete information" (Voss and Post, 1988).

The cognitive computing takes place on different level than what is known from the traditional information and communication technology systems, due to the learning feature. The different level means therefore a higher level, beside the learning feature the cognitive computing's other two additional features are: the modeling and the hypotheses generating (Hurwitz et al., 2015).

In this paper, the modeling principle is in focus, the way of creating a representation of a domain and the understanding how data, information, and knowledge are handled.

The extension of human cognitive capability is in the foregrounds with infocommunications driven features. Both the intra-cognitive (equivalent cognitive capabilities) and inter-cognitive (different cognitive capabilities) modes of 
communication were taken into consideration during the research design, in order to cover the most relevant aspects (Baranyi and Csapo, 2012, Baranyi et al., 2014).

This section tries to reveal the pragmatic approach of human actors, about how they deal with the knowledge. Especially the representation-sharing communication is of importance and examined amongst human entities and infocommunications systems, since having the same information representation and understanding among the actors is one of the key success factors. The augmented cognition is also one of the foundations, this field aims to extend the user's abilities via computational technologies, while examining cognitive aspect like learning capabilities and memory limits (Baranyi and Csapo, 2012). The research itself originates its pillars from this new cognitive entity (human mixed with infocommunications); however, on this level, its goal is not yet to determine clearly that, but more like to perceive it as a complex entity what is a key element in the knowledge-based process management.

The focal point of the research is on the practical side of the knowledge management domain. However, the original point of the whole research is how to realize value of the knowledge management from business point of view, it might show some interesting results for the cognitive field as well, especially about the intended and real practice.

\subsection{Data - Information - Knowledge}

Data, information, and knowledge as concepts are often co-interpreted, although they are not interchangeable. Understanding the difference among these concepts is a key in the KM.

Data is a set of objective facts about events (e.g. database records in an enterprise resource planning system). The cost (capturing it), the speed (how fast it can be retrieved), the amount (how long how wide), and the qualitative characteristics of it are important. The data itself has the same meaning for everybody. The organizations rely heavily on data, therefore it is a must to maintain the continuity of the databases. Data is also essential for creating the information. 
The information gives a context to the data, it originates from the sender and it is given to the receiver. During the information interchange, the original meaning of the data is altered, usually enriched. The data itself does not have applicable meaning itself, the real meaning, for it, is given by its sender, creator. The data can be calculated (e.g. mathematically), can be categorized (assigned units), can be contextualized (it is important to know what is the environment and what is the purpose of the data), can be condensed (summarized in a specific form), and so on.

The information has a broader meaning than the data, and the knowledge has a broader one than the information. The knowledge is a "fluid mix of framed experience, values, contextual information, and expert insight that provides a framework for evaluating and incorporating new experiences and information" (Davenport and Prusak, 1998). The knowledge is applied within the mind of the human beings and it is usually embedded in organizational routines and practices. According to Por (1997), the knowledge is not a thing, it cannot be managed, "it is a capacity of people and communities, continuously generated and renewed in their conversation, to meet new challenges and opportunities".

Giarratano and Riley (1998) interprets information as meta-data, knowledge as metainformation, and on the top level is the meta-knowledge. Cleveland (1982) expanded the three elements with wisdom (meta-knowledge). Wisdom can expressed in terms of knowledge. Wisdom is deeper analyzed by Ackoff (1989), according to the author the wisdom is the ability to judge and involve values what are embedded in the actor. Wisdom's prerequisite is the understanding (the complete process is: data information - knowledge - understanding - wisdom) the process what is based on cognitive and analytical abilities. Por (1997) states that the intelligence should be the prerequisite of the wisdom.

The authors try to grab the phenomenon's essence, the explanations are valid, and it means that the knowledge management cannot be really simplified. Karvalics (2015) gives an exhaustive analysis about the extensions of the data-information-knowledge model. The outcome of the research is that the knowledge management cannot be simplified to linear models, knowledge management needs more dimensions (Wiig, 1993). 


\subsection{Basic definitions}

During the discussion of the organizational mechanisms one of the most important factors in knowledge management is the learning itself, as the renewing and acquiring capability of the knowledge. In the research, the organizational learning, as a synergic series of individual learning, is also covered. However, the explicit processes were taken deeper into consideration in 'Chapter 2', the not documented, implicit processes are examined as well.

Levitt and March (1998) emphasized routines as knowledge repositories, since routines are recurring processes they involve continuously roles, technologies, culture and capabilities. According to them, the organizational learning encodes the lessons in routines, the routines can prevail sometimes after codified rules and activities of human actors. Other authors examined connecting routine-theories, Schulz (1998) the bureaucracy theory, Miner (1990) the evolutionary model, Weick (1991) the culture one. According to the bureaucracy theory, the main finding was that the organizations learn based on rules. Miner (1991) explored that the large departments are not really able to value the jobs, the measurement and assessment capabilities are not on the expected level and an indirect way of thinking has to be applied. According to Weick (1991), the organization's environment is one of the main drivers of the processes, the environment including the culture impact the behaviors massively. The different cultures can cause different interpretations for the same events.

Grant (1996b) examined the knowledge based theories of the firm as a general overview, before introducing Grant's work, the basic supportive elements are shown.

The 'complete' knowledge is added up from the two main types of knowledge: the explicit and the tacit (Polanyi, 1966). The explicit knowledge can be documented, codified, it is objective and impersonal. The explicit knowledge is contextindependent, it can be stored in digital systems, and its transfer is possible. The tacit knowledge is what people carry in their mind, it is difficult to be assessed and evaluated, its transfer is not possible, and its processes are not transparent. The tacit 
knowledge is inexpressible in a codifiable form, it is subjective, personal, and it is context specific. (Hislop, 2013)

There are approaches (Nonaka, 1994) that reveal the substantial steps in the whole phenomenon as a "social learning process", but still, it is not easy to provide a measurable framework. On Figure 11, Nonaka's Socialization-ExternalizationCombination-Internalization (SECI) model is illustrated. Nonaka identified the collective knowledge as continuous and dynamic interactions amongst the tacit and explicit knowledge:

- Socialization: tacit $\rightarrow$ tacit conversion

- Externalization: tacit $\rightarrow$ explicit conversion

- Combination: explicit $\rightarrow$ explicit conversion

- Internalization: explicit $\rightarrow$ tacit conversion

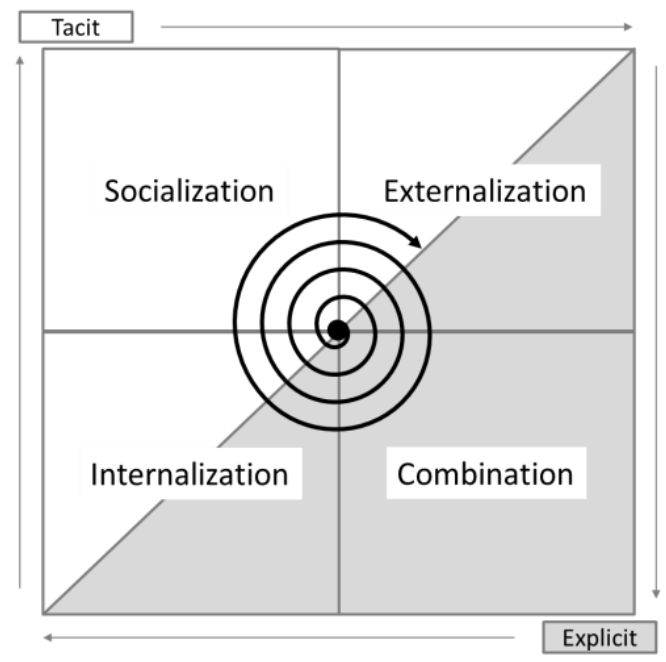

Figure 11 - SECI model

Source: own edition (Nonaka, 1994)

The SECI model approaches the knowledge creation process and provides an overall management framework. The socialization represents the tacit to tacit knowledge transfer and the knowledge conversion. Tacit knowledge is not formalized, and it is environment specific, it needs social interactions in order to be learnable.

During the externalization, the tacit knowledge is somehow documented, therefore it can be the subject of storage, transfer, and learning. The combination means a kind of integration of explicit knowledge sources. The explicit knowledge is collected and 
reedited based on the business requirements. The internalization is the process when the individuals transform the explicit knowledge to tacit. They apply learning to internalize the knowledge.

The socialization might form in individual or team discussion, the externalization might form in documenting the outcomes of a meeting, the internalization might be a learning from a documented event or from a documented artifact, and the combination might be creating a document based on an already created document. These examples are used in the practical research.

Each of the conversion stages can create knowledge independently from each other; on Figure 12 the 'Spiral of Organizational Knowledge Creation' can be seen. Here not just the epistemological dimension is shown, but also the ontological dimension. Depicting the knowledge from ontological aspect shows that the individual, group, organization, and the inter-organization levels consider broadening knowledge. The figure describes the knowledge as part of every process and every role, the upper half (explicit) means that the knowledge can be documented and codified, the under half (tacit) is the part what is more difficult to be managed.

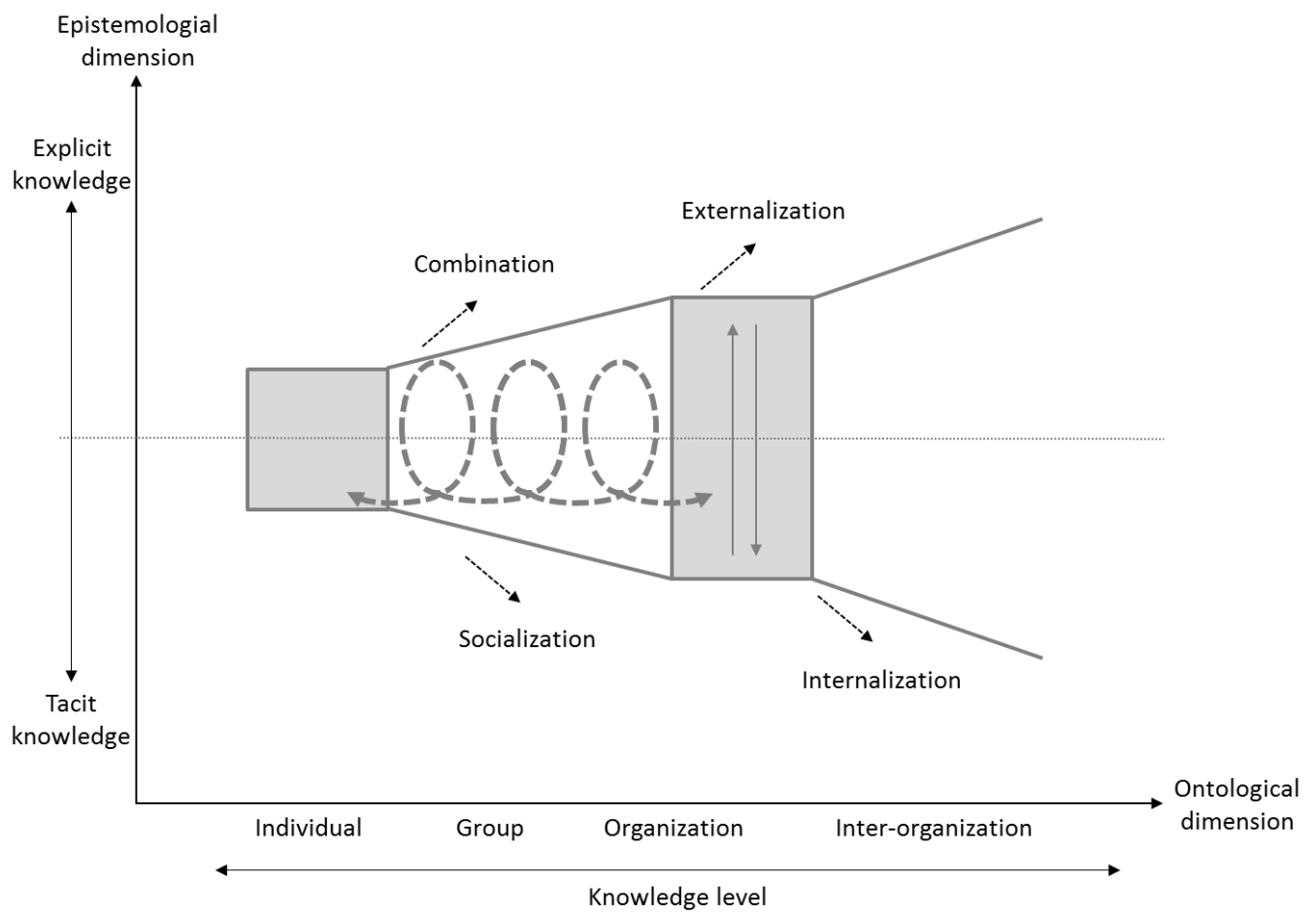

Figure 12 - Spiral of Organizational Knowledge Creation

Source: own edition (Nonaka, 1994) 
The effective knowledge management can be foreseen in the current research something also like a cultural attitude towards the knowledge resources and the relevant business processes. It means that the resource managers and workers are aware of the business objectives and the available resources (both of the human and non-human sides), and they are able to construct a relevant connection amongst them. If they are not able to do this, at least they try to establish the baselines that are the groundings for the possible value-channels within the organizations. Hence the effective knowledge management means not a simplified measuring system, but a holistic view, since the quantitative indicators are usually ad hoc and rare (Smits and De Moor, 2004).

The organizations should be aware of what they know. In a small, localized company everybody might know the right and appropriate coworkers, but over a size of a couple of hundred employees one cannot grasp trustworthy the collective organizational knowledge (Davenport and Prusak, 1998). Furthermore, the existing knowledge is not sufficient in itself, only if it is available and valuable for the given time within the organization. Solving the same problems from zero can diminish the results of previous efforts.

What can be the identified as value drivers in a knowledge management system?

\subsection{Knowledge-intensive organizations}

Starbuck (1992) describes the knowledge-intensive firms (organizations) analogous to the capital-intensive or labor-intensive firms. The latest labels emphasize the importance of the two major inputs: capital and labor. According to Starbuck, the knowledge-intensive organizations implies that the "knowledge has more importance than other inputs". The main characteristic of the knowledge-intensive organization, that it can solve complex problems by creative, innovative procedures. This type of organizations is not information-intensive by definition, the knowledge is in the center. In order to determine whether an organization is knowledge-intensive, the particular knowledge should be analyzed rather than the widely shared knowledge. The 
knowledge may not come from individual people, but it can be embedded in the organization's routines, in cultures, etc.

The knowledge-intensive organizations can be distinguished from the traditional industrial organizations. Alvesson (2001) points out that the knowledge-intensive organizations are those organizations where the overwhelming part of the work is of intellectual nature and where qualified employees form the major part of the workforce. According to Nurmi (1998), these types of organizations transform what they know into knowledge products and services for their customers. The knowledge is of value-added nature in the total value-chain. Therefore, all of the internal processes and practices have to support their internal knowledge assets (Lee, 1999).

The organization uses and values the knowledge, but because it has a tacit dimension, this valuation has an implicit characteristic. The organizations prefer to acquire knowledge based on experience rather than on education, because experience is justified and proven by time (Davenport and Prusak, 1998).

The knowledge economy covers both the knowledge-intensive production and the services sector: both sectors rely dominantly on knowledge workers who possess not just the required skills and expertise, but the ability to facilitate innovations (Drucker, 1969). The postindustrial era promotes the skill development of workers and the shift towards the knowledge-intensive sectors, organizations (OECD, 2000).

According to Kärreman and Alvesson (2004), the knowledge-intensive organizations have a strong knowledge base as a key feature. These types of organizations are staffed by highly qualified employees; these organizations can be preliminary defined as organizations that offer fairly sophisticated knowledge.

There are many different, competing notions, but there is no real consensus. Rylander and Peppard (2005) examined the knowledge-intensive characteristic throughout. They state that the knowledge-intensive organizations have gained already a widespread appeal in the common vocabulary of the business and the policy makers. However, they could not provide the distinctive criteria that would distinguish knowledgeintensive organizations form the others. The literature of the domain faces inconsistencies and difficulties, since it covers everything and nothing at the same time. It is a meaningless category in the technical sense, but is meaningful to many 
scholars and practitioners. Research positioning of the knowledge-intensive organization is not appropriate, they suggest framing the whole topic in a different way.

The knowledge intensity and the level of knowledge can mean other profiles in different sectors, it can be defined with difficulties, but they exist. For making it a possible subject of operationalization, it is necessary to have at least a scale-based measurement. This means a certain information loss, but with its help the handling of the state of adjacent sphere is easier. This can also give a baseline for retrieving consistent conclusions. In the current research, those organizations are knowledgeintensive where the overwhelming value of the work can be attached to highly qualified workforce and where the organizational routines have customer focus.

In the coming point, Grant's concept will be discussed along with the results of other researchers.

\subsection{Knowledge management in organizations}

Grant (1991) identifies the not easily replicable knowledge as a competitive advantage, according to Quinn (1992) the knowledge (especially the tacit) is the most important resource. The value aspect of the knowledge is underpinned, strategically the most important resource for an organization is the knowledge (Grant, 1996b), integrating knowledge to be the inherent part of the organization is key for success.

Grant (1996b) determined three characteristics of knowledge integration:

- efficiency,

- scope,

- flexibility.

The efficiency is based on the level of the common knowledge, for this purpose a basic prerequisite is the common language. Another relevant factor is the frequency and variability of task performance: the higher the variability is, the lower the integrating efficiency is. The structure also has to be considered with a well-organized structure the knowledge integration's difficulties can be reduced. 
Within the scope of knowledge integration Grant (1996b) had the following findings: "different types of specialized knowledge are complements rather than substitutes". Beside this the main outcome is: the greater the scope of the knowledge integration, the more difficult the capability replication.

The flexibility of the knowledge integration has two factors. The first is the characteristic of the knowledge. If the knowledge is explicit then the integration can be established. If it is tacit and the language is not properly aligned then the procedure might be demanding. The other factor is the knowledge transformation. This is a complex task, but one of the key value drivers. The tacit knowledge has a distinguished role, its conversion requires documented steps as well, in order to have it maintained within the organizations. The routine itself is not sufficient when it is about inter-organizational challenges, wherein the language and the environment is not the same.

Grant collected the main types of the knowledge process within an organization; he used March's (1991) tradeoff-approach between exploration and exploitation (Figure 13). The knowledge processes what focus on acquisition of new knowledge is the exploration, while utilization of the existing knowledge is the exploitation. Grant collated the two main types: the related processes and those elements that are the context for the specific knowledge process. 


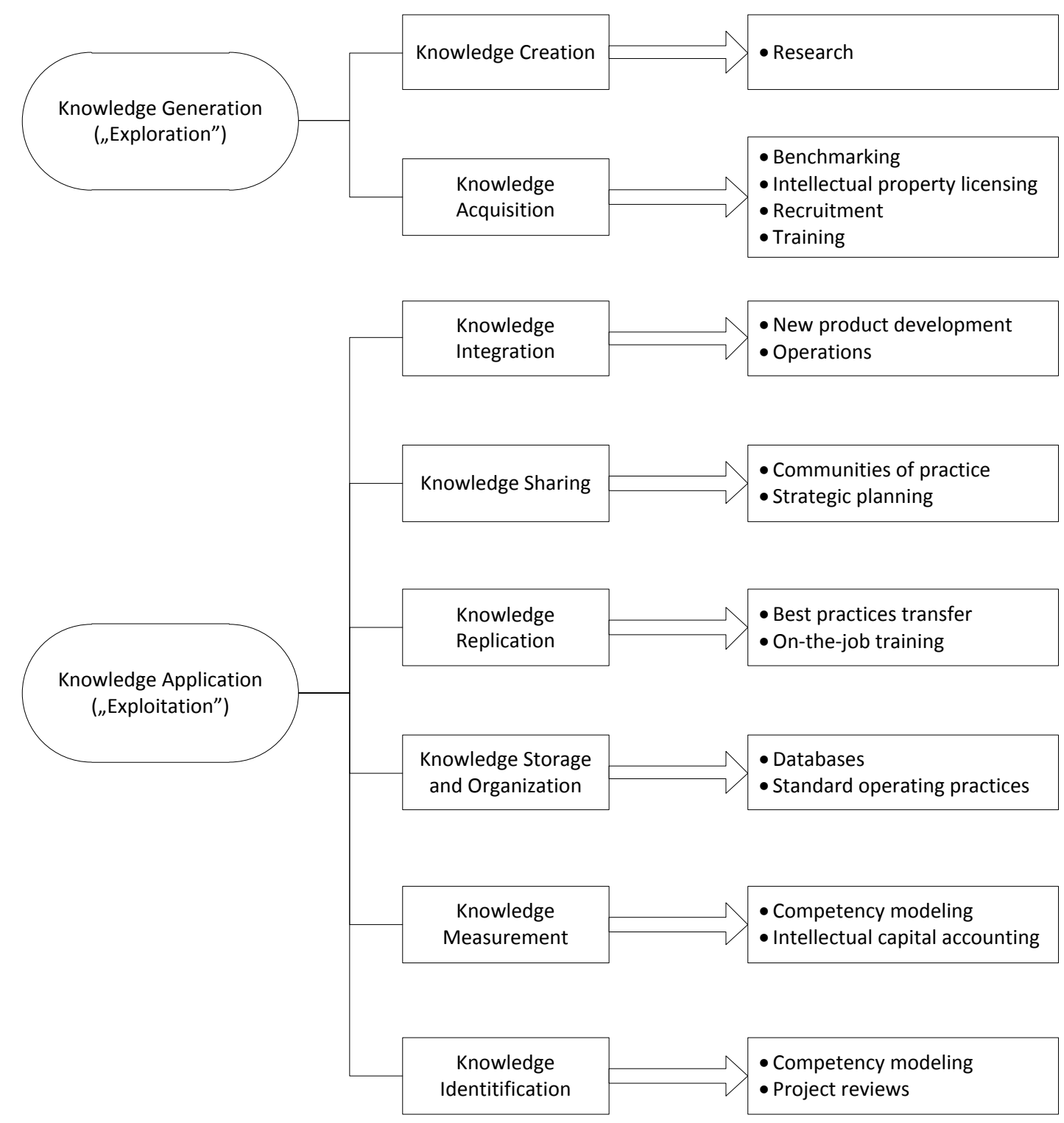

Figure 13 - Types of knowledge process within an organization

Source: own edition (Grant, 2010)

The above classification is engaging for the research, since it has not just the aggregate of the theoretical results, but shows those practices what are already in use within the most organizations, although not necessarily because of the awareness. Not only are the practices listed on the right hand side of the chart, but also the explicit, codified, and documented elements of the whole process map (this can be utilized in practice during the connecting procedure of the $\mathrm{KM}$ and BPM). In addition to the general processes, the knowledge measurement is also the part of the model, this aspect is important for the research.

In the coming paragraph, information-management aspects are introduced. 


\subsection{The source of the knowledge as bridge between the KM and BPM}

The identification of the knowledge source is the first step to provide the logical framework for the valuation of the knowledge. In the knowledge management, the set of all procedures has to imply the human and non-human entities as resources. On one hand, these resources store the knowledge relevant elements of the processes (Grant, 2010); on the other hand, they provide the contextual environment (for example, axioms, references, descriptions, and so on).

For assessing the connection between the knowledge management and the knowledge source related business processes, it is worthwhile to cope with knowledge management as a whole. As the KM process reference, the Method for Business Process Oriented Knowledge Management (GPO-WM®) is used now (Mertins et al., 2003). The method has four steps: 'Generate', 'Store', 'Distribute', and 'Apply'.

The sources might be internal, external, or the mixture of both, usually the later one is the practiced one. The GPO-WM method answers the following questions: what, where, for whom, by who the knowledge is created and by who is used, all of these steps have a focus on how they were achieved. At this point of the analysis, the BPM comes into picture, these processes are already BP-oriented ones, they use intensively the business process management tools and systems. The knowledge source is on one hand document management-based, on the other hand it is role-based, what is actually fully supported by the event-driven process chains (2.3.2). Digging deeper in the latest model, it can be seen that the source of the knowledge will have similar phenomenon when it is applied in the specific step of the knowledge management.

In the 'Generate' step, the source might be internal, in this case it is an own innovation. Or it can be an external one, in this case the innovation is based on external knowledge. The most common case is the mixed knowledge. The situation is very simple in this case, the interpretation is easy. It has to be highlighted here that using external knowledge for generating knowledge, even just a part of it might need some serious precautions. Does the generation of the knowledge have any legal issues, can the knowledge be incorporated, and what is the level of the usage of the external knowledge? If it exceeds a certain level (e.g. too high reliance on external sources), 
then it might be a source of a business risk and might undermine the business continuity.

In the 'Store' step, the source might be the internal human resource and the knowledge base. The mixed storing can have the former ones combined with references to external sources or with a direct connection to an external system. Using an external source has always the risk of unavailability and it has usually an unknown structure, in addition, the external source can be also a dynamic, 'living' business entity and it might collect sensitive data of the profile of the actual knowledge-users what may harm the inner business on the long term.

In the 'Distribute' step, it is a necessity to provide access to every stakeholder at least for the relevant knowledge sources. Distributing knowledge, even just partly, from external source might have legal and business continuity issues (e.g. using not licensed knowledge source, or incorporating a knowledge distribution channel that cannot be managed and maintained continuously, etc.).

The value creation has to be realized in the 'Apply' step. The usage of the internal source should be built in the processes. If the knowledge comes from an external source, it has to be taken into consideration whether the source can be incorporated or not. If yes, with what conditions, if not, what the possibility of the need of reinvention, rediscovery is (Youn et al., 2014).

The utilization of the KM requires the ability to assess the impact and the complexity of the changes. The formalized, codified, documented knowledge elements can be transferred with the help of BPs. If these knowledge elements are repetitive, reoccurring and consistent with low noise level, then they can be embedded in the given environment easier. If the compatibility issues are on low level, then the organizational absorption is easier. The easy replication's assumption is the low complexity that requires low associated resources. Beside this, if the impact's scope is wide, then the resource acquiring is straightforward and simple.

The combination of the KM process' steps with the BPM procedures provides a very clear picture about the process documentations, the processes and the workflows; however, it is still necessary to get the involvement of the corresponding actors and the right attitude. 


\subsection{Knowledge representation}

The knowledge representation is meant to analyze the knowledge and evaluate it from a possible interpretable way.

Normally, the knowledge representation is handled symbolically, it is a body of knowledge. The following definition is widely accepted: "a set of expression in which each piece of knowledge corresponds to one or more expressions, and each expression corresponds to one or more pieces of knowledge" (Paquette, 2010). According to Sowa: "knowledge representation is the application of logic and ontology to the task of constructing computable models for some domain" (Sowa, 2014). The representation is a description, delineation, visualization of the knowledge. In the current research, the knowledge and its representation are not handled separately, because the knowledge representation is not meant to be a meta-model, but more like a presentation of the knowledge.

Although the ontology is not analyzed here detailed, as the main focus is on the business perspective, it is still required to introduce its definition: ontology "provides a shared and common understanding of a domain that can be communicated between people and across application systems" (Fensel et al., 2014); or as per a very much alike definition ontology "is an explicit specification of a conceptualization" (Gruber, 2014).

The shared and common understanding is the enabler of the KM. In this point, the knowledge is handled as a whole. In the current case, the sum of the tacit and explicit knowledge constitute the total. This total is examined with the proviso that it has a partly unknown, not completely revealed segment.

During the assessing of the specific organization's value delivery capability, it is worthy to know what the main drivers are, and what the environment for the driver processes is. 


\subsection{Technical approach}

The simpler processes might run as workflows, but once the complexity is high, a high skillset is needed as well. Documenting the processes simply is not sufficient, the roles that are critical for value creation have to be identified. It is not enough to reveal those roles that conduct the real processes, but it is also needed to determine those actors who have the willingness to share and to store the knowledge (document). If it is not done then the maintainability and the continuity might suffer from its absence on the long run. The following part gives an overview how to catch the most important characteristics of the problem (after the specific work-domain is identified).

First, the process structure has to be outlined (value-added and support process groups), then the process model based on the tasks (organizational, competences, etc.). Among the competences the knowledge elements have to be grabbed. The primary role of the process model is to connect the practice with the knowledge management activities. The process-performers used to recall explicitly the most important elements of their own work and the unique ones. Many of the details might remain unknown because of their hidden routines.

In the second step, the knowledge elements are extracted from the process model, by different transformations inputs can be generated to text mining applications (Ternai and Török, 2011). The text mining solution enriches the basic concepts with utilizing the background materials. Background materials can be anything that can be codified or digitized for technical usage, like: handbooks, databases, etc. (Gillani and Kö, 2014). After the enrichment, the final concept of the domain can be completed. The final output can reveal the hidden knowledge what is needed to be articulated. The enrichment of the original concept can be assessed with that and it can serve as the input for the next phase.

After identifying the complete concept covering the tasks, the job-roles can be structured as well. The role descriptions can already give an articulated environment for handling the workforce demand. This approach might be not just a single run, but also an ongoing activity, not just the current state can be described, but additional solutions can integrated to it. For example, if the system can analyze what are the 
requirements for a specific jobs, then the related learning activities can be integrated to this system. Matching the requirements and the solutions with allowing measurement gives the ability to build up the complete knowledge map in a way that it could be dynamically updated.

If the demands can be structured, there is a possibility to provide similar opportunities to the supply part of the equation. The emphasize should be not on the organizational knowledge (demand), but on the knowledge transfer. If there is a system (e.g. ProKEX) that can ensure the environment for the knowledge transfer (Neusch and Gábor, 2014), then the knowledge of workers can be assessed. Based on the knowledge gap map, the organization or the person can setup a learning path in order to close the gaps.

In digitized systems, it is possible to get the competences of the applicants measured. The learning materials are usually not connected to locations, it is also possible to remotely assess the candidates. The computer-aided aspect cannot only be used for matching the two sides of the equation. The approach can also play a role in identifying critical success factors, since not just a one-time measurement can be done, but life paths can be also followed up what might be the source for recognizing those knowledge elements that are successful in the given environment and whose identification is not trivial. Building up a measurement system on realistic projection of the reality is good input for real talent fostering.

The proper worker's identification is not simple, because their competences cannot be mapped in an intuitive way. For the complete identification, it is not satisfactory to involve just human actors. The given operation-domain has to be explored in an exhaustive manner what requires technical aid, so the essential requirements and compliance (Gábor et al., 2013) can be determined on time.

This technical approach is not discussed in exhaustive manner, its aim was to introduce such solutions that might help the organizations to get a more realistic projection of the reality, since most of the KM-related requirements are not yet processable solely by human actors.

In the following paragraph, the intellectual capital management is introduced in order to have a logical consistency its involvement is also required. 


\subsection{Intellectual capital management}

The intellectual capital (IC) constitutes of knowledge acquisition, knowledge creation, and innovation (Wiig, 1997). The intellectual capital management (ICM) affects the knowledge management. The ICM focuses on maximizing the value from IC and on self-renewal. KM might support the ICM with detailed systematic and explicit processes. The ICM and KM can be synergic for each other, one can enable the other, once their justification can be evidenced (Appendix 5).

Bencsik (2015) identifies two main types of measurement system. The first is the neural network, it is applicable to classify the knowledge in form of facts and rules (Schikuta, 2008). The second measurement system is the analytical systems. The author highlights three main types of these measurement systems:

- Skandia Navigator: Skandia Navigator is the first balanced scorecard (BSC) related to the knowledge management what supposed to measure the IC. As per this model, the market value of the specific company is the sum of the adjusted shareholder's equity (financial capital) and of the intellectual capital. The intellectual capital is the sum of customer capital, organizational capital, and the human capital (Mertins et al., 2003). This model is not punctual, but it can reveal the changes within the ICM and can highlight the critical areas during the ongoing operation.

- Wissensbilanz: the organization handles the knowledge as strategic resource. The method gives a strategic direction to the KM, it follows the changes, and it presents the organization's performance based on these changes.

- Intangible Assets Monitor: this model was proposed by Sveiby (2010), he criticizes the financial measurement systems, because they are not able to measure the intangible assets. Based on this research, he came to the following conclusions: there are organization-level measurements that have financial focus, there are scorecards that try to identify the IC elements, and there are IC assessment methods.

Sveiby (2010) states that the main problem with measuring social phenomena that it will not close to scientific accuracy. According to him, in the ICM context the measurement's aim should not be management control, he suggests using the 
measurement for enhancing the learning motive. The measurement can explore value sources, it can uncover costs, and it can be used on long-term. If the purpose is learning then the buy-in of the stakeholders is easier, since their massive involvement is needed while constructing the related metrics, their presence is critical. Sveiby recommends the following four types of intangibles measurement and assessment system:

- Direct Intellectual Capital method (DIC): estimates the currency-value of intangible assets,

- Market Capitalization Method (MCM): calculates the difference (intellectual capital) between the organization's market capitalization and the stockholder's equity,

- Scorecard Method (SC): the various components of the intellectual capital are identified and indices are assigned to them, the presentation form might be a scorecard or a graph,

- Return on Assets method (ROA): the average earning of the organization for a period of time is divided by the average tangible assets of the organization.

- (The Return on Knowledge (ROK) is an additional approach: the leaders of the knowledge-based organizations should approach the KM measurement by accepting soft indicators rather than demanding hard numbers (Cohen, 2006). Since incorporating knowledge and knowledge bearers covers a longer time span, as a completion the capitalized knowledge might be considered as a longterm asset, and this point of view might be also measured as the return on capitalized knowledge (ROCK).)

The intellectual property plays a critical role in the KM. Knowledge can be also considered as subject of such properties, the switching costs and lock-in might (Varian et al., 2011) be applicable not just amongst business entities, but also within the organization. The individuals might discover their own value and they can strengthen their position, from bargaining perspective as well.

Another interesting approach is the position of patents, trade secrets, and copyrights within the organizations. The economies of scale (volume-centric) or economies of scope (portfolio-, variety-centric) are unique, but the patents, trade secrets, and copyrights are in a more complex situation. These are usually such information that 
organizations possess and do not share widely with others (the patents and the copyrights until their release). If they are disclosed in early stage, then they lose practically they protection, once they are in the public domain, there is no formal way to protect them. This aspect relates to KM via the section 2.2.3.

The leadership should build learning organizations (Senge, 1990, Senge, 2004), Manz and Sims (1991) highlight the leadership roles as enablers within the organizational life. The leadership should give a vision to the associates, they should influence the employees to solve the problems on their own. They have to reflect the resources contained within the human resources. Different leadership and managing roles can be identified also within the knowledge management, if they are not properly handled their behavior might also cause unintended outcomes. One of the affected points might be how to preserve knowledge.

The ICM should be expanded with the knowledge-retention strategies (Davenport et al., 2006) in order to prevent a knowledge-loss problem, the organizations should know the complete set of the knowledge within the organization and they should be aware of the specific actors who maintain this knowledge and are responsible for the operational environment. The knowledge-retention should address the key knowledge vulnerabilities, they should know what a specific person knows and what happens if the individual leaves his/her environment. On the other hand, the organizations should be aware what are the characteristics of the knowledge-loss issues based on the different roles of employees. The researchers identified three network roles within the organizations:

- Central Connector: these roles have technical expertise and organizational memory (Walsh and Ungson, 1991) and have a wide relationship with other resources. In order to replace these roles experiential knowledge and reputation is needed for the given employee, this is needed for shortening the onboarding time in case of replacement.

- Broker: the brokers have broad knowledge and they are able to recognize opportunities, they have a high level of integration of disparate expertise. They are able to coordinate and mobilize disparate groups.

- Peripheral Player: the peripheral players have often marginalized expertise what have indeed the potential to reshape operations. They have a set of 
external relationships, they might have also a direct link to outside knowledge (external).

The measurement systems should focus on both possible benefits and losses, since they are of significant role.

In the next paragraph, the knowledge management-related amendments are introduced.

\subsection{Amendments}

The material resources and the related processes can be measured directly, but the direct measurement is not yet possible in case of immaterial resources. The case of knowledge is quite similar. The knowledge management has more aspects that involve a lot of human aspects and technical aspects. Grant (1996b) highlighted that the different knowledge types might have interrelations amongst each other.

The knowledge can be independent or dependent, if the organizations have to deal with more types of knowledge, then the interrelation might be of significance. The independent knowledge is isolated. In this point, it is not covered, just the connecting ones. Grant's idea to take into consideration the knowledge connections has revealed that the different knowledge types can be handled similar to common goods.
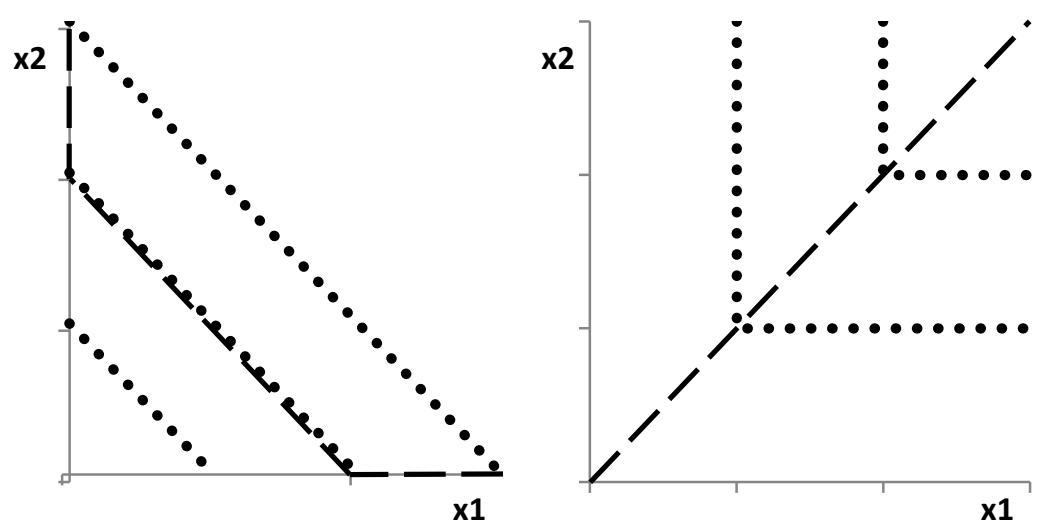

Figure 14 - Substitute knowledge, Complementary knowledge Source: own edition (Varian, 2001) 
On Figure 14, the dotted lines are the indifference curves, the dashed lines are the price offer curves (the substitute knowledge is on the left, the complementary knowledge is on the right). The related knowledge sources' 'price' and availability influence the demand for them. If the knowledge is substitute, that means they can deliver the same outcome for the (internal) buyer, who is in the current case the organization itself, the substitute knowledge elements can compete with each other. On the other hand, there are complementary knowledge sources, these knowledge sources accompany, without each other, they cannot be used for the specific organizational goal.

This aspect is very important in the research, because the efficient knowledge management's prerequisite is whether the owner of the problems are aware of the handled knowledge elements' such characteristics, this perspective counts also.

A similar aspect is whether the KM is capable to reveal the real, complete knowledge within the system. The knowledge is available in distributed way in every case (where there are more human entities), the question is whether it can be absorbed in its actual reality, or there is just an approximation to it. Theoretically, the knowledge assessor should (if not supported by a sophisticated knowledge management system) be able to assess the knowledge of the human resources completely, this situation is a bit paradox, because a human entity is not able to explicitly codify neither his/her own knowledge. In practice, the knowledge management is often used to work allocation purposes, this assumes that the managers are able to identify the substitute knowledge (and the knowledge bearers), because these are those types that can be replaced by each other.

The research covers the rare- or unique knowledge elements, these are those elements that are somewhat isolated. Most of the organizations try to incorporate this type of knowledge, because they would not like to maintain permanently a situation, in which they directly depend on resources that might be temporarily or on long term unavailable.

Singh (1986) identified the slack resources as part of the total resources. In most of the organizations, slack is there, its optimal level is not easy to be determined. The slack within the system is a kind of buffering mechanism against variability (changes in demands, unexpected environmental issues, etc.), knowledge is also a kind of slack 
resource. The knowledge and the knowledge bearers are not always completely utilized, the usage is mostly based on the demand.

The attention management (Simon, 1996) is also very important, since the current domain covers the knowledge and the human entities, it has to be considered what are the people's capabilities. The humans have limited cognitive capabilities, e.g. the short-term memory can deal on average with four items (Cowan, 2001). In an information- and knowledge-intensive environment the information overload might be also an issue, similar is the situation with interaction overload (e.g. social network), multitasking, and interruption. The above-mentioned events can happen of course on individual or on group level.

The associates can be affected by multiple external impulses. In order to make the human resource able to reorient, there is a specific time allowance needed, otherwise the knowledge integration cannot happen. Even therefore, the slack resource is a must.

From psychological perspective, the cognitive dissonance (Festinger, 1957) is also of high importance. The individual who has to deal with two or more contradictory beliefs, ideas at the same time has an internal conflict (in special cases also a conflict of interest) and cannot decide to which he/she should give priority, this causes not just stress, but might end in a significant waiting time (from organizational perspective), especially if it happens on group or organization level. Argyris (1991) pointed out that the overskilled workforce can raise a substantial resistance towards changes and learning what can also raise unanticipated delays within the system.

Cultural differences might be also inputs for conflicting ideas, Hofstede (2005) defined the following dimensions of national cultures:

- power distance,

- individualism,

- masculinity,

- uncertainty avoidance,

- long term orientation,

- and indulgence. 
These ruptures can arise easily even in small groups, so even if these are not in the core of the research, they are shortly introduced, because the knowledge managementculture can suffer a lot because of these, e.g. short term orientation might subserve the prompt business requests versus the learning.

An interesting and connecting outlook is Woolcock's social capital model (Woolcock, 2001), this model is introduced because it gives a widely accepted background to the social variable. Woolcock identified three forms of social capital:

- bonding: strong ties that exist among groups of people that share similar values, interests, and background,

- bridging: bonds between different groups - between generations, cultural, ethnic, and religious groups. These are generally weaker, less intense, attachments,

- linking: ties that connect people to local service providers and resources, this alludes to vertical relations that link people and communities to sources of power and resources that lie beyond the neighborhood in the wider society, notably in formal institutions.

This later aspect is connected to the channels of information dissemination and the knowledge sharing.

In the following section, the research methodology is introduced. 


\section{THE RESEARCH METHODLOGY - INTERRELATION OF THE BUSINESS PROCESSES AND THE KNOWLEDGE MANAGEMENT}

In 'Chapter 1', the research, in 'Chapter 2' and 'Chapter 3', the relevant backgrounds are introduced.

The complete research domain is broaden; therefore, it was needed to narrow the focus of the research to the relevant interrelations of the BPM and the KM. The research relies on previous results of a similar analysis that took place in 2014. The earlier research ran amongst real business entities in order to acquire real information. Its outcome was utilized for building up the current research.

A questionnaire was collated for business entities in this case as well (not appended). The collection of the questionnaires was followed by analyzing the data and a validatory step. Based on the feedback of the opponents of the dissertation, the focus was narrowed further (Appendix 6 - Core questions) in order to get a more coherent view. Just the relevant aspects are utilized, the original version of the questionnaire is used just for collecting background information.

The content of questionnaires grasps the most important recommendations of the researchers and the mandatory elements of the standards and methodologies. The subsection 4.1 covers the BPM, the 4.2 the $\mathrm{KM}$, and the 4.3 the renewal ability. The points' content are in relations with the examined questions:

- Question 1 - Can the application of knowledge management be defined at all? What are the limitations of definability? (1.3.1)

- Question 2 - Is organizational knowledge assessable with the process management tool and concept library and can it be evaluated? Under what circumstances can the assessment and the evaluation be realized? (1.3.2)

- Question 3 - Can the level of knowledge management be defined? Under what circumstances is it possible to determine the levels? (1.3.3) 
- Question 4 - With what accuracy and relevance can the organizational knowledge management be measured based on business process management?

'Appendix 6' shows the interrelations among the specific questions, the theories, the utilized standards, and the methodologies.

\subsection{Business process management}

'Appendix 6 - Core questions - Domain A' is the BPM, it incorporates mainly the organizational roles and the business process management itself.

In the questionnaire, it is examined whether the business processes are identified (A1), whether the BPs are documented (A2) and whether the related documentation is up-todate (A3).

The maintenance of the BPs is interesting not just from the documentation viewpoint. The awareness of the employees (A4), the dynamism of the environment (A5) and the internal processes' characteristic are also covered (A6). Not just the static arrangement is interesting, but also the dynamic mechanisms. The processes might differ, there might be 'one-time' or repetitive processes, there are different aspects, and the goal is to cover the most relevant ones.

The measurement of the organization's throughput is investigated as well, the characteristics are important: are they qualitative or quantitative, does the financial point of view dominate, and so on (A7, A8)?

It is also examined whether the roles are properly distinguished, and what kind of control mechanisms are amongst them. A required domain to be examined is whether the roles have defined responsibilities and accountability, or whether there is an overlapping among them (A9). A connecting topic is whether there are authority issues within the organizations, if yes in what environment (A10). Already on this level, the competent persons and roles are studied (A12, A13). The buildup of the organization (A14) and the number of abandoned business problems (A15) can serve as indicators of the current organizational situation. 
The assessment and evaluation of the BPs might show different results; the aim is to collect the similarities and the success factors that have significant value creation potential and that relates to the work in a knowledge management environment.

In the following point, the knowledge management domain's relation with the questionnaire is introduced.

\subsection{Knowledge management}

In the current research, the knowledge management's scope covers the documentation, the knowledge management as resource management, and the tracing of the knowledge management (Domain B).

The knowledge bearers are examined on individual and on group level. The activities of knowledge application and sharing within groups serves as a relevant input. Similar to 4.1 the persons and the roles are also discussed.

The first part of the questionnaire focuses on the persons. It is examined how the practice identifies the persons within the organization (B1, B2) and checks whether these persons are available within the organization (B3).

Understanding the role of the substitute, complementary, rare-unique and business critical knowledge elements is one of the priorities (3.10). The other one is how to handle them efficiently. If the stakeholders within the organizations have the initial steps set for knowledge management, then they are probably able to identify whether the knowledge is stored in a documented system or not (B11, B12). If it is not stored, or if it is stored but its application needs a considerable time to get it retrieved, that means they have to manage also the knowledge owners, the human resources who possess the knowledge (B4, B5). An interesting area is how aware are the organizations of the different types of knowledge, most significant distinctions are amongst: substitute, complementary, critical and rare, unique knowledge elements (B6). 
The fact whether the employees each other's competencies (B7), the level of explicit knowledge (B8) and the process of the knowledge sharing (B9, B10) reveal the characteristics of the dynamic processes.

There is a dedicated part in the questionnaire for the trainings (B13, B14, B15), these are based mainly on the recommendations of the CMMI and the COBIT.

The latter parts check whether the organizations are able to measure their current level of knowledge, and whether they are aware of the intellectual capital management's basic requirements (B16, B17). Similarly, it is also examined whether the organizations use the best technical and knowledge setup for themselves (B18, B19).

At last, the communication amongst the organizational entities is covered, understanding the common terms semantically within the organization is also analyzed (B20).

Once the organizations are able to identify the knowledge, the conversion into explicit knowledge is possible. The knowledge repositories, knowledge bases might be the center of the knowledge management. Once the knowledge is codified, it can be stored in the systems and used from this source.

If the above-mentioned features are set and maintained in real time, then the initial steps are in place. With the help of them, the measurement systems can have the bases, baselines. The understanding of them is necessary, at least for having the basic concept of the effective knowledge management. On the short run, the organizational roles might try to identify just the short term objectives and they try to shape the work outcomes corresponding to them. In the next paragraph, a very specific knowledge aspect is shortly described, the ability to revive the knowledge structure on different time horizons.

\subsection{Renewal ability}

'Appendix 6 - Core questions - Domain C' covers the renewal ability. Not just the present knowledge state of the specific entities can be examined, but the past (C6, C7) 
and future ones, too. In addition, the learning and renewing ability might give an input also for the innovation. Why the past knowledge structure is important (C1)? The knowledge of former periods might answer the root causes of success or failures. The future knowledge structure might be the part of planning (C5, C9, C10). Even if the today's knowledge is not necessary, it does not mean that it will not be usable in the near future. In the resource management, the planning of this aspect is essential.

The origin of the knowledge can be internal or external, private or public (C3, C4). The organizations might able to develop the knowledge within the organization, but it is interesting whether they want to do that or maybe they want to buy it directly from the market.

The way in that the renewing happens has business process aspects, in a wellstructured environment the coworkers are able to use the shared resources $(\mathrm{C} 2, \mathrm{C} 8)$ of the organization (e.g. desktops connected to the knowledge base). An appropriate assumption might be that a well-working organization can identify the key actors who can help the knowledge transfer. The availability of relevant, reliable, and up-to-date knowledge is supporting the business continuity and the renewal ability as well, if the organizations do not maintain the management systems (BP and KM) as aspect.

In the next paragraph, the practical steps of the research and the research results are introduced. 


\section{RESEARCH}

The research has an explorative direction, it is inductive. The expected outcome is setting (at least) the baselines for theories. A combination of qualitative and quantitative methods are utilized. The main data source comes from the questionnaires, its validation is supported by interviews.

Based on the previously introduced aspects, knowledge-based process management elements were collected and collated as a questionnaire. The research itself has a historical background from 2014, when the first run of the research took place, this former research was also used as reference. Using the experience of the mentioned former research, a bit different and more mature questionnaire was composed with similar domains, but with a more centralized focused (Figure 15).

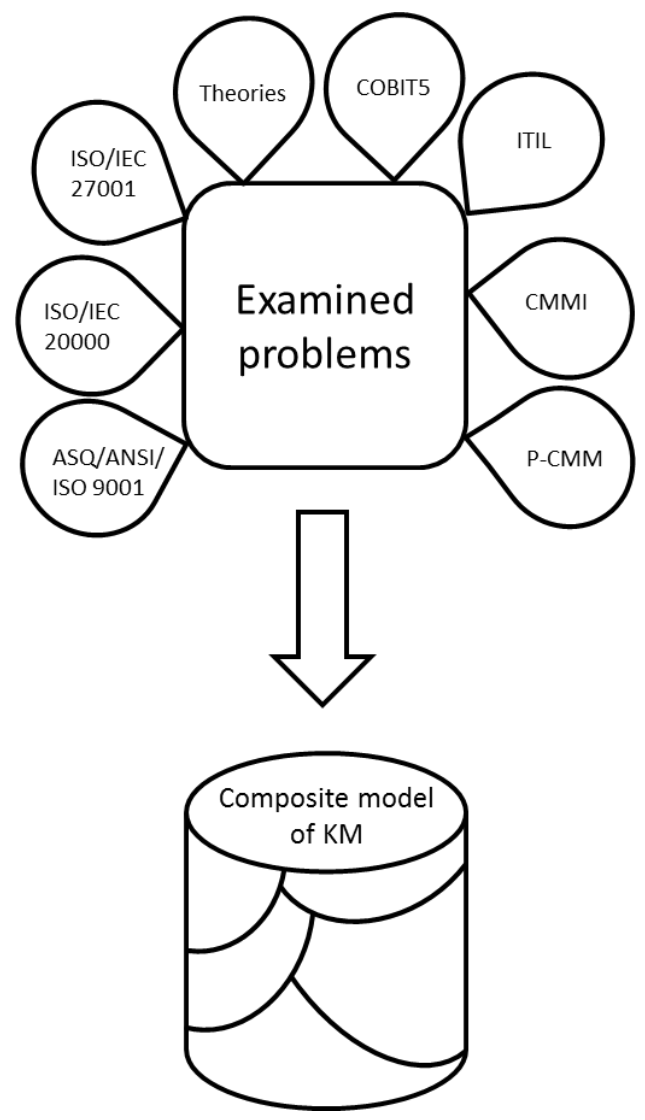

Figure 15 - Model composition 


\subsection{Questionnaires}

The questionnaire gathers the data in quantitative and qualitative way. The individual units provide information about attitudes, knowledge, and opinion about the researchdomain. In the current research, this form is the primary strategy for data collection, and it is used in conjunction with interviewing. During the question-development, many tactical conditions were taken into consideration.

Multiple-choice questions (specific choices), dichotomous questions (yes/no multiplechoice questions), and ranking scales questions (for importance) were utilized. In order to receive some background information about the phenomenon, additional, supportive questions were used as well. They are not the part of the current research, they serve just for giving a general background during the analysis.

The most of the problems can be projected on scales just with difficulties and it implies a specific loss of information, but since the research's nature is explorative this approach is used, because with this a general framework can be used.

\subsubsection{Collection process}

The former research covered 26, in Hungary active, companies (with a response rate of $16.9 \%$ ), the current one covers 100 companies, the overwhelming part settles in European countries with a couple of exceptions. The practical steps of the questionnaire-collection were longer than expected, first it was planned to close it in 30 days during the month April 2015, but finally a three months long interval was required to have it closed by middle of July 2015.

The filling of the questionnaires was anonymous, the handling of the results is subject of confidentiality, the results are evaluated according to this. The potential respondents were selected with judgmental sampling, from the pre-selected respondents quality responses were expected. Official company sites, social network sites, and personal networking were used for establishing contacts. 
The questionnaire was distributed in April 2015, the initial plan was to collect the answers in maximum four weeks. On the first run, 907 entities were asked to fill the online questionnaire, after one month there were just 58 answers. Five entities declared that their company policies prohibit participating in researches: on one hand, their internal processes are private; on the other hand, they did not want to utilize company resources (working hours) for this purpose, all of them were multinational companies. The confidentiality issue shows that some companies take indeed KM very seriously.

As the number of responses was quite low in the early phase, on average it is less than ten percent, an another method was also applied for collecting inputs. The online version was printed and was handed over for 42 participants, one by one. The participants were asked to fill the questionnaire directly and finally they were uploaded to the database. Including the direct requests the overall response rate stayed below ten percent.

At last 100 questionnaires were collected. The number is high, but it needed more resources than awaited, especially the time-consuming interactions needed a lot of effort. In 'Chapter 4', the main research-principles were introduced, in this point, the further steps and results are described.

\subsubsection{Background information}

In this point, the basic results are presented, first a short overview is given about the participating companies' background. Mainly large-sized companies participated in the research (Table 7), the classification is as per the European Commission's recommendation (European-Commission, 2003). 
Table 7 - Company size

\begin{tabular}{|l|c|}
\hline \multicolumn{1}{|c|}{ Company size } & Number \\
\hline Large-sized enterprise & 69 \\
\hline $\begin{array}{l}\text { Medium-sized } \\
\text { enterprise }\end{array}$ & 19 \\
\hline Small-sized enterprise & 7 \\
\hline $\begin{array}{l}\text { Micro-sized } \\
\text { enterprise }\end{array}$ & 5 \\
\hline
\end{tabular}

Most of the companies are active (with the proviso that a company can be active in more domains) on Other Service Activities (43\%), Information and Communication (42\%), Professional, scientific and technical activities (33\%), Administrative and support service activities (30\%) and Manufacturing (29\%) as per the United Nations (UN) classification (United-Nations, 2008). The input for the research is considered valid, because these fields are quite knowledge intensive and the shown background is applicable for these (large-sized organizations in knowledge intensive environment). All the other UN-classes are between $0 \%$ and $20 \%$.

It is also important to mention that $69 \%$ of the answers stated that their company is integrated completely on international level and 6\% does not have any international connections, so the regulatory requirements and the applicability of the standards can be considered justifiable as well. Based on the background of the companies' profile the framework is acknowledged to be valid.

In the coming sub-points, the main domains are examined starting with the business process management.

\subsection{Results of the questionnaires}

In the coming sub-sections the BPM, the KM, and the renewal ability domains' descriptive analysis is presented. 


\subsubsection{Business process management}

The business process management aspect incorporates the business process management and the organizational roles.

The organizations do not face business processes change on short term (Figure 16), in case of the major BPs, most of the changes have a longer run. The organizations do not have to cope with hectic adjustments, they have time to prepare for managing the modified way of working.

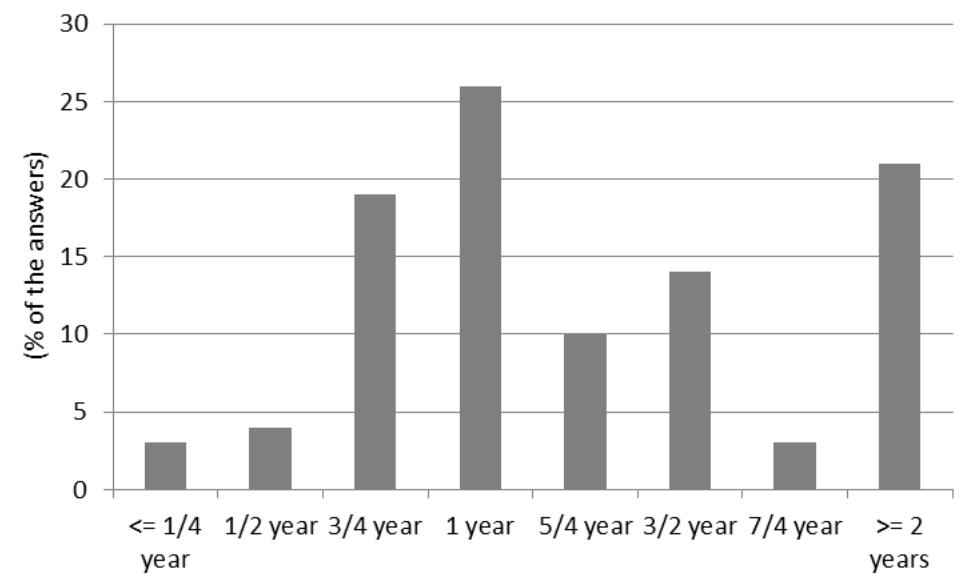

Figure 16 - Changes of BPs

The BPs are typically cyclical, recurrent, the $76 \%$ of the respondents state that the majority of the business processes have a reoccurring characteristic.

The business processes are mainly structured, identified (98\%) but they are integrated completely on a low level (24\%). Structuring and documenting is important ( $55 \%)$, but it is not done in every case, the most of the answers says that not every business process has to be documented. The BPs' documentation happens usually within a quarter year (Figure 17), this is consistent logically with the changes, the impactful business changes happen beyond this interval. 


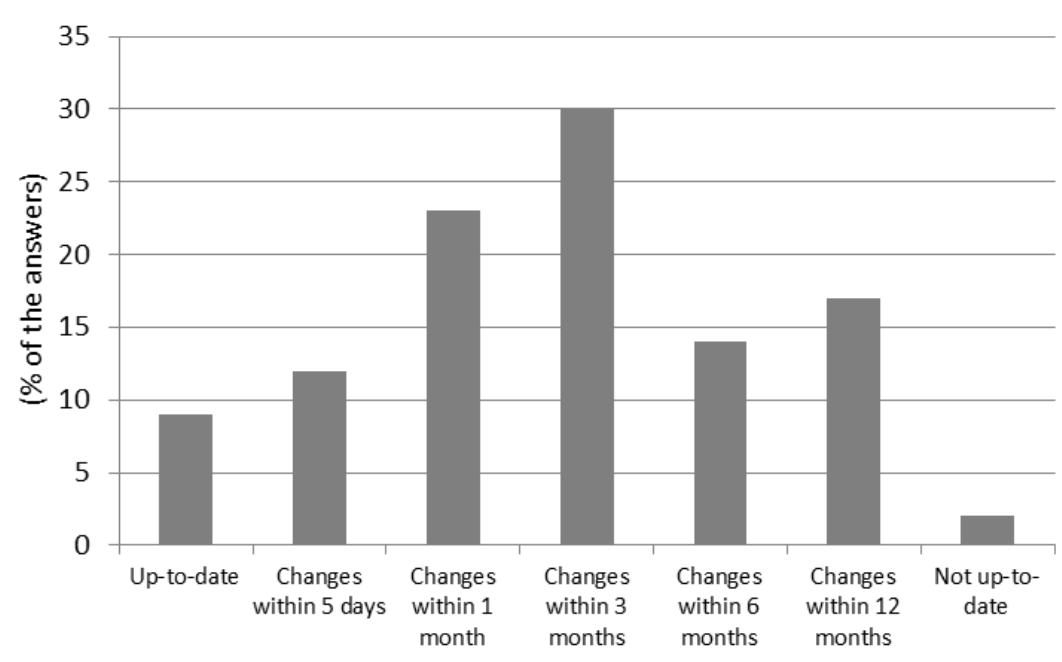

Figure 17 - BP documentation up-to-date?

The employees' awareness of the BPs is high, $79 \%$ of them know at least their own processes completely (53\% know most of the organizational business processes).

Measuring the throughput of the business processes happens usually from financial point of view (48\%) and with lag time (44\%), having a combined qualitative and quantitative measurement system is on low level (25\%).

According to the answers, the roles are partially or completely distinguished into value adding and supportive roles, and amongst the roles the hierarchical relation dominates. Most of the roles has defined responsibility and accountability (78\%), however there might be overlapping among the roles (80\%). It is also highlighted that the coordination amongst the roles requires flexibility, and there might be authority issues that might require intervention. In case of unknown tasks and complex problems the management would be able to find both the competent persons $(84 \%)$ and the roles $(76 \%)$.

$35 \%$ of the respondents say that there are reoccurring problems that are handled ad hoc.

Assessing the business process management shows different results. The answers show that the importance of the proper documentation and having set up rules is high; however, in practice these requirements are not met. There are documented procedures and settings within the organizations; however, they are not always used according to the documented versions (since there is a significant timely discrepancy), plus the 
measurement system has usually just a couple of points in focus, the balanced scorecard approach is in background.

In the following point, the knowledge management-related domain is presented.

\subsubsection{Knowledge management}

The knowledge management's practice has in scope the followings: managing, competence mapping of the human resources, documentation of the knowledge, and the tracing of the knowledge usage.

The most active roles and persons are identified within the organizations $(81 \%)$, and they are usually in distinguished role (91\%). The competent persons (earlier than the specific role) can be reached usually within a reasonable timeframe $(88 \%)$.

The organizations have a knowledge repository (79\%), there is some kind of utilization measurement, but not a complete one.

The results show that the individual competences are documented (88\%) and known by each other within the organization $(71 \%)$.

Understanding the role of the substitute, complementary, rare-unique and business critical knowledge elements is one of the research priorities, the other one is their efficient handling. If there is a competence map in place (66\%), then it is interesting what kind of relations can be retrieved from it. Two-third of the answers states that the organizations have competence map wherein the substitute (74\%) and complementary $(51 \%)$ knowledge elements are traceable. Business critical knowledge elements (63\%), competitive advantage-related knowledge (68\%), and rare, unique knowledge elements $(52 \%)$ are also traceable.

The explicit knowledge dominates the implicit knowledge (77\%), however the knowledge sharing itself is already not so easy (54\%), although its level is known within the organization (69\%). 


\begin{tabular}{|l|c|c|}
\hline \multicolumn{1}{|c|}{ Extract of KM } & Nr. & $\begin{array}{c}\text { \% of } \\
\text { '3 Competence } \\
\text { map' }\end{array}$ \\
\hline 1 Knowledge sharing difficulties & 54 & \\
\hline 2 Ability to find knowledge bearer & 61 & \\
\hline 3 Competence map & 66 & 74 \\
\hline 3.1 Substitute knowledge elements & & 51 \\
\hline 3.2 Complementary knowledge elements & & 63 \\
\hline 3.3 Critical knowledge elements & & 68 \\
\hline $\begin{array}{c}\text { 3.4 Competitive advantage-related } \\
\text { knowledge elements }\end{array}$ & & 52 \\
\hline 3.5 Rare, unique knowledge elements & & \\
\hline
\end{tabular}

The training and learning processes show practical awareness of the general expectations. The employees have a defined training plan for their roles (87\%). Its content has inputs mainly from supervisors and from external parties (e.g., HRM). The employees' inputs (34\%) and the legal obligations (13\%) are not the inherent part of the main training processes.

The business continuity's main characteristic is whether the organizations are able to manage the changes. The organizations' awareness of the intellectual capital management covers the changes amongst the employees. It is mandatory for everybody to participate in a hand over and take over process in case of personal changes (44\% for all, 59\% for specific roles). However, the measurement of the possible business loss caused by leaving employees is not measured punctually (Figure $18)$. 


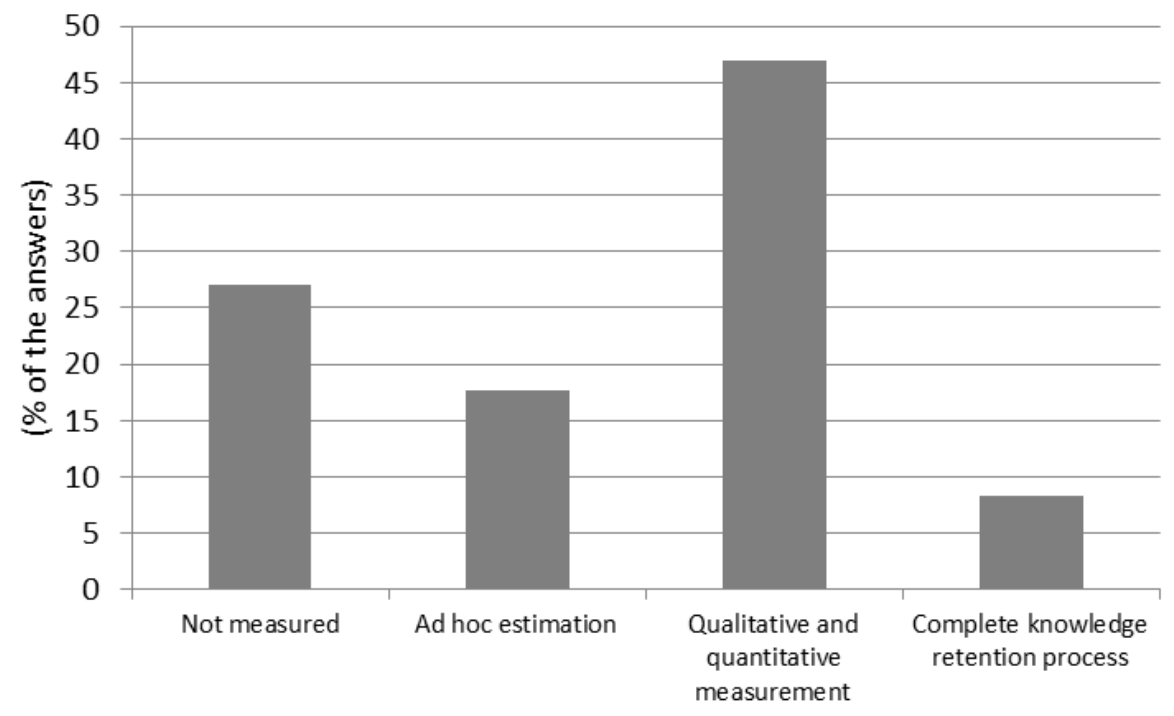

Figure 18 - KM measurement

The organizations use the best technical (78\%) and knowledge (83\%) setup for themselves. The answer givers consider their organizations as knowledge intensive ones and they think that the organizations have to deal with knowledge on strategic level.

Interesting result is that during the operation, the content of common terms can be understood differently (86\%), there are problems with the communication.

In the previous section, it could be seen that the BP management has some difficulties in practice: not everything is stored in the enterprise resource system as they are intended to be. The case is similar at the knowledge management, there are some measurement systems in place, but not every of them are on the same level in case of different entities. The knowledge usage is measured and the competences are set, documented and maintained, but some critical elements miss. There is a competence map in place just in two-third of the organizations. According to the answers, the explicit knowledge dominates, but based on the supportive questions the results show that the tacit knowledge is still really important and the domination of explicit knowledge is questionable.

The knowledge-based process management require a highly flexible system that can incorporate complex variables and environmental events. The BP aspect shows that even the low-level tasks are not completely fulfilled as they intended. 
In the coming sub-point, the knowledge as a permanent change driver is analyzed, where the ability to renew is in foreground.

\subsubsection{Renewal ability}

The organizations try to store knowledge in digital format, in shared systems, and they make it available for the relevant roles, preferably continuously.

Difficulties are in practice that not all the required knowledge can be found within the organizations (in case of $21 \%$ of the answers it cannot be found) and not always in a reasonable timeframe (24\%). The available stored knowledge is described as the following: useful (47\%), relevant (46\%), but reliability (32\%) and being up-to-date $(28 \%)$ are on lower level.

The organizations use also public knowledge sources $(78 \%)$ that is subject to general concerns $(64 \%)$.

The organizations often renew their knowledge (69\%) and the incorporation of new knowledge process does not require difficult procedures $(76 \%)$. The organizations tend to buy the 'knowledge bearer' directly from the workforce market (75\%) and they complete their knowledge with self-developed trainings.

In the questionnaire not just the present state of the specific entities' KM was examined, but the past and future ones, too. According to the answers, the organizations do have outdated knowledge (86\%). The nature of the knowledge explains this result and in the meanwhile the answers show that at least this fact is well-understood.

The next section covers the interviews that serve as the validation of the questionnaire content. 


\subsection{Interviews}

The interviews are meant to be the objective evidence that the chosen method (questionnaires) is fit for its intended use. The interview can reveal whether there is inconsistency between the questionnaire's content and the perception of the respondents.

The interviews are based on the questionnaires, they are semi-structured, the predefined questions come from the questionnaires. The interviewee has freedom to express her/his perceptions related to the domain and how she/he interprets the questions, the interviewer avoids advice-giving, getting involved, and being suggestive.

However, the participation rate in filling the questionnaires was lower than the expectation, organizing the interviews happened without obstacles, the first pool covered five people, and everybody showed intention to participate immediately. Two interviewees were selected from the volunteering group of the questionnaire-fillers.

In order to have a simple overview, the results are presented partly in table format. Table 9 presents the interviewees' profile, Table 10, Table 11, and Table 12 the discrepancies within the domain-related awareness. Since the content was wellunderstood and the response happened based on the interviewees' intention, just some of general remarks are highlighted.

Table 9 - Interview - Interviewee profile

\begin{tabular}{|l|c|c|}
\hline Attributes & Interviewee A & Interviewee B \\
\hline Sector & service & service \\
\hline Designation & leader & associate \\
\hline
\end{tabular}


Table 10 - Interview validation - BPM

\begin{tabular}{|c|c|c|c|}
\hline \multicolumn{2}{|c|}{ Domain A - BPM } & Interviewee A & Interviewee B \\
\hline 15 & $\begin{array}{l}\text { Are there reoccurring abandoned } \\
\text { problems within the organization? }\end{array}$ & $\begin{array}{c}\frac{\text { understanding: }}{\text { small discrepancies }} \\
\frac{\text { answers: small }}{\text { discrepancies }}\end{array}$ & $\begin{array}{c}\text { understanding: OK } \\
\text { answers: as } \\
\text { intended }\end{array}$ \\
\hline
\end{tabular}

The interviewees described the business processes according to the theoretical introduction of the current paper; they could identify the processes and the relevant inputs, outputs. The awareness of the BPs' documentation is similar; the appropriate process characteristics were understood as documentable items.

The interviewees could determine whether the documentation is up-to-date, they could describe the time horizons. Based on the own documentation and the experienced internal practices it could be revealed what are the business processes and how well these processes are known by the employees.

The business process' changes and the related cycles are known and understood as well. The business process metrics were available for the interviewees: the relevant aspects and the measurement's periodicity could be determined.

The role responsibilities were understood, the interviewees could tell whether those are defined, whether they could identify if there are overlaps, and they could also distinguish the value adding and supportive roles.

The competent roles' and persons' characteristics could be revealed, and they could share whether the organization is hierarchical.

The only misunderstanding was in one case: whether there are reoccurring abandoned problems, since the reoccurring abandoned problems are usually not part of the internal documentation the interviewee answered the question as per his own perception, the other interviewee's answer was more factual. 
Table 11 - Interview validation - KM

\begin{tabular}{|c|c|c|c|}
\hline \multicolumn{2}{|r|}{ Domain B - Knowledge management } & Interviewee A & Interviewee B \\
\hline 3 & $\begin{array}{l}\text { Can the competent persons be } \\
\text { reached immediately? }\end{array}$ & $\begin{array}{l}\text { understanding: OK } \\
\text { answers: as } \\
\text { intended }\end{array}$ & $\begin{array}{l}\frac{\text { understanding: }}{\text { small }} \\
\frac{\text { discrepancies }}{\text { answers: small }} \\
\frac{\text { discrepancies }}{\text { discris }}\end{array}$ \\
\hline 8 & $\begin{array}{l}\text { Does the explicit knowledge } \\
\text { dominate within your corporate's } \\
\text { domain? }\end{array}$ & $\begin{array}{l}\text { understanding: OK } \\
\text { answers: as } \\
\text { intended }\end{array}$ & $\begin{array}{l}\frac{\text { understanding: }}{\text { small }} \\
\frac{\text { discrepancies }}{\text { answers: } \text { small }} \\
\frac{\text { discrepancies }}{\text { discre }}\end{array}$ \\
\hline
\end{tabular}

Domain B covered the knowledge management related questions. The identification of the most active roles and persons was understood. The high impact employees' role allocation could be interpreted properly, however the competent persons reachability was mixed up with the competent role in one case, even so the answer was not ambiguous from the point of research.

The interviewees could give a comprehensive feedback about competence documentation: they gave feedback about the passive knowledge and the different types of the knowledge (substitute, complementary, rare-unique, critical, competitive advantage), and they could estimate whether the employees know each other's competencies.

Distinguishing the explicit knowledge was not properly understood in one case, but the interviewee's answer is close to the original meaning.

The routines and procedures of knowledge sharing and its level is known by the interviewees, in addition they can judge whether it is successful or not.

The interviewees are also aware of the knowledge management system and of their internal measurements. They could also give a feedback about the trainings: whether the training have dedicated time, what is the origin of the content and what the rolespecific plans are.

The hand over process' magnitude is known and they could determine its level within their services. The interviewees could give feedback about how their organizations 
handle the potential business losses with regards of knowledge management, they could give a feedback about the utilized solutions.

The interrelation of the corporate strategy and the knowledge management could be revealed as well, just like the internal communication issues.

Table 12 - Interview validation - Renewal

\begin{tabular}{|c|l|c|c|}
\hline \multicolumn{2}{|c|}{ Domain C - Renewal ability } & Interviewee A & Interviewee B \\
\hline 4 & $\begin{array}{l}\text { The usage of public knowledge } \\
\text { sources might be a concern? }\end{array}$ & $\begin{array}{c}\frac{\text { understanding: }}{\text { small discrepancies }} \\
\frac{\text { answers: as }}{\underline{\text { intended }}}\end{array}$ & $\begin{array}{c}\text { understanding: OK } \\
\text { answers: as } \\
\text { intended }\end{array}$ \\
\hline 6 & $\begin{array}{l}\text { Does the organization have } \\
\text { outdated knowledge? }\end{array}$ & $\begin{array}{c}\frac{\text { understanding: }}{\text { small discrepancies }} \\
\frac{\text { answers: } \text { as }}{\underline{\text { intended }}}\end{array}$ & $\begin{array}{c}\text { understanding: OK } \\
\text { answers: as } \\
\text { intended }\end{array}$ \\
\hline
\end{tabular}

Similar to the knowledge repository the interviewees could give feedback about the available knowledge's characteristics at their organizations.

The interviewees were aware of how the knowledge was stored, they could handle in which format the knowledge was maintained and who could access it. They could distinguish the public and private sources of the knowledge, and they could appraise whether their current practice is a subject of concern or not. In one case the public knowledge source was meant solely as Internet's public domain, since it is about a digitized organization, this answer is accepted as relevant.

Renewing the current knowledge and evaluating the presence of outdated knowledge was also quite straightforward for them, however in one case the outdated knowledge was interpreted as the not actively used knowledge, since in this specific context its meaning is similar, it is accepted as well.

The interviewees could also tell whether the required knowledge was available within their organizations, and if it was there they could give a relevant answer about the timeframe of its rediscovery of (re)finding. 
The answer givers had confident feedback about the changes by hiring new employees, they could evaluate whether the newly hired employees already had the required knowledge.

The situation of incorporating the new knowledge could be also pointed out without any difficulties.

Based on the answers of the two interviewees, the questionnaires' results are accepted as valid, there are few, marginal discrepancies and there are no coincidences.

In the next section, the research results are interpreted from the original viewpoint of the research.

\subsection{Interpretation of the research results}

As grounding the interpretation, some basic interrelations (semantics) are introduced.

A cause produces an effect, this is also known as causation. Two variables may be causally associated depending how the research is conducted. Two variables can be found also associated or correlated, that does not mean necessarily a cause-and-effect relationship between them. The proving of the causality has to be based on welldesigned experiments or several observational studies, since the not proper structuring of the phenomenon can lead to misinterpretation. This research's intended outcome, beside exploring the phenomenon from given point of view, is to provide information for later causation-researches on the same domain. In the current research some of the most significant correlation coefficients are presents in an extent to which two variables tend to correlate.

The answers were converted to number in order to give the baseline for measurements. The conversion is based on the related theories, standards, and methodologies. The highest correlations are presented on Table 13. The two affected variables and the correlation coefficient are listed, the $\alpha=0.01$ (linear relationship based on Appendix 7.1). 
The results were also validated by the Spearman rank-order correlation (monotonic relationship) and they were visually checked (based on Appendix 7.3). The related Tvalues, the Spearman-coefficients, and the scatter diagrams, since they bear similar results.

Table 13 - General findings

\begin{tabular}{|c|c|c|c|c|c|}
\hline $\mathrm{Nr}$. & & Variable 1 & & Variable 2 & $\mathrm{r}$ \\
\hline 1 & A1 & $\begin{array}{l}\text { Are the business processes } \\
\text { identified? }\end{array}$ & $\mathrm{A} 2$ & $\begin{array}{l}\text { Are the business processes } \\
\text { documented? }\end{array}$ & 0.59 \\
\hline 2 & $\mathrm{~A} 2$ & $\begin{array}{l}\text { Are the business processes } \\
\text { documented? }\end{array}$ & A9 & $\begin{array}{l}\text { Are the responsibilities } \\
\text { defined (roles)? }\end{array}$ & 0.61 \\
\hline 3 & $\mathrm{~A} 2$ & $\begin{array}{l}\text { Are the business processes } \\
\text { documented? }\end{array}$ & B6 & $\begin{array}{l}\text { Are the different type of } \\
\text { knowledge elements } \\
\text { measured? (critical) }\end{array}$ & 0.57 \\
\hline 4 & A6 & $\begin{array}{l}\text { Are the business processes } \\
\text { cyclical? }\end{array}$ & A14 & $\begin{array}{l}\text { Is the organization } \\
\text { hierarchical? }\end{array}$ & 0.55 \\
\hline 5 & A9 & $\begin{array}{l}\text { Are the responsibilities } \\
\text { defined (roles)? }\end{array}$ & B6 & $\begin{array}{l}\text { Are the different type of } \\
\text { knowledge elements } \\
\text { measured? (critical) }\end{array}$ & 0.57 \\
\hline 6 & A12 & $\begin{array}{l}\text { Can the competent roles be } \\
\text { identified? }\end{array}$ & A 13 & $\begin{array}{l}\text { Can the competent persons } \\
\text { be identified? }\end{array}$ & 0.57 \\
\hline 7 & A12 & $\begin{array}{l}\text { Can the competent roles be } \\
\text { identified? }\end{array}$ & B6 & $\begin{array}{l}\text { Are the different type of } \\
\text { knowledge elements } \\
\text { measured? } \\
\text { (complementary) }\end{array}$ & -0.54 \\
\hline 8 & B5 & $\begin{array}{l}\text { Is the passive knowledge } \\
\text { of the employees } \\
\text { documented? }\end{array}$ & B16 & $\begin{array}{l}\text { Is it a mandatory process to } \\
\text { hand over the knowledge } \\
\text { before role changes? }\end{array}$ & -0.55 \\
\hline 9 & B5 & $\begin{array}{l}\text { Is the passive knowledge } \\
\text { of the employees } \\
\text { documented? }\end{array}$ & $\mathrm{C} 1$ & $\begin{array}{l}\text { What kind of } \\
\text { characteristics does the } \\
\text { available knowledge have } \\
\text { at your organization? } \\
\text { (reliable) }\end{array}$ & -0.56 \\
\hline 10 & B6 & $\begin{array}{l}\text { Are the different type of } \\
\text { knowledge elements } \\
\text { measured? (competitive } \\
\text { advantage) }\end{array}$ & $\mathrm{C} 2$ & $\begin{array}{l}\text { Is the knowledge stored in } \\
\text { digital format, in shared } \\
\text { systems? }\end{array}$ & 0.56 \\
\hline 11 & B6 & $\begin{array}{l}\text { Are the different type of } \\
\text { knowledge elements } \\
\text { measured? (substitute) }\end{array}$ & $\mathrm{C} 2$ & $\begin{array}{l}\text { Is the knowledge stored in } \\
\text { digital format, in shared } \\
\text { systems? }\end{array}$ & 0.66 \\
\hline 12 & B9 & $\begin{array}{l}\text { Is the level of knowledge } \\
\text { sharing known within your } \\
\text { organization? }\end{array}$ & B17 & $\begin{array}{l}\text { Do you measure the } \\
\text { business loss of leaving } \\
\text { employees? }\end{array}$ & 0.54 \\
\hline 13 & B10 & $\begin{array}{l}\text { How successful is the } \\
\text { knowledge sharing within } \\
\text { the organization? }\end{array}$ & B1 & $\begin{array}{l}\text { Are the most active roles } \\
\text { and persons identified? }\end{array}$ & 0.59 \\
\hline
\end{tabular}




\begin{tabular}{|c|c|l|c|l|l|}
\hline 14 & B10 & $\begin{array}{l}\text { How successful is the } \\
\text { knowledge sharing within } \\
\text { the organization? }\end{array}$ & C2 & $\begin{array}{l}\text { Is the knowledge stored in } \\
\text { digital format, in shared } \\
\text { systems? }\end{array}$ & 0.56 \\
\hline 15 & B11 & $\begin{array}{l}\text { Do you have a knowledge } \\
\text { repository? }\end{array}$ & C2 & $\begin{array}{l}\text { Is the knowledge stored in } \\
\text { digital format, in shared } \\
\text { systems? }\end{array}$ & 0.67 \\
\hline 16 & B16 & $\begin{array}{l}\text { Is it a mandatory process to } \\
\text { hand over the knowledge } \\
\text { before role changes? }\end{array}$ & C1 & $\begin{array}{l}\text { What kind of } \\
\text { characteristics does the } \\
\text { available knowledge have } \\
\text { at your organization? } \\
\text { (reliable) }\end{array}$ & 0.58 \\
\hline B18 & $\begin{array}{l}\text { Does your organization use } \\
\text { the best solutions against } \\
\text { the business problems? } \\
\text { (knowledge) }\end{array}$ & B18 & $\begin{array}{l}\text { Does your organization use } \\
\text { the best solutions against } \\
\text { the business problems? } \\
\text { (technical) }\end{array}$ & 0.55 \\
\hline
\end{tabular}

The general findings show that the composite model of theories, standards, and methodologies indeed show significant interrelations. The rejection region's limits are -2.626 and 2.626, the listed items are correlating considering $\alpha=0.01$. (The reject regions might vary based on the number of the pairs, but since the $\alpha=0.01$ the limits are seen as valid, a similar approach is applied in the later cases.)

The business process documentation correlates with the business process identification, the defined responsibilities (roles), and the high level mapping of critical competencies. The roles definition's level correlates with the mapping of critical competencies also.

The more reoccurring the business processes are, the higher the applied hierarchy within the organization is (Table $13 \mathrm{Nr} .7$ ).

The competent roles are associated with the competent persons positively, the competent roles and the complementary knowledge mapping has a negative relationship.

The documentation of passive knowledge does not correlate with the hand over and take over procedure, and it is negatively associated with the reliable knowledge. The hand over take over procedure correlates with the reliable quality nature of the available knowledge. 
The competitive and substitute knowledge elements' mapping is positively associated with the level of digitally stored knowledge.

The knowledge sharing correlates with KM measurement system, with the identification of the most active roles and persons, and whether the knowledge is stored in digital format in a shared systems. The knowledge repository and the shared system are also positively associated, actually this is trivial, it gives information about the background how it works in practice.

Whether the organizations use the best knowledge set and technical set is also associated positively.

In case of the competence map, the variables are binary, for them, another correlationmethod is utilized (Appendix 7.2).

Table 14 - Competence map

\begin{tabular}{|c|l|l|c|}
\hline Nr. & \multicolumn{1}{|c|}{ Variable 1 } & \multicolumn{1}{c|}{ Variable 2 } & $\varphi$ \\
\hline 1 & Substitute & Complementary & 0.62 \\
\hline 2 & Substitute & Rare & 0.54 \\
\hline 3 & Substitute & Critical & 0.51 \\
\hline 4 & Substitute & Competitive & 0.58 \\
\hline 5 & Complementary & Rare & 0.78 \\
\hline 6 & Complementary & Critical & 0.68 \\
\hline 7 & Complementary & Competitive & 0.61 \\
\hline 8 & Rare & Critical & 0.56 \\
\hline 9 & Rare & Competitive & 0.54 \\
\hline 10 & Critical & Competitive & 0.61 \\
\hline
\end{tabular}

The two affected variables, the correlation coefficient $(\varphi)$ are listed. The rejection region's limit is $6.63(\alpha=0.01)$. The presented variables are correlated. The practice about measuring the competencies shows an understanding about the different interrelations of the competencies.

The general findings gave a highlight about the most interrelated variables, in the coming four sub-sections the same methodology is used to deliver answers for the research questions. 


\subsubsection{Answers to Question 1}

Under what circumstances is the knowledge management applied? Can it be defined? What are the characteristics?

For interpretation the strongest correlations are selected. The assumptions for the sufficient level of the applicability of the KM (Table 15) is whether the competencies are documented (B4), whether there is a knowledge repository (B11), whether there are training plans are in place (B13), and whether the knowledge management is handled as a component of the strategy (B19). 52 entities were taken into consideration from the 100. The rejection region's limits are -2.678 and 2.678 , the listed items are correlating considering $\alpha=0.01$.

Table 15 - KM applicable

\begin{tabular}{|c|c|c|c|c|c|}
\hline $\mathrm{Nr}$. & & Variable 1 & & Variable 2 & $\mathrm{r}$ \\
\hline 1 & A8 & $\begin{array}{l}\text { Is the measurement real- } \\
\text { time? }\end{array}$ & A12 & $\begin{array}{l}\text { Can the competent roles be } \\
\text { identified? }\end{array}$ & 0.70 \\
\hline 2 & A6 & $\begin{array}{l}\text { Are the business processes } \\
\text { cyclical? }\end{array}$ & A14 & $\begin{array}{l}\text { Is the organization } \\
\text { hierarchical? }\end{array}$ & 0.79 \\
\hline 3 & A4 & $\begin{array}{l}\text { Do the employees know } \\
\text { the business processes? }\end{array}$ & B6 & $\begin{array}{l}\text { Are the different type of } \\
\text { knowledge elements } \\
\text { measured? } \\
\text { (complementary) }\end{array}$ & 0.66 \\
\hline 4 & A6 & $\begin{array}{l}\text { Are the business processes } \\
\text { cyclical? }\end{array}$ & B10 & $\begin{array}{l}\text { How successful is the } \\
\text { knowledge sharing within } \\
\text { the organization? }\end{array}$ & 0.68 \\
\hline 5 & A6 & $\begin{array}{l}\text { Are the business processes } \\
\text { cyclical? }\end{array}$ & B16 & $\begin{array}{l}\text { Is it a mandatory process to } \\
\text { hand over the knowledge } \\
\text { before role changes? }\end{array}$ & 0.81 \\
\hline 6 & A6 & $\begin{array}{l}\text { Are the business processes } \\
\text { cyclical? }\end{array}$ & $\mathrm{C} 1$ & $\begin{array}{l}\text { What kind of } \\
\text { characteristics does the } \\
\text { available knowledge have } \\
\text { at your organization? } \\
\text { (reliable) }\end{array}$ & 0.75 \\
\hline
\end{tabular}




\begin{tabular}{|c|c|c|c|c|c|}
\hline 7 & A7 & $\begin{array}{l}\text { Are the business processes } \\
\text { measured (all relevant } \\
\text { aspects)? }\end{array}$ & $\mathrm{C} 1$ & $\begin{array}{l}\text { What kind of } \\
\text { characteristics does the } \\
\text { available knowledge have } \\
\text { at your organization? } \\
\text { (reliable) }\end{array}$ & 0.65 \\
\hline 8 & A8 & $\begin{array}{l}\text { Is the measurement real- } \\
\text { time? }\end{array}$ & $\mathrm{C} 1$ & $\begin{array}{l}\text { What kind of } \\
\text { characteristics does the } \\
\text { available knowledge have } \\
\text { at your organization? } \\
\text { (reliable) }\end{array}$ & 0.66 \\
\hline 9 & B5 & $\begin{array}{l}\text { Is the passive knowledge of } \\
\text { the employees } \\
\text { documented? }\end{array}$ & B16 & $\begin{array}{l}\text { Is it a mandatory process to } \\
\text { hand over the knowledge } \\
\text { before role changes? }\end{array}$ & -0.65 \\
\hline 10 & B5 & $\begin{array}{l}\text { Is the passive knowledge of } \\
\text { the employees } \\
\text { documented? }\end{array}$ & $\mathrm{C} 1$ & $\begin{array}{l}\text { What kind of } \\
\text { characteristics does the } \\
\text { available knowledge have } \\
\text { at your organization? } \\
\text { (reliable) }\end{array}$ & -0.74 \\
\hline 11 & B6 & $\begin{array}{l}\text { Are the different type of } \\
\text { knowledge elements } \\
\text { measured? (competitive } \\
\text { advantage) }\end{array}$ & $\mathrm{C} 2$ & $\begin{array}{l}\text { Is the knowledge stored in } \\
\text { digital format, in shared } \\
\text { systems? }\end{array}$ & 0.67 \\
\hline 12 & B11 & $\begin{array}{l}\text { Do you have a knowledge } \\
\text { repository? }\end{array}$ & B15 & $\begin{array}{l}\text { Do the employees have a } \\
\text { dedicated time for fulfilling } \\
\text { the trainings? }\end{array}$ & 0.86 \\
\hline 13 & B16 & $\begin{array}{l}\text { Is it a mandatory process to } \\
\text { hand over the knowledge } \\
\text { before role changes? }\end{array}$ & $\mathrm{C} 1$ & $\begin{array}{l}\text { What kind of } \\
\text { characteristics does the } \\
\text { available knowledge have } \\
\text { at your organization? } \\
\text { (reliable) }\end{array}$ & 0.90 \\
\hline 14 & B18 & $\begin{array}{l}\text { Does your organization use } \\
\text { the best solutions against } \\
\text { the business problems? } \\
\text { (technical) }\end{array}$ & B18 & $\begin{array}{l}\text { Does your organization use } \\
\text { the best solutions against } \\
\text { the business problems? } \\
\text { (knowledge) }\end{array}$ & 0.66 \\
\hline 15 & $\mathrm{C} 2$ & $\begin{array}{l}\text { Is the knowledge stored in } \\
\text { digital format, in shared } \\
\text { systems? }\end{array}$ & C3 & $\begin{array}{l}\text { Does your organization use } \\
\text { public knowledge sources? }\end{array}$ & 0.74 \\
\hline
\end{tabular}

In case the organizations have detailed measurement, parallel the competent roles are identified better, and the organizations' operation is based on reliable knowledge. The 
more cyclical business processes are associated with more hierarchical organizations, and the knowledge sharing is more successful within similar organization. The hand over take over processes are on higher level, and the organizations are working with reliable knowledge resources.

The organizations, what have reliable knowledge, have better BP measurement system in place, they document the passive knowledge of the employees (this is opposite of Table $18 \mathrm{Nr} .5$ ), and they have a mandatory hand over take over process (this is similar to Table 18 Nr. 6). Documenting the passive knowledge and having hand over process are negatively correlated.

Knowing the BPs by the employees correlates positively with measuring complementary knowledge elements.

Having a digitized knowledge sharing system positively correlates with measuring the competitive advantages and with the utilization of public knowledge sources. There is also a strong positive correlation among having a knowledge repository and dedicating time for trainings. The organizations utilize acceptable solutions against business problems both from technical and organizational (KM) aspects. The competence measurement is not discussed here details, all the correlations (positive) are significant expect the relation of the knowledge repository and the measurement of the complementary knowledge.

The applied KM's relevance is high in case of cyclical business processes, the organizations' work is based on reliable knowledge, the digitization of the KM systems is an enabler for other KM-related processes. In the meanwhile, the passive, not utilized knowledge of the workforce is not considered as an inherent part of the KM processes.

\subsubsection{Answers to Question 2, Question 3}

Under what circumstances is the knowledge management measured? Can it be measured? What are the characteristics? Under what circumstances is the applied level 
of the knowledge management determined? Can it be determined? What are the characteristics?

First, the high level KM-related characteristics are introduced, then the low level. The $\mathrm{KM}$ is considered to be on high level if there are measured competencies (B6), if the knowledge sharing is known (B9), if the knowledge repository's utilization is measured (B12), and if the knowledge bearers are measured (B17). 41 entities were taken into consideration from the 100 (Table 16). The rejection region's limits are 2.704 and 2.704, the listed items are correlating considering $\alpha=0.01$.

Table 16 - High level KM

\begin{tabular}{|c|c|c|c|c|c|}
\hline $\mathrm{Nr}$. & & Variable 1 & & Variable 2 & $\mathrm{r}$ \\
\hline 1 & A6 & $\begin{array}{l}\text { Are the business processes } \\
\text { cyclical? }\end{array}$ & A8 & $\begin{array}{l}\text { Is the measurement real- } \\
\text { time? }\end{array}$ & 0.75 \\
\hline 2 & A6 & $\begin{array}{l}\text { Are the business processes } \\
\text { cyclical? }\end{array}$ & A12 & $\begin{array}{l}\text { Can the competent roles be } \\
\text { identified? }\end{array}$ & -0.70 \\
\hline 3 & A 8 & $\begin{array}{l}\text { Is the measurement real- } \\
\text { time? }\end{array}$ & A12 & $\begin{array}{l}\text { Can the competent roles be } \\
\text { identified? }\end{array}$ & 0.76 \\
\hline 4 & A12 & $\begin{array}{l}\text { Can the competent roles be } \\
\text { identified? }\end{array}$ & B5 & $\begin{array}{l}\text { Is the passive knowledge } \\
\text { of the employees } \\
\text { documented? }\end{array}$ & -0.70 \\
\hline 5 & A6 & $\begin{array}{l}\text { Are the business processes } \\
\text { cyclical? }\end{array}$ & B16 & $\begin{array}{l}\text { Is it a mandatory process to } \\
\text { hand over the knowledge } \\
\text { before role changes? }\end{array}$ & 0.95 \\
\hline 6 & A7 & $\begin{array}{l}\text { Are the business processes } \\
\text { measured (all relevant } \\
\text { aspects)? }\end{array}$ & B16 & $\begin{array}{l}\text { Is it a mandatory process to } \\
\text { hand over the knowledge } \\
\text { before role changes? }\end{array}$ & 0.71 \\
\hline 7 & A8 & $\begin{array}{l}\text { Is the measurement real- } \\
\text { time? }\end{array}$ & B16 & $\begin{array}{l}\text { Is it a mandatory process to } \\
\text { hand over the knowledge } \\
\text { before role changes? }\end{array}$ & 0.75 \\
\hline 8 & A12 & $\begin{array}{l}\text { Can the competent roles be } \\
\text { identified? }\end{array}$ & B16 & $\begin{array}{l}\text { Is it a mandatory process to } \\
\text { hand over the knowledge } \\
\text { before role changes? }\end{array}$ & 0.76 \\
\hline 9 & B5 & $\begin{array}{l}\text { Is the passive knowledge } \\
\text { of the employees } \\
\text { documented? }\end{array}$ & B16 & $\begin{array}{l}\text { Is it a mandatory process to } \\
\text { hand over the knowledge } \\
\text { before role changes? }\end{array}$ & -0.71 \\
\hline 10 & A6 & $\begin{array}{l}\text { Are the business processes } \\
\text { cyclical? }\end{array}$ & $\mathrm{C} 1$ & $\begin{array}{l}\text { What kind of } \\
\text { characteristics does the } \\
\text { available knowledge have } \\
\text { at your organization? } \\
\text { (reliable) }\end{array}$ & 0.80 \\
\hline
\end{tabular}




\begin{tabular}{|c|c|c|c|c|c|}
\hline 11 & B8 & $\begin{array}{l}\text { Does the explicit } \\
\text { knowledge dominate } \\
\text { within your corporate's } \\
\text { domain? }\end{array}$ & $\mathrm{C} 1$ & $\begin{array}{l}\text { What kind of } \\
\text { characteristics does the } \\
\text { available knowledge have } \\
\text { at your organization? } \\
\text { (reliable) }\end{array}$ & 0.74 \\
\hline 12 & B12 & $\begin{array}{l}\text { Is the knowledge } \\
\text { repository's utilization } \\
\text { measured? }\end{array}$ & $\mathrm{C} 1$ & $\begin{array}{l}\text { What kind of } \\
\text { characteristics does the } \\
\text { available knowledge have } \\
\text { at your organization? } \\
\text { (reliable) }\end{array}$ & 0.76 \\
\hline 13 & B5 & $\begin{array}{l}\text { Is the passive knowledge } \\
\text { of the employees } \\
\text { documented? }\end{array}$ & $\mathrm{C} 1$ & $\begin{array}{l}\text { What kind of } \\
\text { characteristics does the } \\
\text { available knowledge have } \\
\text { at your organization? } \\
\text { (reliable) }\end{array}$ & -0.80 \\
\hline 14 & B16 & $\begin{array}{l}\text { Is it a mandatory process to } \\
\text { hand over the knowledge } \\
\text { before role changes? }\end{array}$ & $\mathrm{C} 1$ & $\begin{array}{l}\text { What kind of } \\
\text { characteristics does the } \\
\text { available knowledge have } \\
\text { at your organization? } \\
\text { (reliable) }\end{array}$ & 0.85 \\
\hline 15 & B5 & $\begin{array}{l}\text { Is the passive knowledge of } \\
\text { the employees } \\
\text { documented? }\end{array}$ & C8 & $\begin{array}{l}\text { The required knowledge } \\
\text { can be found within your } \\
\text { organization in a } \\
\text { reasonable timeframe? }\end{array}$ & 0.69 \\
\hline 16 & C8 & $\begin{array}{l}\text { The required knowledge } \\
\text { can be found within your } \\
\text { organization in a } \\
\text { reasonable timeframe? }\end{array}$ & $\mathrm{C} 1$ & $\begin{array}{l}\text { What kind of } \\
\text { characteristics does the } \\
\text { available knowledge have } \\
\text { at your organization? } \\
\text { (reliable) }\end{array}$ & -0.71 \\
\hline
\end{tabular}

The highly cyclical business processes correlate positively with the real-time measurement of the BPs, with the mandatory hand over take over processes, and with having reliable knowledge. It correlates negatively with competent role identification.

The competent roles identification correlates positively with real-time measurement of the BPs and it is negatively correlated with the documentation of the passive knowledge of the employees.

Having a mandatory hand over take over process for the employees before role changes positively correlates with having a BP measurement mechanism what covers all relevant aspect, with real-time BP measurement, and with competent role identification. It correlates negatively with passive knowledge documentation. 
Similar is the case of having reliable knowledge within the organization, it correlates negatively also with having the passive knowledge of the employees documented. However reliable knowledge correlates positively with the domination of explicit knowledge, with measuring the knowledge repository's utilization, and with having a mandatory hand over take over process. Having reliable knowledge correlates negatively with the ability to find it within a reasonable timeframe.

The ability to find the required knowledge within the organization correlates positively with the documentation of passive knowledge of the employees.

Measuring the different type of competencies correlates with each other.

The high level KM's characteristics show that the reliable knowledge is one of the most significant factors among the interrelations. Another key outcome is that the more highly cyclical business processes and the better measurement of the BPs are positively correlated.

The low level KM is complementary to the high level. 59 entities were taken into consideration from the 100 (Table 17). The rejection region's limits are -2.66 and 2.66, the listed items are correlating considering $\alpha=0.01$.

Table 17 - Low level KM

\begin{tabular}{|c|c|l|c|l|c|}
\hline Nr. & \multicolumn{2}{|c|}{ Variable 1 } & \multicolumn{2}{|c|}{ Variable 2 } & $\mathrm{r}$ \\
\hline 1 & A1 & $\begin{array}{l}\text { Are the business processes } \\
\text { identified? }\end{array}$ & A2 & $\begin{array}{l}\text { Are the business processes } \\
\text { documented? }\end{array}$ & 0.62 \\
\hline 2 & A2 & $\begin{array}{l}\text { Are the business processes } \\
\text { documented? }\end{array}$ & A9 & $\begin{array}{l}\text { Are the responsibilities } \\
\text { defined (roles)? }\end{array}$ & 0.66 \\
\hline 3 & A1 & $\begin{array}{l}\text { Are the business processes } \\
\text { identified? }\end{array}$ & B6 & $\begin{array}{l}\text { Are the different type of } \\
\text { knowledge elements } \\
\text { measured? (critical) }\end{array}$ & 0.66 \\
\hline 5 & A9 & $\begin{array}{l}\text { Are the business processes } \\
\text { documented? }\end{array}$ & B6 & $\begin{array}{l}\text { Are the different type of } \\
\text { knowledge elements } \\
\text { measured? (critical) }\end{array}$ & 0.65 \\
\hline 6 & A14 & $\begin{array}{l}\text { Is the responsibilities } \\
\text { hierarchical? }\end{array}$ & B17 & $\begin{array}{l}\text { Do you measure the } \\
\text { business loss of leaving } \\
\text { employees? }\end{array}$ & 0.55 \\
\hline
\end{tabular}




\begin{tabular}{|c|c|c|c|c|c|}
\hline 7 & B6 & $\begin{array}{l}\text { Are the different type of } \\
\text { knowledge elements } \\
\text { measured? (substitute) }\end{array}$ & B7 & $\begin{array}{l}\text { Do the employees know } \\
\text { each other's competencies? }\end{array}$ & 0.74 \\
\hline 8 & B6 & $\begin{array}{l}\text { Are the different type of } \\
\text { knowledge elements } \\
\text { measured? } \\
\text { (complementary) }\end{array}$ & B7 & $\begin{array}{l}\text { Do the employees know } \\
\text { each other's competencies? }\end{array}$ & 0.84 \\
\hline 9 & B6 & $\begin{array}{l}\text { Are the different type of } \\
\text { knowledge elements } \\
\text { measured? (rare-unique) }\end{array}$ & B7 & $\begin{array}{l}\text { Do the employees know } \\
\text { each other's competencies? }\end{array}$ & 0.71 \\
\hline 10 & B6 & $\begin{array}{l}\text { Are the different type of } \\
\text { knowledge elements } \\
\text { measured (critical)? }\end{array}$ & B7 & $\begin{array}{l}\text { Do the employees know } \\
\text { each other's competencies? }\end{array}$ & 0.77 \\
\hline 11 & B6 & $\begin{array}{l}\text { Are the different type of } \\
\text { knowledge elements } \\
\text { measured? (competitive } \\
\text { advantage) }\end{array}$ & B7 & $\begin{array}{l}\text { Do the employees know } \\
\text { each other's competencies? }\end{array}$ & 0.76 \\
\hline 12 & B6 & $\begin{array}{l}\text { Are the different type of } \\
\text { knowledge elements } \\
\text { measured? (substitute) }\end{array}$ & C3 & $\begin{array}{l}\text { Does your organization use } \\
\text { public knowledge sources? }\end{array}$ & 0.58 \\
\hline 13 & B6 & $\begin{array}{l}\text { Are the different type of } \\
\text { knowledge elements } \\
\text { measured? (rare-unique) }\end{array}$ & $\mathrm{C} 2$ & $\begin{array}{l}\text { Is the knowledge stored in } \\
\text { digital format, in shared } \\
\text { systems? }\end{array}$ & 0.58 \\
\hline 14 & B7 & $\begin{array}{l}\text { Do the employees know } \\
\text { each other's competencies? }\end{array}$ & C3 & $\begin{array}{l}\text { Does your organization use } \\
\text { public knowledge sources? }\end{array}$ & 0.56 \\
\hline 15 & B12 & $\begin{array}{l}\text { Is the knowledge } \\
\text { repository's utilization } \\
\text { measured? }\end{array}$ & C3 & $\begin{array}{l}\text { Does your organization use } \\
\text { public knowledge sources? }\end{array}$ & 0.60 \\
\hline
\end{tabular}

On low level, KM the BPM's principles prevail. The fact that the BPs are documented correlates positively with the high level identification of the BPs and with the mature level of role definitions. Measuring the critical knowledge elements correlates positively with BP identification and documentation.

The assessing and evaluating (Table $17 \mathrm{Nr}$. 5-6) correlate with the role definition and having a more hierarchical organization.

The fact, whether the employees know each other's competencies, is positively correlated with the measurement of the different knowledge elements (substitute, complementary, rare-unique, critical, competitive advantage). It correlates positively also with utilization of public knowledge sources. 
Utilizing public knowledge sources correlates positively with knowledge repository measurement and with the measurement of substitute knowledge elements.

Measuring the rare-unique knowledge elements correlates positively with storing knowledge in digitized format.

Measurement the different type of competencies correlates with each other.

The low level KM applies the most important basic principles of the BPM. The BP documentation is tightly connected to the operative work (critical knowledge elements are taken into consideration). The more hierarchical the organization is, the higher the measurement level is. The higher the measurement level is, the better the employees rely on documented procedures.

\subsubsection{Answers to Question 4}

On what level can the organizational knowledge be assessed and evaluated based on business process management? What are the characteristics?

The strongest correlations are selected for interpretation. The assumptions for the sufficient level of business process management is whether the business processes are identified (A1), whether they are structured and documented (A2), and whether the employees know the BPs (A4.). 37 entities were taken into consideration from the 100 (Table 18). The rejection region's limits are -2.704 and 2.704 , the listed items are correlating considering $\alpha=0.01$.

Having disjoined roles correlates negatively with the organizational ability to find the competent persons. Documenting the passive knowledge of the employees correlates negatively with the ability of identifying the competent roles, with having mandatory hand over process before role changes, and with the available reliable knowledge.

Having available reliable knowledge within the organization correlates positively with real-time measurement of the processes, with hand over processes, but it is negatively correlated with hiring employees who possesses the required knowledge. 
The organizations that have a high level BPM, rely less on persons, handling passive knowledge is not part of the hand over take over processes, it is not connected to having reliable knowledge. The organizations that have more real-time measurements, have reliable knowledge within the organization. The reliable knowledge is not based on 'bought' resources, but on proven experiences.

Table 18 - KM based on BPM

\begin{tabular}{|c|c|c|c|c|c|}
\hline Nr. & \multicolumn{2}{|r|}{ Variable 1} & \multicolumn{2}{|r|}{ Variable 2} & $\mathrm{r}$ \\
\hline 1 & A10 & Are the roles disjoined? & A13 & $\begin{array}{l}\text { Can the competent persons } \\
\text { be identified? }\end{array}$ & -0.65 \\
\hline 2 & A12 & $\begin{array}{l}\text { Can the competent roles be } \\
\text { identified? }\end{array}$ & B5 & $\begin{array}{l}\text { Is the passive knowledge } \\
\text { of the employees } \\
\text { documented? }\end{array}$ & -0.66 \\
\hline 3 & A8 & $\begin{array}{l}\text { Is the measurement real- } \\
\text { time? }\end{array}$ & C1 & $\begin{array}{l}\text { What kind of } \\
\text { characteristics does the } \\
\text { available knowledge have } \\
\text { at your organization? } \\
\text { (reliable) }\end{array}$ & 0.67 \\
\hline 4 & B5 & $\begin{array}{l}\text { Is the passive knowledge of } \\
\text { the employees } \\
\text { documented? }\end{array}$ & B16 & $\begin{array}{l}\text { Is it a mandatory process to } \\
\text { hand over the knowledge } \\
\text { before role changes? }\end{array}$ & -0.65 \\
\hline 5 & B5 & $\begin{array}{l}\text { Is the passive knowledge of } \\
\text { the employees } \\
\text { documented? }\end{array}$ & $\mathrm{C} 1$ & $\begin{array}{l}\text { What kind of } \\
\text { characteristics does the } \\
\text { available knowledge have } \\
\text { at your organization? } \\
\text { (reliable) }\end{array}$ & -0.66 \\
\hline 6 & B16 & $\begin{array}{l}\text { Is it a mandatory process to } \\
\text { hand over the knowledge } \\
\text { before role changes? }\end{array}$ & C1 & $\begin{array}{l}\text { What kind of } \\
\text { characteristics does the } \\
\text { available knowledge have } \\
\text { at your organization? } \\
\text { (reliable) }\end{array}$ & 0.75 \\
\hline 7 & C9 & $\begin{array}{l}\text { Do the newly hired } \\
\text { employees have the } \\
\text { required knowledge? }\end{array}$ & $\mathrm{C} 1$ & $\begin{array}{l}\text { What kind of } \\
\text { characteristics does the } \\
\text { available knowledge have } \\
\text { at your organization? } \\
\text { (reliable) }\end{array}$ & -0.67 \\
\hline
\end{tabular}


Table 19 - Competence map - KM based on BPM

\begin{tabular}{|c|l|l|c|}
\hline Nr. & \multicolumn{1}{|c|}{ Variable 1 } & \multicolumn{1}{c|}{ Variable 2 } & $\varphi$ \\
\hline 1 & Substitute & Complementary & 0.56 \\
\hline 2 & Substitute & Rare & 0.42 \\
\hline 3 & Substitute & Critical & 0.70 \\
\hline 4 & Substitute & Competitive & 1.00 \\
\hline 5 & Complementary & Rare & 0.85 \\
\hline 6 & Complementary & Critical & 0.35 \\
\hline 7 & Complementary & Competitive & 0.56 \\
\hline 8 & Rare & Critical & 0.24 \\
\hline 9 & Rare & Competitive & 0.42 \\
\hline 10 & Critical & Competitive & 0.70 \\
\hline
\end{tabular}

The competence map covers binary variables $(\alpha=0.01$, rejection region's limit is 6.63). The variables are correlated. Critical knowledge element is not correlated with complementary and rare competencies; substitute does not correlate with rare competencies. The variables have positive correlations with having knowledge repository and dedicated time for trainings.

The substitute and competitive competencies have a very strong correlation. Having the required level of substitute knowledge bearers within the organization is definitely a competitive factor in organizations where the BPM is on high level.

In the next section, the research is summarized in a synthesis.

\subsection{Synthesis of the research}

The organizations that have a high level BPM rely less on persons. The utilized knowledge's most significant characteristic is whether it is reliable. The reliable knowledge is not based on 'bought' resources, but on proven experiences. Maintaining the BPs' principles has a strong, positive correlation with BP-awareness. The applied role definitions and the competence-mapping have an adequate, positive correlation.

In case of applied $\mathrm{KM}$, the dense and repetitive business processes are the characteristic of hierarchical organizations. The applied KM relevance is high in case 
of cyclical business processes. In a measured KM environment, the impactful roles and persons are known, the knowledge is stored in a digitized system, the digitization of the KM systems is an enabler for other KM-related processes. The not utilized knowledge of the workforce is not part of the $\mathrm{KM}$, the main focus is on the reliable knowledge.

The high level KM has the following correlations: cyclical BPs have positive interrelations with real-time measurement, hand over take over processes, and having reliable knowledge. Having a mandatory hand over take over process positively correlates with having a detailed and real-time BP measurement mechanism, and competent role identification. The high level KM's characteristics show that the reliable knowledge is one of the most significant factors among the interrelations.

The low level KM bears the BPM's principles. The mature BPs bear high awareness of the BPs. The fact, whether the employees know each other's competencies, is positively correlated with the measurement of the different knowledge elements (critical knowledge is the most significant). Measurement of the different type of competencies correlates with each other. The more hierarchical the organization is, the higher the measurement level is. The higher the measurement level is, the better the employees rely on documented procedures.

The examined problem is covered from more aspects, based on the theories, methodologies, and standards. It can be stated that the cycles of the BPs processes are one of the drivers of the KM (Finding 1). Since the BP's cyclical characteristic is mainly driven from the environment, the organizations do not have direct influence on them, so this is an external driver of the applied KM.

Another important finding is that the organizations' work is based on reliable knowledge (Finding 2), wherein the KM awareness is high. The reliable knowledge has to be based on experience which is justified on certain amount of time. Therefore, the phenomenon of the reliable knowledge has to be operationalized in later researches.

The last finding (Finding 3) is that the low level KM covers the main principles of the BPM. This means that the BPM's main principles are indeed utilized with each other. Once the BPM is utilized, it is used from a holistic viewpoint. 


\subsection{Generalization of the research}

The BPM's KM-related expectations have to be translated into a measurement system that can give a clear view about the current business needs, the available solutions, and the required level of knowledge management. The most critical phenomenon to be covered is the knowledge management itself.

Aligning to the reality requires having every significant element of the business to be evaluated. One of the most important issues is to reveal the current level of the knowledge management, and the desired level of it. For this purpose, the BPM can be used.

The current research is based on quantified data; for getting a clear picture, it was also needed to identify the key steps of the knowledge management systems, the source of the knowledge, and the intensity of the used knowledge. In addition, it is needed to reveal those roles which enable the organization to utilize the combination of these.

The business stakeholders face a lot of challenges: the $\mathrm{KM}$ and the intellectual property management takes a lot of corporate resources and the usage of these resources has to be evidenced. In order to make the stakeholders able to represent the value of the knowledge they need a holistic management aspect. They have to keep in mind that the current BPMs cannot deliver the best answers for every question; however, they are already on a very appealing level.

Figure 19 shows that the knowledge management's level and the realized value should be somehow measured, the prerequisite for this is to have the corresponding BPM in place. 


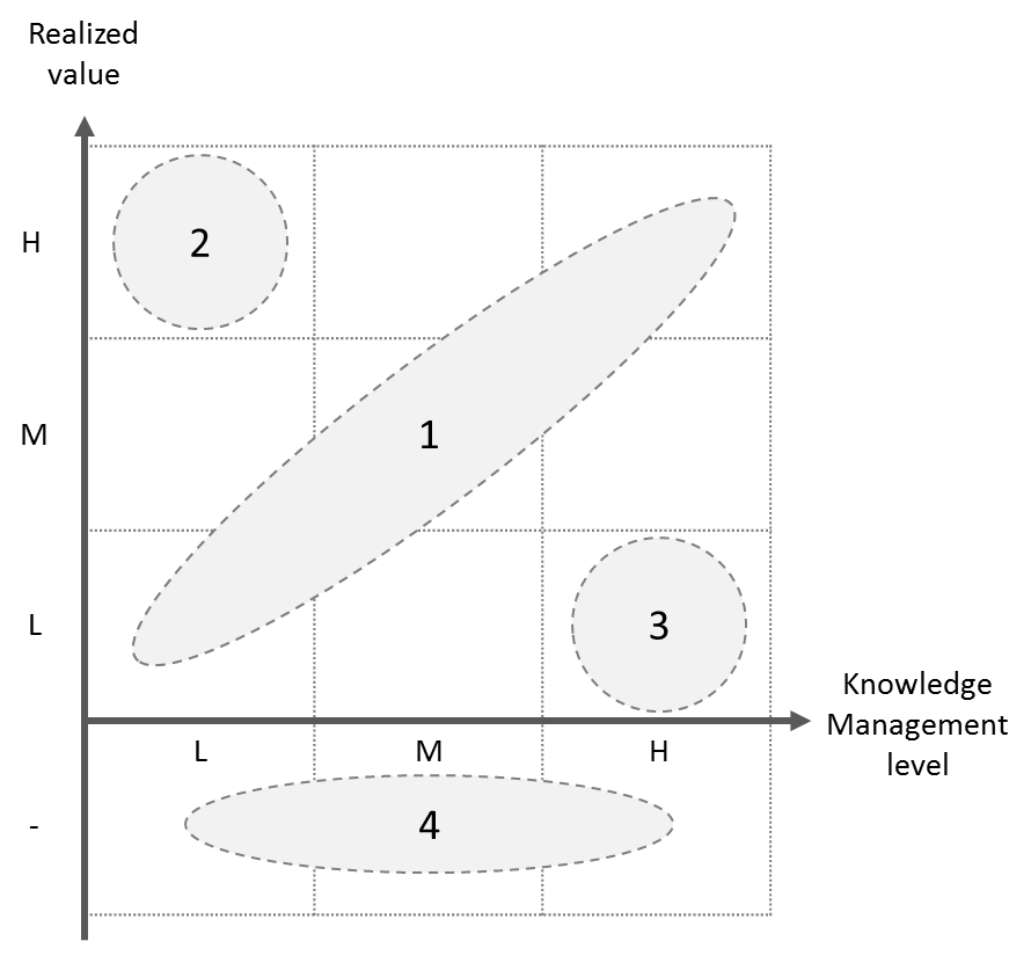

Figure 19 - Relation of Realized value and Knowledge Management level Source: own edition

Both the knowledge management level and the realized value might be on low (L), medium $(\mathrm{M})$ and high $(\mathrm{H})$ level; moreover, the realized value might be negative on short term (-). There can be four general cases distinguished:

- 1 - Balanced behavior

- 2 - Value driving

- 3 - Slack knowledge

- 4 - Underperforming

In case of balanced behavior ('1'), the relation of the value and the knowledge management level have a positive linear connection. The business entity with this characteristic shows 'healthy' behavior, it is the normal case of the knowledge-based value delivery. The entities in this group show the signs of a predictable behavior, the managed utilization of knowledge pairs up with realizing value. This type might strive for reaching case ' 2 ' or to be a visionary leader within its segment. In both cases, a necessity is to incorporate an innovation that can be maintained on the long term.

Having not sufficient control on the knowledge management can be the cause of unwanted knowledge transfer to external parties. This type might be also in prior state 
of revealing its innovation for the publicity, and if it is caught by external parties, it can be fatal for the given entity. The continuous monitoring of the competitors and the revealing of every kind of knowledge transfer to external parties should be a priority if the strategy of the entity demands it.

The intellectual capital management and the knowledge management should be in a coherent risk management framework. The risk assessment has to incorporate at least the philosophy of the introduced BPM and $\mathrm{KM}$ in order to implement the proper control mechanisms. Measuring and assessing the knowledge management might be a key on the long term, especially in the value-added organizations where the knowledge might be transferred with ease.

In case of value driving (' 2 ') the entities might have something very unique instrument or procedure behind the public revealed business processes. For example, this type might have trade secrets, patents, economies of scale, long term lock-in strategies, good reputation, brand, unique organization structure and so on, that are not incorporated as pure knowledge but those are more like private values, which are partly known or unknown for the publicity. The other factor is the problem of the, since the market value, the real value and the utilized value might significantly differ.

Since every entity would like to maximize the realized value with keeping down the level of any kind of resources, this situation is unique. This kind of units can typically operate as subsidiaries of a parent organization.

The knowledge management level can be low when the normal operations are based probably on withheld information that is not known for the environment and competitors. Securing this kind of information might be one of the top priority of these entities. This type can also heavily focus on informal relationships; in this case, it might be important to hide this from the publicity.

Having a type like this as an operative unit means that for achieving this state the knowledge was somewhere established, maybe it is not anymore with the organization (or within), but earlier it should had been there. Now that knowledge also might be 
built in the procedures or it is externally driven and it is not part of the internal processes.

The value driving can be a purely operative entity. These entities do not deal with establishing new knowledge elements, the possibility of recombination of the current knowledge and invention might be low. These types may want to keep their position, they lay the stress on maintaining the current asymmetric situation that might be mainly based on information.

Since these entities do not have high knowledge capacity on the operative location, it means that their services and products might be easily copied. One of the main points might be to secure the intellectual property, the other is to prevent for external parties to gain too deep understanding about the internal procedures. Based on the size of the entity, there is another concern: if this type of entities reaches the 'too big to fail' status, then the control might be lost on the details from internal point of view. This type of organizations might focus on preserving its status.

Slack knowledge (' 3 ') case has significant not realized value versus the expectation regarding the high level knowledge management. The organization itself might be overcomplicated or valuated unrealistic or not on proper term. It might also have a wrong knowledge structure that only allows a wrongly focused but high-level knowledge management. This can cause value leaks; its symptoms can be probably easily identified on the short term.

This model should not be common in the real economy, since it would not survive on the long term. It shows that the activities or the business of the affected entities is in a wrong scenario, in a planning phase, or this entity might be an element of a larger structure.

Underperforming ('4') cannot be maintained on long term. If the realized value is not positive, it means that the organization consumes its own resources gradually. The knowledge level and the related KM are not in the proper environment. Since this case might be mainly driven by the environment, the KM might have no real effect on the 
situation, unless it has prepared for a high-scale change and they are in the preliminary stage.

The research gave the background information for drawing the baselines for the generalization. If the KM follows the BPM basic standards, then the organizations' state can, at least, be approximated from the KM perspective, and the precautions can be done according to the situation. 


\section{CONCLUSION}

The research revealed significant factors: the aspects of the business process management, the knowledge management, and the renewing ability showed real, practical phenomena.

The business processes bear the value creation ability of the organizations and the possibility of growth. The goal-oriented, efficient, and effective proceedings of the processes are the conditions of creating the value. The knowledge is usually an invisible factor within the processes, but also an inherent one, without that the business processes cannot work.

In order to control the organizational knowledge properly there is a need for a framework in which the knowledge management's interactions can be measured, assessed, evaluated, and at last, with the help of this kind of feedback, the corrective actions can be conducted. On one hand, this might be the fine-tuning of the value creating processes; on the other hand, this framework allows a near-optimal business process - knowledge management alignment, and on the top of this, it can help with planning the future knowledge resource management.

The organizational objectives can be fulfilled if the persons have specific roles assigned. Assigning the responsibilities is a necessity in order to maintain the accountability for completing the expected tasks while using organizational resources. Without an understanding of the responsibilities, the organizations can face chaos.

The knowledge intensive organizations highly rely on knowledge which is either bought directly from the workforce market or which is built up within the organizations. The competence of the employees has to be evaluated considering the acquired knowledge.

What is valuable and what is not valuable can be set based on the BPs. The organizational objectives determine the value which is usually derived from the 
customer's demands. The outcome of this research helps to outline a framework in which the BP and the KM can be measured.

The realized business value might be not just positive but negative (from business perspective). If the knowledge awareness can be properly measured, that means that the organizational knowledge can be evaluated, and the knowledge management's applicability can be defined.

Once the applicability is defined, then the knowledge management's status can be approximated. With the proper utilization of the KM, the organization's knowledge level can also be determined. The knowledge management's level might be low (negative gap), when the requirements are not met, or high when the requirements can be met and there is additional extra resource within the system (positive gap). The balanced and acceptable level is between these two, but for determining this, it is required to have the knowledge awareness processes set.

Summarizing the main findings, it can be stated that the knowledge management has difficulties with being measured properly. The key outcome of this research is that the business cycles' density has a major influence on the established KM. The higher their density is, the more mature the measurement's maturity is.

The other identified findings have a correlating nature, the organizational processes are measured on higher level if the organizations have reliable knowledge on hand, and if the $\mathrm{KM}$ is on high level. If it is on low level, the organizations' internal processes are based on the BPM's main principles, and the KM's principles can be perceived in a few places, isolated.

The BPM's aspects prevails in both high and low level of KM. If the BPM's applied level is low, but if the organizations are still able to manage the business problems, then it means that there is an organic renewal ability within the organization that is self-regulating.

In the future, the related researches should focus on how one can determine the minimum level of the knowledge, the maximum, and average of a specific business unit. The minimum should be the level where the organization can still survive, the 
maximum level where the interactions of the employees are still manageable without imposing risks from their behavior, and the average should approximate the optimum both from the operational and financial point of view.

Further elements that might be covered are: the revealing of the unknown, but used knowledge, and the price of knowledge retention versus the price of reinventing the knowledge. 


\section{Publication List}

Journal

SZMODICS, P. 2017. High-skilled immigrant on the job markets, initiators of change. Journal of Knowledge Economy, 1-14. Print ISSN-1868-7865. Online ISSN-1868-7873. DOI-10-1007/s13132-017-0495-8.

SZMODICS, P. 2014. Evaluated knowledge representation. SEFBIS Journal, 9, 1, 28-35. HU-ISSN-1788-2265.

Conference proceedings

SZMODICS, P. 2015. Knowledge-based Process Management. In: CogInfoCom 2015, $6^{\text {th }}$ IEEE Conference on Cognitive Infocommunications, 19-21 October 2015 Győr. IEEE, 33-37. DOI-101109/CogInfoCom.2015.7390560.

SZMODICS, P. 2015. A tudásmenedzsment értékelése folyamatmenedzsment alapokon. In: BUZÁS, N. \& PRÓNAY, S. eds. Tudásteremtés és alkalmazás a modern társadalomban, 15-16 October 2015 Szeged. Szegedi Tudományegyetem Interdiszciplináris Központ, 288-298. ISBN-978-963306-412-2.

SZMODICS, P. 2015. Knowledge management and value creation. In: Challenges in economic and technological development, 15-16 October 2015 Lillafüred. University of Miskolc, 185-196. ISBN-978-963-358-1001.

Conference presentations

SZMODICS, P. The knowledge, the business process, and the business value. $12^{\text {th }}$ International Conference on Business Information Systems, 6-7 November 2015 Veszprém.

SZMODICS, P. How to use the knowledge-based process management to prevent organizational abuse. $15^{\text {th }}$ Annual Conference of European Society of Criminology, 2-5 September 2015 Porto. 


\section{Posters}

SZMODICS, P. Evaluated knowledge representation based on BPM aspects. $11^{\text {th }}$ International Conference on Business Information Systems, 7-8 November 2014 Budapest.

SZMODICS, P. Knowledge representation and risk identification. $14^{\text {th }}$ Annual Conference of European Society of Criminology, 10-13 September 2014 Prague. 


\section{Acronyms}

\begin{tabular}{|c|c|}
\hline ANSI & American National Standards Institute \\
\hline APO & Align, Plan and Organize (in COBIT) \\
\hline ASQ & American Society for Quality \\
\hline BAI & Build, Acquire and Implement (in COBIT) \\
\hline $\mathrm{BP}$ & Business Process \\
\hline BPDM & Business Process Definition Metamodel \\
\hline BPEL & Business Process Execution Language \\
\hline BPM & Business Process Management \\
\hline BPMN & Business Process Model and Notation \\
\hline BPQL & Business Process Query Language \\
\hline BPR & Business Process Reengineering \\
\hline BPRI & Business Process Runtime Interface \\
\hline $\mathrm{BSC}$ & Balanced Scorecard \\
\hline CIA & Confidentiality, Integrity, Availability \\
\hline $\mathrm{CM}$ & Change Management \\
\hline CMMI & Capability Maturity Model Integration \\
\hline COBIT & $\begin{array}{l}\text { Control Objective for Information and Related } \\
\text { Technology }\end{array}$ \\
\hline DIC & Direct Intellectual Capital method \\
\hline DIKW & Data-to-Information-to-Knowledge-to-Wisdom \\
\hline DSS & Deliver, Service and Support (in COBIT) \\
\hline EDM & Evaluate, Direct and Monitor (in COBIT) \\
\hline EPC & Event-drive Process Chain \\
\hline GG & Generic Goals (in CMMI) \\
\hline GP & General Practices (in CMMI) \\
\hline GPO-WM & $\begin{array}{l}\text { Geschäftsprozessorientierten } \\
\text { Wissensmanagement }\end{array}$ \\
\hline HRM & Human Resource Management \\
\hline IC & Intellectual Capital \\
\hline ICM & Intellectual Capital Management \\
\hline ICT & Information and Communication Technology \\
\hline IEC & International Electrotechnical Commission \\
\hline
\end{tabular}




\begin{tabular}{|l|l|}
\hline ISACA & $\begin{array}{l}\text { Information Systems Audit and Control } \\
\text { Association }\end{array}$ \\
\hline ISO & International Organization for Standardization \\
\hline ITIL & Information Technology Infrastructure Library \\
\hline ITSM & Information Technology Service Management \\
\hline KN & Knowledge Base \\
\hline KM & Knowledge Management \\
\hline KPI & Key Performance Indicator \\
\hline KSA & Knowledge, Skills, Abilities \\
\hline MCM & Market Capitalization Method \\
\hline MEA & Monitor, Evaluate and Assess (in COBIT) \\
\hline OECD & $\begin{array}{l}\text { Organisation for Economic Co-operation and } \\
\text { Development }\end{array}$ \\
\hline OGC & Office of Government Commerce \\
\hline OMG & Object Management Group \\
\hline OPM & $\begin{array}{l}\text { Organizational Performance Management (in } \\
\text { CMMI) }\end{array}$ \\
\hline OT & Organizational Training (in CMMI) \\
\hline PCMM & People Capability Maturity Model \\
\hline PRM & Process Reference Model \\
\hline QMS & Quality Management System \\
\hline ROA & Return on Assets \\
\hline ROK & Return on Knowledge \\
\hline ROCK & Return on Capitalized Knowledge \\
\hline SC & Scorecard Method \\
\hline SECI & $\begin{array}{l}\text { Socialization-Externalization-Combination- } \\
\text { Internalization }\end{array}$ \\
\hline SEI & $\begin{array}{l}\text { Software Engineering Institute, Carnegie } \\
\text { Mellon University }\end{array}$ \\
\hline SG & Specific Goals (in CMMI) \\
\hline SKMS & Service Knowledge Management System \\
\hline SLA & Service Level Agreement \\
\hline SME & Subject Matter Expert \\
\hline SMS & SPaice Management System \\
\hline TQM & Practices (in CMMI) \\
\hline
\end{tabular}




\begin{tabular}{|l|l|}
\hline TR & Technical Record \\
\hline UML & Unified Modeling Language \\
\hline UN & United Nations \\
\hline WMC & Workflow Management Coalition \\
\hline WSFL & Web Services Flow Language \\
\hline XLANG & Web Services for Business Process Design \\
\hline XML & Extensible Markup Language \\
\hline XPDL & XML Process Definition Language \\
\hline
\end{tabular}




\section{Glossary}

\begin{tabular}{|c|c|}
\hline Augment & $\begin{array}{l}\text { Increase the size or value of something by adding } \\
\text { something to it }\end{array}$ \\
\hline Cognitive & $\begin{array}{l}\text { Psychological processes involved in acquisition and } \\
\text { understanding of knowledge, formation of beliefs and } \\
\text { attitudes }\end{array}$ \\
\hline Competence & $\begin{array}{l}\text { Describes a person's capability to do something } \\
\text { adequately (general ability) }\end{array}$ \\
\hline Competency & $\begin{array}{l}\text { Describes a person's capability to do something } \\
\text { adequately (ability to perform a certain task) }\end{array}$ \\
\hline Constraint & $\begin{array}{l}\text { Anything that limits an organization achieving higher } \\
\text { performance }\end{array}$ \\
\hline Disambiguation & The act of making something clear \\
\hline Enabler & $\begin{array}{l}\text { Anything that allows an organization achieving higher } \\
\text { performance }\end{array}$ \\
\hline Epistemology & $\begin{array}{l}\text { The theory of knowledge, with regard to its methods, } \\
\text { validity, and scope }\end{array}$ \\
\hline Evidence & $\begin{array}{l}\text { The available body of facts or information indicating } \\
\text { whether a belief or proposition is true or valid }\end{array}$ \\
\hline Rediscovery & $\begin{array}{l}\text { To discover again or independently of someone who } \\
\text { has made a prior discovery }\end{array}$ \\
\hline Reinvention & $\begin{array}{l}\text { To invent again or anew, especially without knowing } \\
\text { that the invention already exists }\end{array}$ \\
\hline Ontology & $\begin{array}{l}\text { The branch of metaphysics dealing with the nature of } \\
\text { being }\end{array}$ \\
\hline Semantics & $\begin{array}{l}\text { It is the subfield that is devoted to the study of } \\
\text { meaning, as inherent at the levels of words, phrases, } \\
\text { etc. }\end{array}$ \\
\hline Slack resource & $\begin{array}{l}\text { In the business and management the level of available } \\
\text { resources }\end{array}$ \\
\hline Syntax & $\begin{array}{l}\text { The arrangement of words and phrases to create well- } \\
\text { formed sentences in a language, The structure of } \\
\text { statements in a computer language }\end{array}$ \\
\hline
\end{tabular}




\section{List of References}

ACKOFF, R. L. 1989. From data to wisdom. Journal of Applied System Analysis, 16, 3-9.

ALVESSON, M. 2001. Knowledge Work: Ambiguity, Image and Identity. Human Relations, 54, 7, 863-886.

ANONYMOUS 2015. BPMN 2.0 - Business Process Model and Notation.

ANONYMOUS. 2016a. Key performance indicators for Knowledge Management.

Available: http://saas.y-

im.de/smHelp/Content/BestPracticesGuide_PD/KnowledgeManagementBestPrac tice/Key_performance_indicators_for_Knowledge_Management.htm [Accessed 1-August-2016].

ANONYMOUS. 2016b. Knowledge Management User Roles. Available: http://saas.yim.de/smHelp/Content/BestPracticesGuide_PD/KnowledgeManagementBestPrac tice/Knowledge_Management_User_roles.htm [Accessed 1-August-2016].

ARGYRIS, C. 1991. Teaching smart people how to learn. Harvard Business Review, May-June, 99-109.

ASQ/ANSI/ISO 2015.9001 Quality management systems - Requirements, Geneva, International Organization for Standardization.

BABBIE, E. R. 2003. The practice of social research, Budapest, Ballasi Kiadó.

BARANYI, P. \& CSAPO, A. 2012. Definition and Synergies of Cognitive Infocommunications. Acta Polytechnica Hungarica, 9, 67-83.

BARANYI, P., CSAPO, A. \& VARLAKI, P. 2014. An overview of research trends in CogInfoCom, Tihany, Hungary, Institute of Electrical and Electronics Engineers Inc.

BARLOW, A. C. 2012. Interviews. In: A.J., M., G., D. \& E., W. (eds.) Encyclopedia of Case Study Research. Thousand Oaks: SAGE Publications.

BECK, U. 1992. Risk Society, London, Sage.

BENBASAT, I., GOLDSTEIN, D. K. \& MEAD, M. 1987. The Case Research Strategy in Studies of Information Research. MIS Quarterly, 11, 3, 369-386. 
BENCSIK, A. 2015. A tudásmenedzsment elméletben és gyakorlatban, Budapest, Akadémiai Kiadó Zrt.

BERNSTEIN, D. E. 2001. The Past, Present, and Future of the General Acceptance Test. Law and Economics Research Paper Series, 1-7.

BOCK, C. 2008. Introduction to the Business Process Definition Metamodel. Object Management Group.

BRADBURN, N. M., SUDMAN, S. \& WANSINK, B. 2004. Asking questions : the definitive guide to questionnaire design-- for market research, political polls, and social and health questionnaires, San Francisco, John Wiley \& Sons, Jossey-Bass.

CALISKAN-ISLAM, A., HARANG, R., LIU, A., NARAYANAN, A., VOSS, C., YAMAGUCHI, F. \& GREENSTADT, R. De-anonymizing Programmers via Code Stylometry. 24th USENIX Security Symposium, 2015 Washington, D.C.: USENIX, 255-270.

CALISKAN-ISLAM, A., YAMAGUCHI, F., DAUBER, E., RIECK, K., HARANG, R., GREENSTADT, R. \& NARAYANAN, A. 2016. When Coding Style Survives Compilation: De-anonymizing Programmers from Executable Binaries. Computer Science - Cryptography and Security [Online]. Available: https://arxiv.org/abs/1512.08546.

CERULlO, V. \& CERULLO, M. J. 2004. Business Continuity Planning: A Comprehensive Approach. Information Systems Management, 21, 3, 70-78.

CHASTEAUNEUF, C. 2010. Questionnaires. In: A.J., M., G., D. \& E., W. (eds.) Encyclopedia of Case Study Research. Thousand Oaks: SAGE Publications.

CLEVELAND, H. 1982. Information as a resource. The Futurist, 16, 6, 34-39.

COHEN, D. 2006. What's Your Return on Knowledge? Harvard Business Review, 84, 12.

COWAN, N. 2001. The magical number 4 in short-term memory: a reconsideration of mental storage capacity. The Behavioral and Brain Sciences, 24, 1, 87-114.

CURTIS, W., HEFLEY, W. \& MILLER, S. 2009. People Capability Maturity Model (P-CMM). Pittsburgh: Carnegie Mellon University - Software Engineering Institute.

CSEPREGI, L. 2010. BPM and workflow. Budapest: Corvinus University of Budapest. 
DAVENPORT, T. 1993. Process Innovation: Reengineering work through information technology, Boston, Harvard Business School Press.

DAVENPORT, T. H., PARISE, S. \& CROSS, R. 2006. Strategies for Preventing a Knowledge-Loss Crisis. MIT Sloan Management Review, 47, 4, 30-38.

DAVENPORT, T. H. \& PRUSAK, L. 1998. Working Knowledge: How Organizations Manage What They Know, Boston, Mass, Harvard Business School Press.

DEAR, M. J. \& MOOS, A. I. 1986. Structuration theory in urban analysis: 2. Empirical application. Environment and Planning A, 18, 357-373.

DELAK, B. 2015. How to Evaluate Knowledge and Knowledge Management in the Organization Using COBIT 5. ISACA Journal, 2015, 3, 19-23.

DRUCKER, P. 1969. The age of discontinuity: guidelines to our changing society, New York, Harper \& Row.

ERIKSSON, P. \& KOVALAINEN, A. 2012. Case Study Research in Business and Management. In: A.J., M., G., D. \& E., W. (eds.) Encyclopedia of Case Study Research. Thousand Oaks: SAGE Publications.

EUROPEAN-COMMISSION 2003. Commission Recommendation 2003/361/EC. European Commission: Official Journal of the European Union, 124, 36.

FENSEL, D., HORROCKS, I., VAN HARMELEN, F., MCGUINNESS, D. \& PATEL-SCHNEIDER, P. F. 2014. OIL: Ontology Infrastructure to Enable the Semantic Web. Leipzig: Universität Leipzig.

FESTINGER, L. 1957. A Theory of Cognitive Dissonance, Stanford, Stanford University Press.

GÁBOR, A., KÖ, A., SZABÓ, I., TERNAI, K. \& K., V. 2013. Compliance check in semantic business process management. Lecture Notes In Computer Science, $8186,353-362$.

GALLIERS, R. D. 1998. Reflection on BPR, IT and Organisational Change. Information Technology and Organisational Transformation: Innovation for the 21 st Century Organisation. Chichester: Wiley.

GALUNIC, D. C. \& RODAN, S. 1998. Resource Recombinations in the Firm: Knowledge Structures and the Potential for Schumpeterian Innovation. Strategic Management Journal, 19, 12, 1193-1201. 
GIARRATANO, J. C. \& RILEY, G. D. 1998. Expert Systems: Principles and Programming, Boston, Massachusetts, PWS Publishing.

GIDDENS, A. 1990. The Consequences of Modernity, Stanford, California, Stanford University Press.

GIDDENS, A. 1991. Modernity and Self-Identitiy: Self and Society in the Late Modern Age, Stanford, California, Stanford University Press.

GILLANI, S. A. \& KÖ, A. 2014. Process-Based Knowledge Extraction in a Public Authority: A Text Mining Approach. Lecture Notes In Computer Science, 8650, 91-103.

GRANT, R. M. 1991. The Resource-based Theory of Competitive Advantage:

Implications for Strategy Formulation. California Management Review, 33, 3, 114-135.

GRANT, R. M. 1996a. Prospering in Dynamically-Competitive Environments:

Organizational Capability as Knowledge Integration. Organization Science, 7, 4 (Jul. - Aug.), 375-387.

GRANT, R. M. 1996b. Toward a Knowledge Based Theory of the Firm. Strategic Management Journal, 17, Winter Special Issue, 109-122.

GRANT, R. M. 2010. Contemporary Strategy Analysis, Chichester, John Wiley \& Sons Ltd.

GREINER, L. 1972. Evolution and revolution as organizations grow. Harvard Business Review, 1972, July-August, 165-174.

GRUBER, T. R. 2014. What is an Ontology? Stanford: Stanford University.

HAMMER, M. \& CHAMPY, J. 1993. Reengineering the Corporation: A Manifesto for Business Revolution, New York, Harper Collins Publishers.

HARVEY, M. 2005. Essential business process modeling, Sebastopol, O’Reilly Media.

HILL, J. 2010. Do You Understand the Difference Between Workflow and BPM? Available: http://blogs.gartner.com/janelle-hill/2010/04/22/do-you-understandthe-difference-between-workflow-and-bpm/ [Accessed 18-August-2016].

HISLOP, D. 2013. Knowledge Management in Organizations - A Critical Introduction, Oxford, Oxford University Press. 
HOFSTEDE, G. 2005. Cultures and organizations: software of the mind, New York, McGraw-Hill.

HOLLINGSWORTH, D. 1995. The Workflow Reference Model. Workflow Managment Coalition.

HURWITZ, J., KAUFMAN, M. \& BOWLES, A. 2015. Cognitive Computing and Big Data Analytics, John Wiley \& Sons.

ISACA 2012. COBIT5 - A Business Framework for the Governance and Management of Enterprise IT, Rolling Meadows, ISACA.

ISO. 2013. 90006 Information technology - Guidelines for the application of ISO 9001:2008 to IT service management and its integration with ISO/IEC 200001:2011. Available: https://www.iso.org/obp/ui/\#iso:std:iso-iec:tr:90006:ed1:v1:en [Accessed 18-August-2016].

ISO 2015. 9000 Quality management systems - Fundamentals and vocabulary, Geneva, International Organization for Standardization.

ISO/IEC 2010. TR 20000-4 Information technology - Service management - Part 4: Process reference model, Geneva, International Organization for Standardization, International Electrotechnical Commission.

ISO/IEC 2013. 27001 Information technology - Security techniques - Information security management systems - Requirements, Geneva, International Organization for Standardization, International Electrotechnical Commission.

ISO/IEC 2016a. 27000 Information technology - Security techniques - Information security management systems - Overview and vocabulary, Geneva, International Organization for Standardization, International Electrotechnical Commission.

ISO/IEC 2016b. ISO/IEC 27K, Geneva, International Organization for Standardization, International Electrotechnical Commission.

JICK, T. D. 1979. Mixing Qualitative and Quantitative Methods: Triangulation in Action. Administrative Science Quarterly, 24, 4, 602-611.

KÄRREMAN, D. \& ALVESSON, M. 2004. Cages in Tandem: Management Control, Social Identity, and Identification in a Knowledge-Intensive Firm. Organization, $11,1,149-175$.

KLIMKÓ, G. 2001. Organizational knowledge extraction from business process models. Corvinus University of Budapest. 
KO, R. K. L., LEE, S. S. G. \& LEE, E. W. 2009. Business process management (BPM) standards: a survey. Business Process Management Journal, 15, 5, 744791.

KOVÁCS, E. 2011. Pénzügyi adatok statisztikai elemzése, Budapest, Tanszék Kft.

KUBIAK, T. M. \& BENBOW, D. W. 2009. The Certified Six Sigma Black Belt Handbook, Milwaukee, ASQ Quality Press.

KUNAS, M. 2012. Implementing von Service-Qualität basierend auf ISO/IEC 20000. IT Governance Ltd.

LAWRENCE, P. 1997. Workflow Handbook, The United Kingdom, John Wiley \& Sons Ltd.

LEE, S. H. 1999. Taxonomy of HRM policies of knowledge-based firms: A resourcebased explanation. International Journal of Innovation Management, 3, 4, 379395.

LEVITT, B. \& J.G., M. 1998. Organizational Learning. Annual Review of Sociology, 319-340.

LEYMANN, F. 2001. The web services flow language (WSFL 1.0). Available: http://www-4.ibm.com/software/solutions/webservices/pdf/WSFL.pdf [Accessed 18-August-2016].

LOCKETT, A. \& THOMPSON, S. 2004. Edith Penrose's contributions to the resource-based view: an alternative perspective. Journal of Management Studies, 41, 193-203.

MANZ, C. C. \& SIMS, H. P. 1991. SuperLeadership: Beyond the myth of heroic leadership. Organizational Dynamics, 19, 4, 18-35.

MARCH, J. G. 1991. Exploration and Exploitation in Organizational Learning. Organization Science, 2, 71-78.

MERTINS, K., HEISIG, P. \& VORBECK, J. 2003. Knowledge Management, Berling, Springer.

MINER, A. S. 1990. Structural Evolution through Idiosyncratic Jobs: The Potential for Unplanned Learning. Organization Science, 1, 2, 195-210.

MINER, A. S. 1991. Organizational Evolution and the Social Ecology of Jobs. American Sociological Review, 56, 6, 772-785. 
MOHR, L. 1982. Explaining Organizational Behavior: The Limits and Possibilities of Theory and Research, San Francisco, Jossey-Bass.

MUNRO, R. A., RAMU, G. \& ZRYMIAK, D. J. 2015. The Certified Six Sigma Green Belt Handbook, Milwaukee, ASQ Quality Press.

NEUSCH, G. \& GÁBOR, A. ProKEX - Integrated Platform for process-based knowledge extraction. 7th International Conference of Education, Research and Innovation, 2014 Seville, Spain. IATED, 3972-3977.

NONAKA, I. 1994. A Dynamic Theory of Organizational Knowledge Creation. Organization Science, 5, 1, 18-20.

NURMI, R. 1998. Knowledge-intensive firms. Business Horizons, 41, 3, $26-32$.

OECD 2000. Knowledge management in the learning economy, Paris, OECD.

OGC, O. O. G. C. 2007. ITIL ${ }^{\circledR}$ The Official Introduction to the ITIL Service Lifecycle, London, The Stationary Office, Office of Government Commerce.

OGC, O. O. G. C. 2011. ITIL ${ }^{\circledR}$ Service Transition, London, The Stationary Office, Office of Government Commerce.

OMG 2011. Business Process Model and Notation (BPMN). Needham: Object Management Group.

OMG 2015. Unified Modeling Language ${ }^{\mathrm{TM}}$ (OMG UML). Needham: Object Management Group.

OSBORNE, M. J. 2004. An introduction to Game Theory, New York, Oxford University Press.

PAQUETTE, G. 2010. Visual Ontology Modeling and the Semantic Web. In: PAQUETTE, G. (ed.) Visual Knowleldge Modeling for Semantic Web Technologies. Canada LICEF Research Center: IGI Global.

PATTON, M. Q. 1999. Enhancing the quality and credibility of qualitative analysis. HSR: Health Services Research, 34, 5, 1189-1208.

POLANYI, M. 1966. The Tacit Dimension, New York, Doubleday \& Company Inc.

POR, G. Designing Knowledge Ecosystems for Communities of Practice. Advancing Organizational Capability Via Knowledge Management, 1997 Los Angeles. Community Intelligence Labs. 
PORTER, M. E. 1985. Competitive Advantage: Creating and Sustaining Superior Performance, New York, Simon and Schuster.

PYZDEK, T. 2003. The Six Sigma Handbook, New York, McGraw-Hill.

QUINN, J. B. 1992. Intelligent Enterprise, New York, Free Press.

RUMMLER, G. A. \& BRACHE, A. P. 1995. Improving Performance: How to manage the white space on the organizational chart, San Francisco, Jossey-Bass.

RYLANDER, A. \& PEPPARD, J. 2005. What Really is a Knowledge-Intensive Firm? - (Re)Framing Research in the "Knowledge Economy". Organization, 2005, 10.

SAMUELSON, P. A. \& NORDHAUS, W. D. 2010. Economics, Irwin, McGraw-Hill.

SCHEER, A. W. 1992. Architecture of Integrated Information Systems - Foundations of Enterprise-Modelling, Heidelberg, Springer.

SCHEER, A. W. 1998. ARIS - business process modeling, Saarbrücken, Saarland University.

SCHIKUTA, E. 2008. Neural network and database systems. Available: https://arxiv.org/pdf/0802.3582.

SCHULZ, M. 1998. Limits to Bureaucratic Growth: The Density Dependence of Organizational Rule Births. Administrative Science Quarterly, 43, 4, 845-876.

SCHWARTZ, S. H. \& BOEHNKE, K. 2004. Evaluating the structure of human values with confirmatory factor analysis. Journal of Research in Personality, 38, 230255.

SCOTT, B. R. 1971. Stages of corporate development. Boston: Harvard Business School.

SEI, S. E. I. 2010a. CMMI for Acquisition, Version 1.3. Pittsburgh: Carnegie Mellon University - Software Engineering Institute.

SEI, S. E. I. 2010b. CMMI for Development, Version 1.3. Pittsburgh: Carnegie Mellon University - Software Engineering Institute.

SEI, S. E. I. 2010c. CMMI for Services, Version 1.3. Pittsburgh: Carnegie Mellon University - Software Engineering Institute.

SENGE, P. M. 1990. The Leader's New Work: Building Learning Organizations. MIT Sloan Management Review, 32, 1 (Fall), 7-23. 
SENGE, P. M. 2004. The Fifth Discipline: The art and practice of the learning organization, New York, New York, Doubleday.

SHANNON, C. E. 1948. A Mathematical Theory of Communication. The Bell System Technical Journal, 27, 3, 392-403.

SIMON, H. A. 1996. The Sciences of the Artificial, Cambridge, MA, The MIT Press.

SINGH, J. V. 1986. Performance, slack and risk taking in organizational decision making. Academy of Management Journal, 29, 3, 562-585.

SKYRME, D. 2011. Organizing for Knowledge Management. Available: http://www.skyrme.com/kmroadmap/roles.htm\#skills [Accessed 1-August2016].

SMITH, A. \& ZEITHAML, C. 1996. Baby Bells, Garbage Cans, and Hypercompetition. Organization Science, 7, 4, 388-399.

SMITS, M. \& DE MOOR, A. 2004. Effective Knowledge Management in KnowledgeIntensive Organizations. Available:

www2.warwick.ac.uk/fac/soc/wbs/conf/olkc/archive/h-3_smits.pdf [Accessed 1July-2015].

SOWA, J. F. 2014. Preface to Knowledge Representation. Available: www2.warwick.ac.uk/fac/soc/wbs/conf/olkc/archive/h-3_smits.pdf [Accessed 18-August-2016].

STARBUCK, W. H. 1992. Learning by knowledge-intensive firms. Journal of Management Studies, 29, 6, 713-740.

STIGLITZ, J. E. 2004. Information and the Change in the Paradigm in Economics. The American Economist, 47, 2-3.

SVEIBY, K. E. 2010. Method for Measuring Intangible Assets. Available: http://www.sveiby.com/articles/IntangibleMethods.htm [Accessed 27-August2015].

SZABÓ, Z. 2000. A szervezeti információfeldolgozás strukturális és technológiai tényezőinek összerendelése. Corvinus University of Budapest.

TERNAI, K. \& TÖRÖK, M. Semantic modeling for automated workflow software generation - An open model. 5th International Conference on Software, Knowledge Information, Industrial Management and Applications, 2011 Benevento, Italy. 
THATTE, S. 2001. XLANG-Web services for business process design. Available: http://www.gotdotnet.com/team/xml_wsspecs/xlang-c/default.htm [Accessed 1July-2015].

TÖRÖK, M. 2014. Organizational knowledge extraction from business process models. Corvinus University of Budapest.

UNITED-NATIONS. 2008. International Standard Industrial Classification of All Economic Activities, ISIC Rev. 4. Available: http://unstats.un.org/unsd/cr/registry/regcst.asp?Cl=27 [Accessed 20-Jan-2016].

VAN DE VEN, A. H. 1992. Suggestions for studying strategy process: A research note. Strategic Management Journal, 13, Special Issue: Strategy Process: Managing Corporate, 169-188.

VARGA, K. 2014. A szemantikus folyamatmenedzsment hasznositási lehetösége az üzleti folyamatok tudásalapú fejlesztésében. Corvinus University of Budapest.

VARIAN, H. R. 2001. Intermediate Microeconomics, Budapest, KJK-KERSZÖV.

VARIAN, H. R., FARRELL, J. \& SHAPIRO, C. 2011. The Economics of Information Technology, Cambridge, Cambridge University Press.

VOSS, J. F. \& POST, T. A. 1988. On the solving of ill-structured problems. In: CHI, M. T. H., GLASER, R. \& FARR, M. J. (eds.) The nature of expertise. Hillsdale, NJ: Lawrence Erlbaum Associates.

WALSH, J. P. \& UNGSON, G. R. 1991. Organizational Memory. Academy of Management Review, 16, 57-91.

WEBB, E. J., CAMPBELL, D. T., SCHWARTZ, R. D. \& SECHREST, L. 1966. Unobtrusive Measures. Nonreactive Research, Chicago, Rand McNally.

WEICK, K. E. 1991. The Nontraditional Quality of Organizational Learning. Organization Science, 2, 1, 116-124.

WELCH, C. H. 2006. Flexible standards, deferential review: Daubert's legacy of confusion. Harvard Journal of Law \& Public Policy, 29, 3, 1085.

WIIG, K. 1993. Knowledge management foundations, Arlington, Texas, Schema Press.

WIIG, K. 1997. Integrating intellectual capital and knowledge management. Long Range Planning, 30, 3, 399-405. 
WMC. 2015. Workflow Management Coalition Terminology \& Glossary. Available: https://samenvattingen.interactief.utwente.nl/images/e/e2/BPS_samenvatting2.pdf [Accessed 18-August2016].

WOOLCOCK, M. 2001. The Place of Social Capital in Understanding Social and Economic Outcomes. Canadian Journal of Policy Research, 2, 1, 11-17.

YIN, R. K. 1994a. Case Study Research: Design and Methods - Second Edition, Thousand Oaks, SAGE Publications.

YIN, R. K. 1994b. Discovering the future of the case study method in evaluation research. American Journal of Evaluation, 15, 3, 283-290.

YOUN, H., BETTENCOURT, L. M. A., STRUMSKY, D. \& LOBO, J. 2014. Invention as a Combinatorial Process: Evidence from U.S. Patents. [Accessed 18-August-2016].

Z. KARVALICS, L. Kiindulópontok a DIK-modell dekonstruálásához, avagy a tudásmenedzsment egyik ,szent tehenének” végnapjai. In: BUZÁS, N. \& PRÓNAY, S., eds. Tudásteremtés és -alkalmazás a modern társadalomban, 15-16 October 2015 Szeged. Szegedi Tudományegyetem Interdiszciplináris Tudásmenedzsment Kutatóközpont, 240-253. 


\section{Appendix}

1 Extract from the ASQ/ANSI/ISO 9001:2015

(ASQ/ANSI/ISO, 2015)

\begin{tabular}{|l|l|}
\hline \multicolumn{2}{|c|}{ ASQ/ANSI/ISO 9001:2015 } \\
\hline \multicolumn{2}{|c|}{ 7 Support } \\
\hline 7.1 & Resources \\
\hline 7.1 .1 & General \\
\hline 7.1 .2 & People \\
\hline 7.1 .3 & Infrastructure \\
\hline 7.1 .4 & $\begin{array}{l}\text { Environment for the operation of } \\
\text { processes }\end{array}$ \\
\hline 7.1 .5 & Monitoring and measuring resources \\
\hline 7.1 .5 .1 & General \\
\hline 7.1 .5 .2 & Measurement traceability \\
\hline 7.1 .6 & Organizational knowledge \\
\hline 7.2 & Competence \\
\hline 7.3 & Awareness \\
\hline 7.4 & Communication \\
\hline 7.5 & Documented information \\
\hline 7.5 .1 & General \\
\hline 7.5 .2 & Creating and updating \\
\hline 7.5 .3 & Control of documented information \\
\hline & \\
\hline &
\end{tabular}


2 Extract from ISO/IEC 20000

(ISO/IEC, 2010)

\begin{tabular}{|l|l|}
\hline \multicolumn{2}{|c|}{ Parts of ISO/IEC 20000 } \\
\hline ISO/IEC 20000-1:2011 & $\begin{array}{l}\text { Service Management System } \\
\text { Requirements }\end{array}$ \\
\hline ISO/IEC 20000-2:2012 & $\begin{array}{l}\text { Guidance on the application of service } \\
\text { management systems (SMS) }\end{array}$ \\
\hline ISO/IEC 20000-3:2013 & $\begin{array}{l}\text { Guidance on scope definition and } \\
\text { applicability of ISO/IEC 20000-1 }\end{array}$ \\
\hline ISO/IEC TR 20000-4:2010 & Process reference model \\
\hline ISO/IEC TR 20000-5:2013 & $\begin{array}{l}\text { Exemplar implementation plan for } \\
\text { ISO/IEC 20000-1 }\end{array}$ \\
\hline ISO/IEC TR 20000-9:2015 & $\begin{array}{l}\text { Guidance on the application of ISO/IEC } \\
\text { 20000-1 to cloud services }\end{array}$ \\
\hline ISO/IEC TR 20000-10:2015 & Concepts and terminology \\
\hline ISO/IEC TR 20000-11:2015 & $\begin{array}{l}\text { Guidance on the relationship between } \\
\text { ISO/IEC 20000-1:2011 and service } \\
\text { management frameworks: ITIL® }\end{array}$ \\
\hline
\end{tabular}




\section{Extract from ISO/IEC 27K}

(ISO/IEC, 2016b)

\section{Parts of ISO/IEC 27K}

\begin{tabular}{|c|c|}
\hline $\begin{array}{l}\text { ISO/IEC } \\
27000: 2016\end{array}$ & $\begin{array}{l}\text { Information technology -- Security techniques -- Information } \\
\text { security management systems -- Overview and vocabulary }\end{array}$ \\
\hline $\begin{array}{l}\text { ISO/IEC } \\
27001: 2013\end{array}$ & $\begin{array}{l}\text { Information technology -- Security techniques -- Information } \\
\text { security management systems -- Requirements }\end{array}$ \\
\hline $\begin{array}{l}\text { ISO/IEC } \\
27002: 2013\end{array}$ & $\begin{array}{l}\text { Information technology -- Security techniques -- Code of } \\
\text { practice for information security controls }\end{array}$ \\
\hline $\begin{array}{l}\text { ISO/IEC } \\
27003: 2010\end{array}$ & $\begin{array}{l}\text { Information technology -- Security techniques -- Information } \\
\text { security management system implementation guidance }\end{array}$ \\
\hline $\begin{array}{l}\text { ISO/IEC } \\
27004: 2016\end{array}$ & $\begin{array}{l}\text { Information technology -- Security techniques -- Information } \\
\text { security management -- Measurement }\end{array}$ \\
\hline $\begin{array}{l}\text { ISO/IEC } \\
27005: 2011\end{array}$ & $\begin{array}{l}\text { Information technology -- Security techniques -- Information } \\
\text { security risk management }\end{array}$ \\
\hline $\begin{array}{l}\text { ISO/IEC } \\
\text { 27006:2015 }\end{array}$ & $\begin{array}{l}\text { Information technology -- Security techniques -- } \\
\text { Requirements for bodies providing audit and certification of } \\
\text { information security management systems }\end{array}$ \\
\hline $\begin{array}{l}\text { ISO/IEC } \\
27007: 2011\end{array}$ & $\begin{array}{l}\text { Information technology -- Security techniques -- Guidelines } \\
\text { for information security management systems auditing }\end{array}$ \\
\hline $\begin{array}{l}\text { ISO/IEC TR } \\
27008: 2011\end{array}$ & $\begin{array}{l}\text { Information technology -- Security techniques -- Guidelines } \\
\text { for auditors on information security controls }\end{array}$ \\
\hline $\begin{array}{l}\text { ISO/IEC } \\
\text { 27009:2016 }\end{array}$ & $\begin{array}{l}\text { Information technology -- Security techniques -- Information } \\
\text { security management for inter-sector and inter-organizational } \\
\text { communications }\end{array}$ \\
\hline $\begin{array}{l}\text { ISO/IEC } \\
\text { 27010:2015 }\end{array}$ & $\begin{array}{l}\text { Information technology -- Security techniques -- Information } \\
\text { security management guidelines for telecommunications } \\
\text { organizations based on ISO/IEC } 27002\end{array}$ \\
\hline$\ldots$ & $\ldots$ \\
\hline
\end{tabular}




\section{Extract from the CMMI Processes and Practices}

The Capability Maturity Model Integration for Services contains 24 'Process Areas' (PA) and 2 'Generic Goals' (GG). The PAs have 'Specific Goals' (SG) and 'Specific Practices' (SP), the GGs have 'Generic Practices' (GP). The maturity levels have defined requirements, in addition the previous levels' requirements have to be met, too. (SEI, 2010c)

\section{Maturity Level 2 - Managed}

$\mathrm{CM}$ - Configuration Management

MA - Measurement and Analysis

PPQA - Process and Product Quality Assurance

REQM - Requirements Management

SAM - Supplier Agreement Management

SD - Service Delivery

WMC - Work Monitoring and Control

WP - Work Planning

\section{Maturity Level 3 - Defined}

CAM - Capacity and Availability Management

DAR - Decision Analysis and Resolution

IRP - Incident Resolution and Prevention

IWM - Integrated Work Management

OPD - Organizational Process Definition

OPF - Organizational Process Focus

OT - Organizational Training

The purpose of Organizational Training (OT) is to develop skills and knowledge of people so they perform their roles effectively and efficiently.

$S G 1$ A training capability, which supports the roles in the organization, is established and maintained.

- SP 1.1 Establish and maintain strategic training needs of the organization.

- SP 1.2 Determine which training needs are the responsibility of the organization and which are left to the individual work group or support group.

- SP 1.3 Establish and maintain an organizational training tactical plan.

- SP 1.4 Establish and maintain a training capability to address organizational training needs.

$S G 2$ Training for individuals to perform their roles effectively is provided.

- SP 2.1 Deliver training following the organizational training tactical plan.

- SP 2.2 Establish and maintain records of organizational training.

- $\quad$ SP 2.3 Assess the effectiveness of the organization's training program. 
RSKM - Risk Management

SCON - Service Continuity

SSD - Service System Development

SST - Service System Transition

STSM - Strategic Service Management

Maturity Level 4 - Quantitatively Managed

OPP - Organizational Process Performance

QPM - Quantitative Project Management

\section{Maturity Level 5 - Optimizing}

CAR - Causal Analysis and Resolution

\section{OPM - Organizational Performance Management}

The purpose of Organizational Performance Management (OPM) is to proactively manage the organization's performance to meet its business objectives.

SG 1 The organization's business performance is managed using statistical and other quantitative techniques to understand process performance shortfalls, and to identify areas for process improvement.

- SP 1.1 Maintain business objectives based on an understanding of business strategies and actual performance results.

- SP 1.2 Analyze process-performance data to determine the organization's ability to meet identified business objectives.

- SP 1.3 Identify potential areas for improvement that could contribute to meeting business objectives.

SG 2 Improvements are proactively identified, evaluated using statistical and other quantitative techniques, and selected for deployment based on their contribution to meeting quality and process-performance objectives.

- SP 2.1 Elicit and categorize suggested improvements.

- SP 2.2 Analyze suggested improvements for their possible impact on achieving the organization's quality and process-performance objectives.

- $\quad$ SP 2.3 Validate selected improvements.

- SP 2.4 Select and implement improvements for deployment throughout the organization based on an evaluation of costs, benefits and other factors.

SG 3 Measurable improvements to the organization's processes and technologies are deployed and evaluated using statistical and other quantitative techniques.

- SP 3.1 Establish and maintain plans for deploying selected improvements.

- SP 3.2 Manage the deployment of selected improvements.

- $\quad$ SP 3.3 Evaluate the effects of deployed improvements on quality and process performance using statistical and other quantitative techniques. 


\section{Generic Goals}

\section{GG 1 Achieve Specific Goals}

The specific goals of the process area are supported by the process of transforming identifiable input work products into identifiable output work products.

GP 1.1 Perform the specific practices of the process area to develop work products and provide services to achieve the specific goals of the process area.

\section{GG 2 Institutionalize a Managed Process}

The process is institutionalized as a managed process.

GP 2.1 Establish and maintain an organizational policy for planning and performing the process.

GP 2.2 Establish and maintain the plan for performing the process.

GP 2.3 Provide adequate resources for performing the process, developing the work products, and providing the services of the process.

GP 2.4 Assign responsibility and authority for performing the process, developing the work products, and providing the services of the process.

GP 2.5 Train the people performing or supporting the process as needed.

GP 2.6 Place selected work products of the process under appropriate levels of control.

GP 2.7 Identify and involve the relevant stakeholders of the process as planned.

GP 2.8 Monitor and control the process against the plan for performing the process and take appropriate corrective action.

GP 2.9 Objectively evaluate adherence of the process and selected work products against the process description, standards, and procedures, and address noncompliance.

GP 2.10 Review the activities, status, and results of the process with higher level management and resolve issues.

\section{GG 3 Institutionalize a Defined Process}

The process is institutionalized as a defined process.

GP 3.1 Establish and maintain the description of a defined process.

GP 3.2 Collect process-related experiences derived from planning and performing the process to support the future use and improvement of the organization's processes and process assets. 


\section{The relationship between ICM and KM}

(Wiig, 1997)

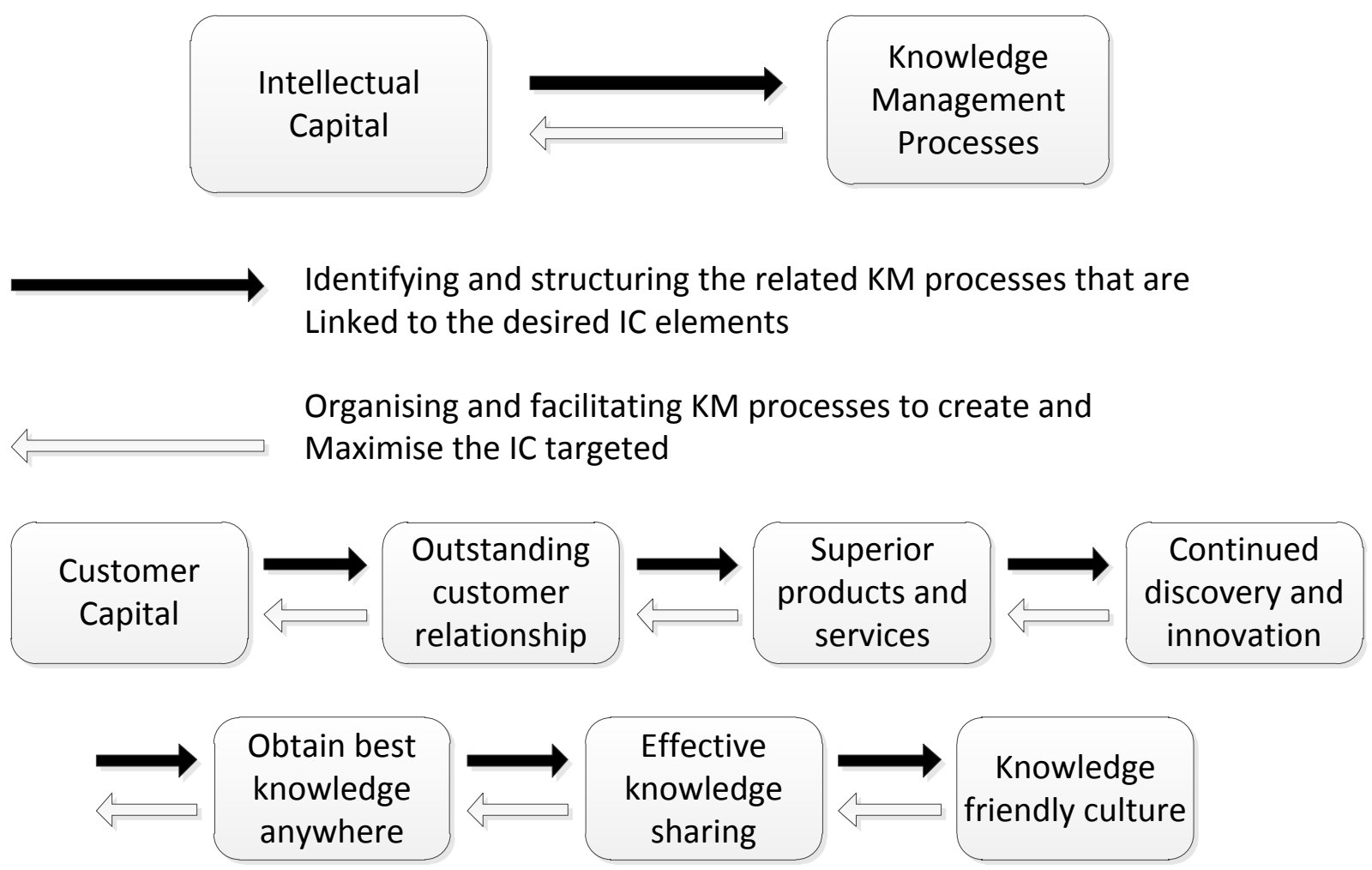

The relationship between IC and KM (Wiig, 1997) 


\section{Core questions}

Domain A - Business process management

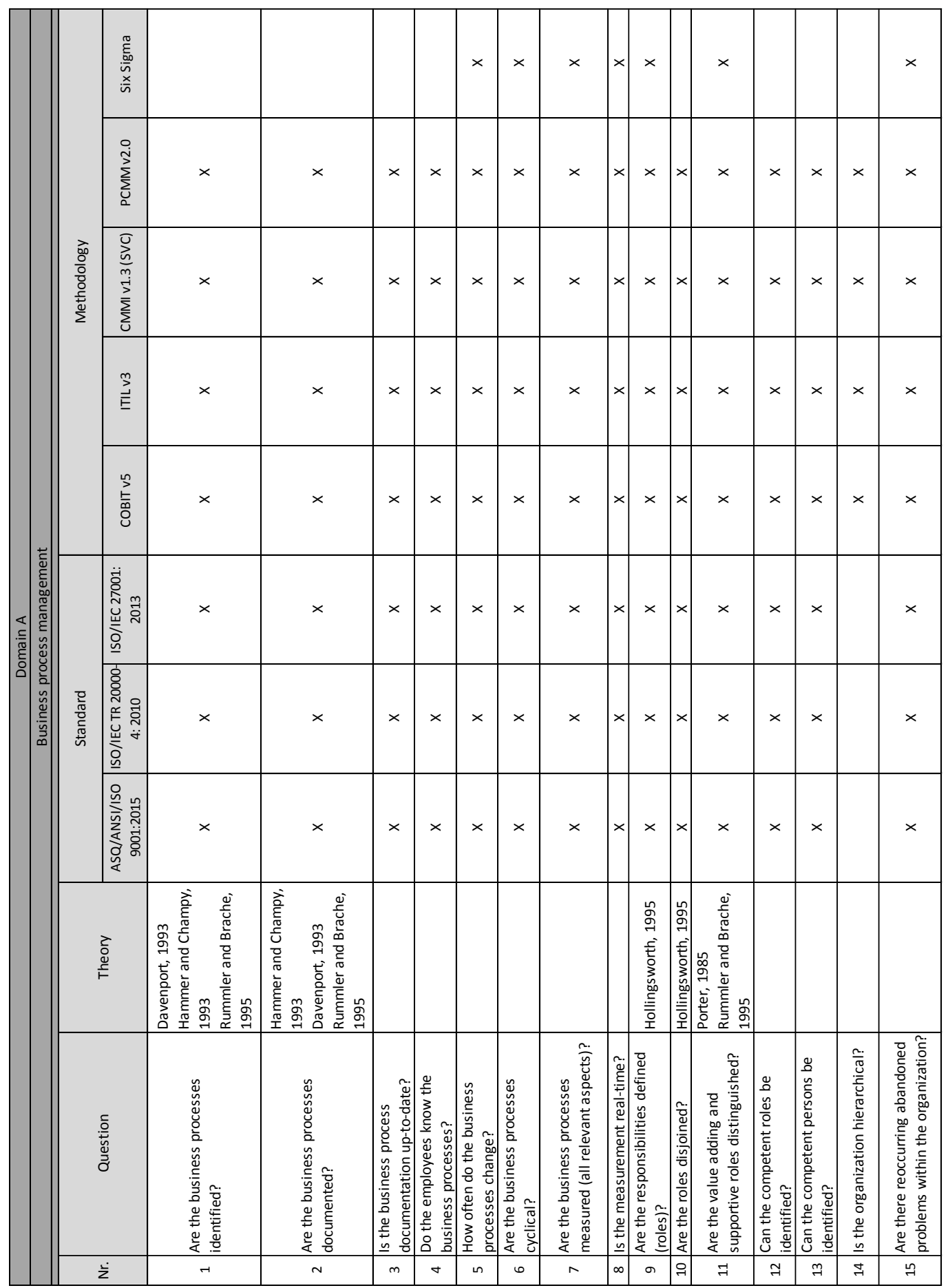


Domain B - Knowledge management

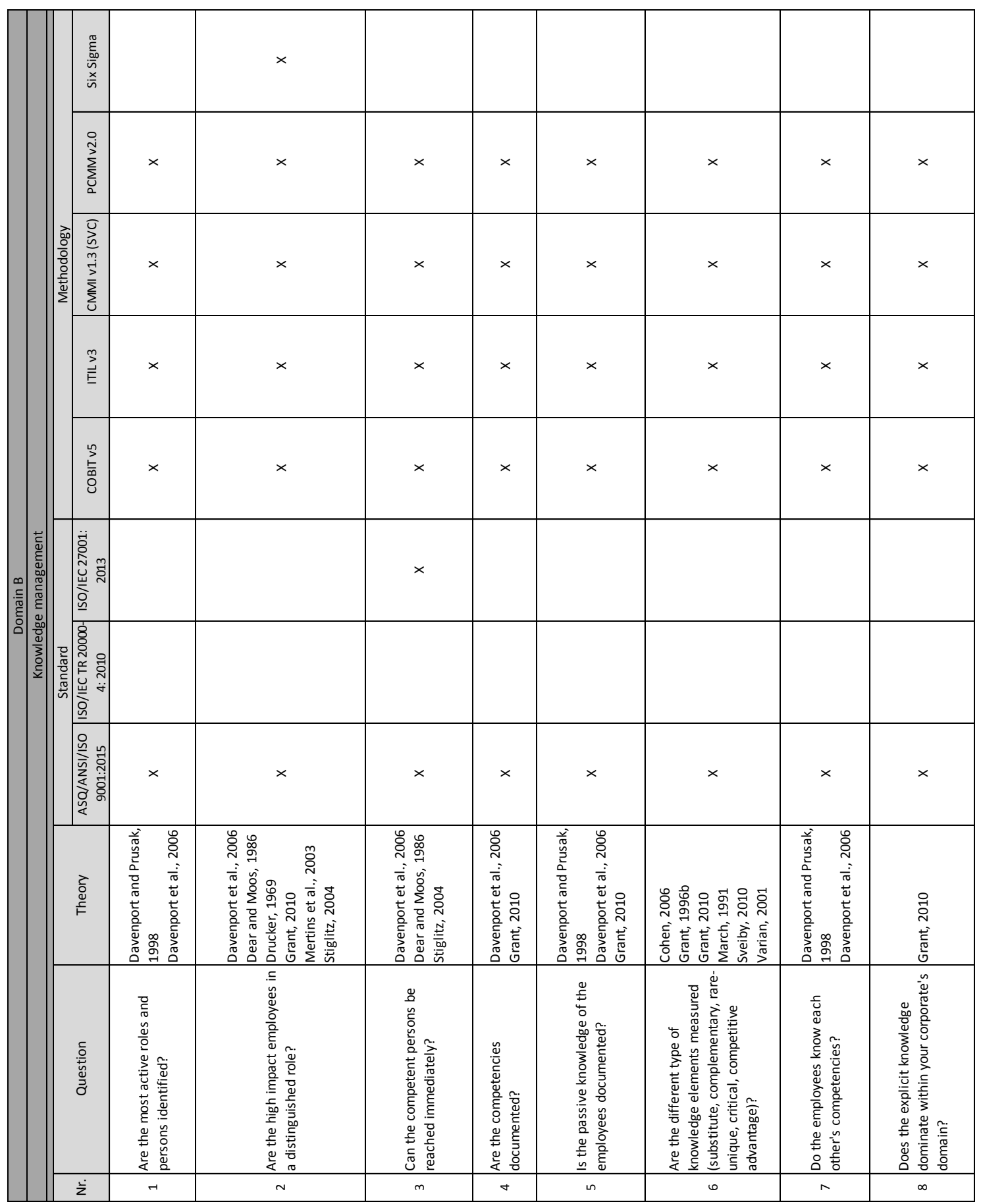




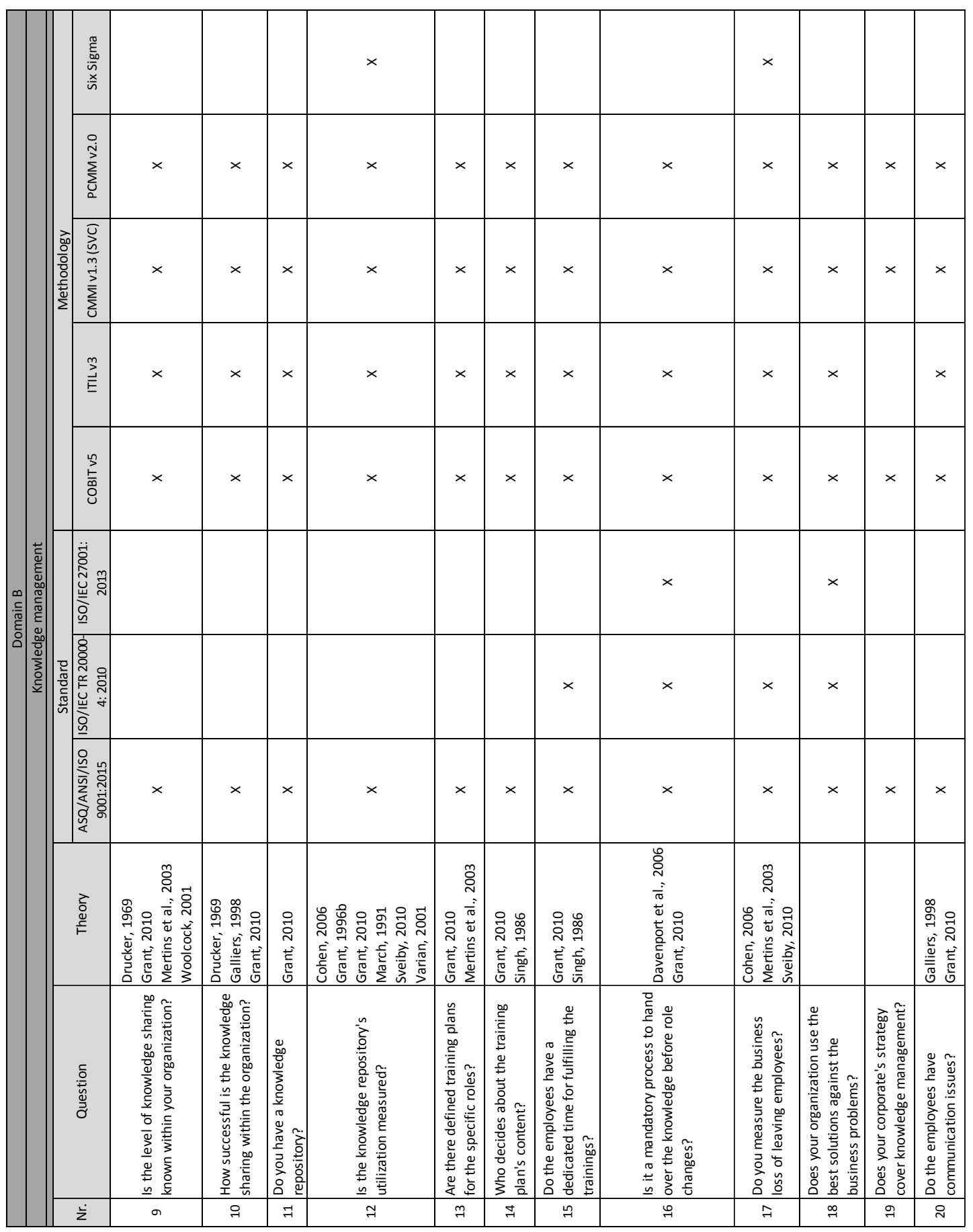




\section{Domain C - Renewal ability}

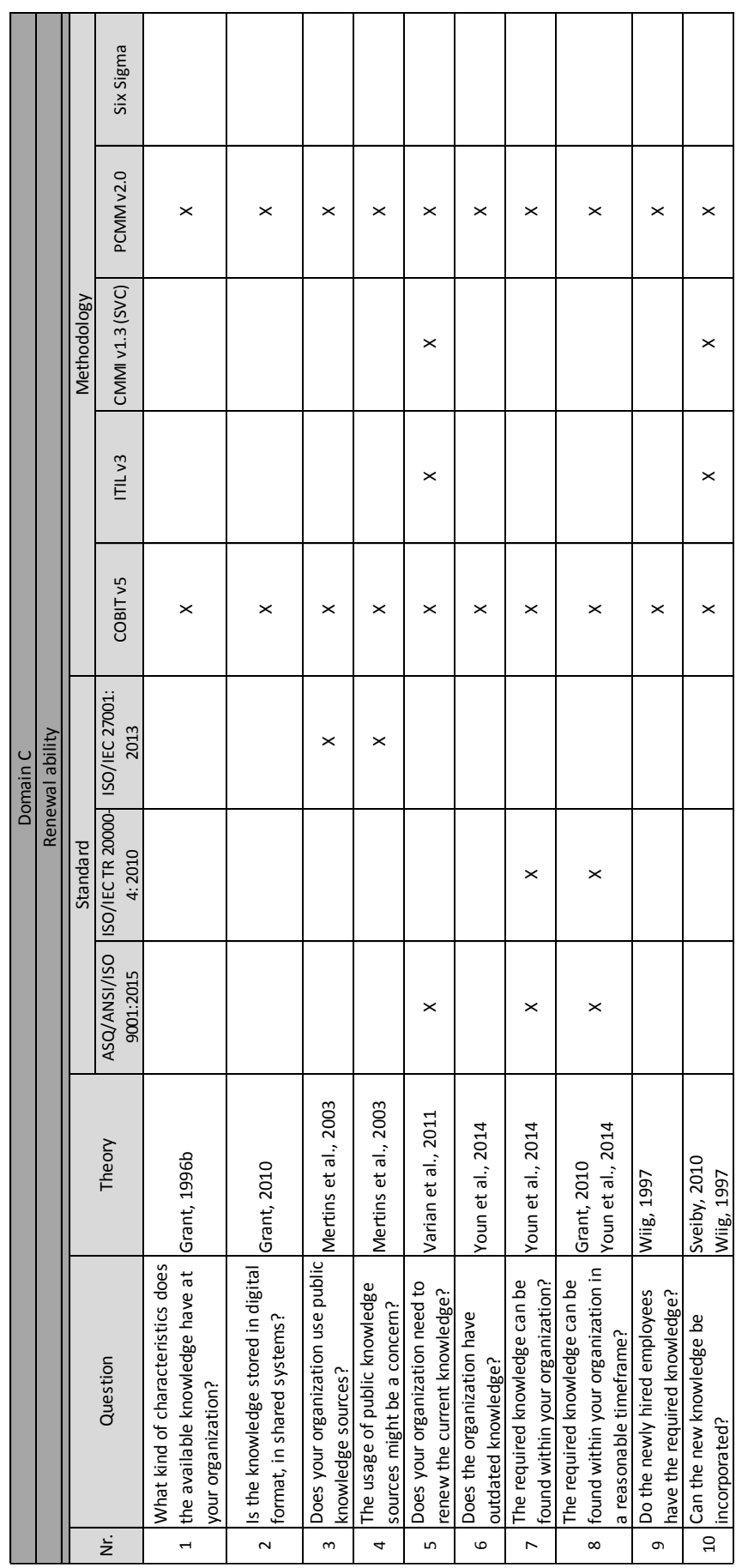




\section{Correlation coefficient}

(This point is based on external resources (Kubiak and Benbow, 2009).)

\subsection{Correlation calculation (Pearson)}

"Correlation is finding a relationship between two or more sets of data. It measures direction (negative, positive) and strength (strong, moderate, and weak) of the relationships between variables. The strength of the relationship between $\mathrm{x}$ and $\mathrm{y}$ measured by how close the correlation coefficient is to +1.0 or -1.0 . When $r$ is positive, the relationship between $\mathrm{x}$ and $\mathrm{y}$ is positive, and when $\mathrm{r}$ is negative, the relationship is negative. A correlation coefficient close to zero is evidence that there is no relationship between $\mathrm{x}$ and $\mathrm{y}$.

We can calculate the correlation coefficient using the following formula:

$$
r=\frac{1}{n-1} \sum \frac{(x-\bar{x})(y-\bar{y})}{S_{x} S_{y}}
$$

where $\mathrm{n}=$ number of paired samples, $\overline{\mathrm{X}}$ and $\overline{\mathrm{Y}}$ are mean values of $\mathrm{x}$ and $\mathrm{y}$, and $\mathrm{S}_{\mathrm{x}}$ and $\mathrm{S}_{\mathrm{y}}$ are standard deviations od samples $\mathrm{x}, \mathrm{y}$.

Procedure for Calculating the Correlation Coefficient

1. Calculate the mean for all $x$ values $(\bar{x})$ and the mean for all $y$ values $(\bar{y})$

2. Calculate the standard deviation of all $\mathrm{x}$ values $\left(\mathrm{S}_{\mathrm{x}}\right)$ and the standard deviation for $\mathrm{y}$ values values $\left(\mathrm{S}_{\mathrm{y}}\right)$

3. Calculate $(x-\bar{x})$ and $(y-\bar{y})$ for each pair $(x, y)$ and then multiply these differences together

4. Get the sum by adding all these products of differences together

5. Divide the sum by $S_{x} X S_{y}$

6. Divide the result of step 5 by $n-1$, where $n$ is the number of $(x, y)$ pairs

\section{Hypothesis test for the correlation coefficient}

$\mathrm{H}_{0}: \rho=0$ 
$\mathrm{H}_{\mathrm{a}}: \rho \neq 0$

Test statistic: $T=\frac{r \sqrt{n-2}}{\sqrt{1-r^{2}}}$

$$
t_{\frac{\alpha}{2}}, n-2
$$

If $\mathrm{T}>t_{\frac{\alpha}{2}, n-2}$, then null hypothesis is rejected that $\rho=0 . "$

\subsection{Correlation calculation (Mean square contingency coefficient)}

"The phi coefficient $(\varphi)$ is a measure for association for two binary variables. It is related to the chi-squared statistic.

Two binary variables are considered positively associated if most of the data falls along the diagonal cells. They are negatively associated if most of the data falls of the diagonal.

\begin{tabular}{|c|c|c|c|}
\hline & $\mathrm{y}=1$ & $\mathrm{y}=0$ & total \\
\hline $\mathrm{x}=1$ & $\mathrm{n}_{11}$ & $\mathrm{n}_{10}$ & $\mathrm{n}_{1} \bullet$ \\
\hline $\mathrm{x}=0$ & $\mathrm{n}_{01}$ & $\mathrm{n}_{00}$ & $\mathrm{n}_{0} \bullet$ \\
\hline total & $\mathrm{n}_{\bullet}$ & $\mathrm{n}_{\bullet}$ & $\mathrm{n}$ \\
\hline
\end{tabular}

$$
\varphi=\frac{n_{11} n_{00}-n_{10} n_{01}}{\sqrt{n_{1 \bullet} n_{0 \bullet} n_{\bullet 0} n_{\bullet 1}}}
$$

\section{Hypothesis test for the correlation coefficient}

$(\mathrm{r}=$ row, $\mathrm{c}=$ column $)$

$\mathrm{H}_{0}: \mathrm{p}_{\mathrm{ij}}=\mathrm{p}_{\mathrm{i} \bullet \mathrm{p}_{\bullet j}}$

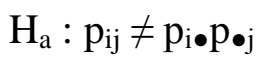

Based on $\chi^{2}=\sum_{i=1}^{r} \sum_{j=1}^{c} \frac{\left(n_{i j}-n_{i \bullet} n_{\bullet} / n_{\bullet \bullet}\right)^{2}}{n_{i \bullet} n_{\bullet j} / n_{\bullet \bullet}}$ the test statistic (contingence chi square):

$$
\chi^{2}=\sum_{i=1}^{r} \sum_{j=1}^{c}\left(o_{i j}-e_{i j}\right)^{2} / e_{i j}
$$


( $n_{i j}$ are the observed values $\sim o_{i j}$, the product of the marginal relative frequencies

$$
\begin{gathered}
\left.\left(n_{i \bullet} n_{\bullet j} / n_{\bullet \bullet}\right) \text { called expected values } e_{i j}\right) \\
\chi_{\alpha}^{2}((r-1)(c-1))
\end{gathered}
$$

If the test statistic $>\chi_{\alpha}^{2}((r-1)(c-1))$, then null hypothesis is rejected that there is no correlation."

\subsection{Scatter diagrams}

"The scatter diagram is a visual tool used to display relationships or associations between two variables, cause and effect, etc. The plot pattern identifies whether there is any positive or negative correlation, or no correlation. There is also the possibility for a nonlinear relationship between the variables. The positive correlation between variables does not mean there is a cause-and-effect relationship. When $\mathrm{r}$ is positive, the scatter diagram displays a positive slope, and when $r$ is negative it displays a negative slope. The closer $r$ is to 1 or -1 , the stronger the association between the two variables and the higher the likelihood that the variables are related." 